The difluoroalkylation/ $\mathrm{C}-\mathrm{H}$ annulation cascade reaction induced by visible-light photoredox catalysis

\author{
Jin Li, ${ }^{\mathrm{a}}$ Jingzhi Chen, ${ }^{\mathrm{a}}$ Wei Jiao, ${ }^{\mathrm{a}}$ Guoqiang Wang, ${ }^{\mathrm{b}}$ Ying $\mathrm{Li},{ }^{\mathrm{a}} \mathrm{Xu}$ Cheng ${ }^{\mathrm{a}}$ and Guigen $\mathrm{Li}^{\mathrm{a}}$ \\ Inistitute of Chemistry and Biomedical Scienece, School of Chemistry and Chemical Engineering, \\ Nanjing University, Nanjing, China, 210023.E-mail: chengxu@nju.edu.cn \\ Department of Chemistry and Biochemistry, Texas Tech University, Lubbock, Texas, United States
}

Table of Contents

1. DFT CALCULATION

2. COPIES OF ${ }^{1} \mathrm{H}$ NMR, ${ }^{13} \mathrm{C}$ NMR SPECTRA FOR THE SUBSTRATES 


\section{DFT calculation}

All calculations were performed with the Gaussian 09 package $^{[1]}$. Geometries of all structures were fully optimized and characterized by vibrational frequency calculations at the UB3LYP ${ }^{[2]} / 6-311 \mathrm{G}++(\mathrm{d}, \mathrm{p})$ level of theory. The calculated gas-phase Gibbs free energies refer to $298.15 \mathrm{~K}$ and $1 \mathrm{~atm}$.<smiles>CC/C=C(/CC(F)(F)F)c1cccc(OC)c1</smiles>

\begin{tabular}{|c|c|c|c|c|c|}
\hline \multirow{2}{*}{$\begin{array}{l}\text { Center } \\
\text { Number }\end{array}$} & \multirow{2}{*}{$\begin{array}{l}\text { Atomic } \\
\text { Number }\end{array}$} & \multirow{2}{*}{$\begin{array}{l}\text { Atomic } \\
\text { Type }\end{array}$} & \multicolumn{3}{|c|}{ Coordinates (Angstroms) } \\
\hline & & & $\mathrm{X}$ & $\mathrm{Y}$ & \\
\hline 1 & 6 & 0 & 1.471722 & 0.371950 & 0.186948 \\
\hline 2 & 6 & 0 & 1.754549 & 0.294936 & 1.560382 \\
\hline 3 & 6 & 0 & 2.670986 & -0.636557 & 2.030986 \\
\hline 4 & 6 & 0 & 3.328246 & -1.507822 & 1.160160 \\
\hline 5 & 6 & 0 & 3.048785 & -1.436327 & -0.206639 \\
\hline 6 & 6 & 0 & 2.121105 & -0.503914 & -0.682826 \\
\hline 7 & 6 & 0 & 0.485682 & 1.360629 & -0.343668 \\
\hline 8 & 6 & 0 & 0.602240 & 2.685795 & -0.173077 \\
\hline 9 & 6 & 0 & -0.688096 & 0.814712 & -1.138569 \\
\hline 10 & 6 & 0 & -1.807601 & 0.244705 & -0.282108 \\
\hline 11 & 9 & 0 & -1.341485 & -0.769875 & 0.524988 \\
\hline 12 & 9 & 0 & -2.296770 & 1.217061 & 0.570023 \\
\hline 13 & 6 & 0 & 1.717595 & 3.437496 & 0.504704 \\
\hline 14 & 6 & 0 & 2.270031 & 4.542580 & -0.336132 \\
\hline 15 & 8 & 0 & 3.627053 & -2.227939 & -1.157435 \\
\hline 16 & 6 & 0 & 4.583368 & -3.195970 & -0.747704 \\
\hline 17 & 6 & 0 & -3.004661 & -0.300040 & -1.118498 \\
\hline 18 & 8 & 0 & -3.001708 & -0.185159 & -2.315104 \\
\hline 19 & 8 & 0 & -4.031580 & -0.882411 & -0.493453 \\
\hline 20 & 6 & 0 & -5.550959 & -1.583863 & 1.205150 \\
\hline 21 & 6 & 0 & -4.138438 & -1.103231 & 0.947080 \\
\hline 22 & 1 & 0 & 1.236854 & 0.948243 & 2.251908 \\
\hline 23 & 1 & 0 & 2.879388 & -0.696763 & 3.093596 \\
\hline 24 & 1 & 0 & 4.036968 & -2.224319 & 1.552476 \\
\hline 25 & 1 & 0 & 1.938025 & -0.473069 & -1.750701 \\
\hline 26 & 1 & 0 & -0.175852 & 3.317591 & -0.597345 \\
\hline 27 & 1 & 0 & -1.132893 & 1.595720 & -1.756215 \\
\hline 28 & 1 & 0 & -0.373087 & 0.019266 & -1.817434 \\
\hline
\end{tabular}




$\begin{array}{rrrrrr}29 & 1 & 0 & 1.351571 & 3.857171 & 1.452955 \\ 30 & 1 & 0 & 2.518664 & 2.739661 & 0.789920 \\ 31 & 1 & 0 & 2.781956 & 5.380372 & 0.121393 \\ 32 & 1 & 0 & 2.291373 & 4.458618 & -1.416038 \\ 33 & 1 & 0 & 4.906688 & -3.697927 & -1.658166 \\ 34 & 1 & 0 & 5.448180 & -2.725946 & -0.266903 \\ 35 & 1 & 0 & 4.142105 & -3.931511 & -0.066287 \\ 36 & 1 & 0 & -5.678027 & -1.779434 & 2.273469 \\ 37 & 1 & 0 & -6.281504 & -0.830997 & 0.902461 \\ 38 & 1 & 0 & -5.755631 & -2.506497 & 0.658436 \\ 39 & 1 & 0 & -3.398598 & -1.849408 & 1.236820 \\ 40 & 1 & 0 & -3.929329 & -0.171847 & 1.471359\end{array}$

Zero-point correction $=$

Thermal correction to Energy=

Thermal correction to Enthalpy=

Thermal correction to Gibbs Free Energy=

Sum of electronic and zero-point Energies=

Sum of electronic and thermal Energies=

Sum of electronic and thermal Enthalpies=

Sum of electronic and thermal Free Energies=
0.317474 (Hartree/Particle)

0.340198

0.341142

0.261577

$-1046.392403$

$-1046.369679$

$-1046.368735$

$-1046.448300$<smiles>CCOC(=O)C(F)(F)CC1=CCCc2c(OC)cccc21</smiles>

\begin{tabular}{rrrrrr} 
Center & Atomic & Atomic & \multicolumn{2}{c}{ Coordinates (Angstroms) } \\
Number & Number & Type & X & Z \\
1 & 6 & 0 & -2.622145 & 1.566980 & 0.848631 \\
2 & 6 & 0 & -1.592633 & 1.479651 & 1.799531 \\
3 & 6 & 0 & -0.619895 & 0.488283 & 1.714568 \\
4 & 6 & 0 & -0.657027 & -0.458330 & 0.683718 \\
5 & 6 & 0 & -1.717053 & -0.406825 & -0.258666 \\
6 & 6 & 0 & -2.665089 & 0.647181 & -0.189999 \\
7 & 6 & 0 & 0.258421 & -1.618660 & 0.634795 \\
8 & 6 & 0 & -0.177819 & -2.846538 & 0.297170 \\
9 & 6 & 0 & -1.592831 & -3.274421 & -0.020888 \\
10 & 6 & 0 & -2.686710 & -2.331848 & 0.383023 \\
11 & 6 & 0 & 1.722764 & -1.415384 & 0.976587 \\
12 & 6 & 0 & 2.584951 & -0.956197 & -0.198275 \\
13 & 9 & 0 & 3.886152 & -0.818795 & 0.243732
\end{tabular}




\begin{tabular}{|c|c|c|c|c|c|}
\hline 14 & 9 & 0 & 2.609266 & -1.914668 & -1.166133 \\
\hline 15 & 6 & 0 & 2.161604 & 0.378097 & -0.859764 \\
\hline 16 & 8 & 0 & 1.707710 & 0.462425 & -1.967777 \\
\hline 17 & 8 & 0 & -3.586638 & 0.645868 & -1.195240 \\
\hline 18 & 6 & 0 & -4.568646 & 1.673434 & -1.218193 \\
\hline 19 & 8 & 0 & 2.363020 & 1.389401 & -0.012747 \\
\hline 20 & 6 & 0 & 2.368623 & 3.708900 & 0.587782 \\
\hline 21 & 6 & 0 & 1.970166 & 2.711285 & -0.478469 \\
\hline 22 & 1 & 0 & -3.354197 & 2.359592 & 0.926705 \\
\hline 23 & 1 & 0 & -1.561496 & 2.197697 & 2.611107 \\
\hline 24 & 1 & 0 & 0.151204 & 0.439041 & 2.473945 \\
\hline 25 & 1 & 0 & -1.608122 & -0.904370 & -1.213625 \\
\hline 26 & 1 & 0 & 0.554708 & -3.648944 & 0.259736 \\
\hline 27 & 1 & 0 & -1.658829 & -3.488087 & -1.096536 \\
\hline 28 & 1 & 0 & -1.751269 & -4.250211 & 0.466062 \\
\hline 29 & 1 & 0 & -3.598523 & -2.317083 & -0.203014 \\
\hline 30 & 1 & 0 & -2.803345 & -2.107037 & 1.437520 \\
\hline 31 & 1 & 0 & 1.853519 & -0.676514 & 1.768853 \\
\hline 32 & 1 & 0 & 2.172423 & -2.350147 & 1.319782 \\
\hline 33 & 1 & 0 & -5.175147 & 1.486544 & -2.102816 \\
\hline 34 & 1 & 0 & -5.205120 & 1.637415 & -0.327351 \\
\hline 35 & 1 & 0 & -4.106708 & 2.663559 & -1.296579 \\
\hline 36 & 1 & 0 & 2.087765 & 4.715684 & 0.267192 \\
\hline 37 & 1 & 0 & 1.862543 & 3.496709 & 1.531826 \\
\hline 38 & 1 & 0 & 3.447174 & 3.691292 & 0.758179 \\
\hline 39 & 1 & 0 & 2.469655 & 2.901122 & -1.430328 \\
\hline 40 & 1 & 0 & 0.892185 & 2.699700 & -0.652258 \\
\hline
\end{tabular}

Zero-point correction=

Thermal correction to Energy=

Thermal correction to Enthalpy=

Thermal correction to Gibbs Free Energy=

Sum of electronic and zero-point Energies=

Sum of electronic and thermal Energies=

Sum of electronic and thermal Enthalpies=

Sum of electronic and thermal Free Energies=
0.318868 (Hartree/Particle)

$$
\begin{aligned}
& 0.339868 \\
& 0.340813
\end{aligned}
$$

0.266374

$-1046.388937$

$-1046.367937$

$-1046.366992$

$-1046.441431$<smiles>CCOC(=O)C(F)(F)CC1=CCCc2ccc(OC)cc21</smiles>

Center Atomic Atomic Coordinates (Angstroms)




\begin{tabular}{|c|c|c|c|c|c|}
\hline Number & Number & Type & $X$ & Y & Z \\
\hline 1 & 6 & 0 & 3.182640 & -0.313685 & -0.992369 \\
\hline 2 & 6 & 0 & 2.740335 & -0.693802 & 0.289396 \\
\hline 3 & 6 & 0 & 1.553559 & -0.167946 & 0.803922 \\
\hline 4 & 6 & 0 & 0.802121 & 0.756632 & 0.067519 \\
\hline 5 & 6 & 0 & 1.277037 & 1.188553 & -1.203595 \\
\hline 6 & 6 & 0 & 2.445414 & 0.581351 & -1.735597 \\
\hline 7 & 6 & 0 & -0.371764 & 1.442249 & 0.647156 \\
\hline 8 & 6 & 0 & -0.576887 & 2.759024 & 0.455074 \\
\hline 9 & 6 & 0 & 0.311740 & 3.733885 & -0.282930 \\
\hline 10 & 6 & 0 & 1.705949 & 3.269727 & -0.590186 \\
\hline 11 & 6 & 0 & -1.363053 & 0.642919 & 1.476016 \\
\hline 12 & 6 & 0 & -2.566821 & 0.123167 & 0.692254 \\
\hline 13 & 9 & 0 & -3.383961 & -0.570464 & 1.564640 \\
\hline 14 & 9 & 0 & -3.308542 & 1.166219 & 0.225338 \\
\hline 15 & 6 & 0 & -2.263798 & -0.811992 & -0.505764 \\
\hline 16 & 8 & 0 & -2.491630 & -0.524319 & -1.648808 \\
\hline 17 & 8 & 0 & 3.538415 & -1.589321 & 0.944599 \\
\hline 18 & 6 & 0 & 3.159678 & -2.018281 & 2.245092 \\
\hline 19 & 8 & 0 & -1.740726 & -1.959231 & -0.067416 \\
\hline 20 & 6 & 0 & -0.128892 & -2.828858 & -1.720617 \\
\hline 21 & 6 & 0 & -1.485856 & -2.995925 & -1.062276 \\
\hline 22 & 1 & 0 & 4.089695 & -0.762099 & -1.380136 \\
\hline 23 & 1 & 0 & 1.223450 & -0.449699 & 1.794683 \\
\hline 24 & 1 & 0 & 0.570071 & 1.635349 & -1.891319 \\
\hline 25 & 1 & 0 & 2.768675 & 0.840594 & -2.737704 \\
\hline 26 & 1 & 0 & -1.470340 & 3.201067 & 0.888276 \\
\hline 27 & 1 & 0 & -0.197822 & 4.034503 & -1.208850 \\
\hline 28 & 1 & 0 & 0.353147 & 4.654298 & 0.321403 \\
\hline 29 & 1 & 0 & 2.196086 & 3.684352 & -1.464863 \\
\hline 30 & 1 & 0 & 2.366175 & 3.059311 & 0.244512 \\
\hline 31 & 1 & 0 & -0.893738 & -0.225978 & 1.938784 \\
\hline 32 & 1 & 0 & -1.785153 & 1.255075 & 2.277006 \\
\hline 33 & 1 & 0 & 3.931844 & -2.716178 & 2.564761 \\
\hline 34 & 1 & 0 & 3.117951 & -1.178285 & 2.947232 \\
\hline 35 & 1 & 0 & 2.191459 & -2.530853 & 2.232870 \\
\hline 36 & 1 & 0 & 0.043228 & -3.667525 & -2.401709 \\
\hline 37 & 1 & 0 & -0.080508 & -1.904888 & -2.297741 \\
\hline 38 & 1 & 0 & 0.671494 & -2.819855 & -0.978600 \\
\hline 39 & 1 & 0 & -1.546489 & -3.921069 & -0.489547 \\
\hline 40 & 1 & 0 & -2.293576 & -2.969052 & -1.794443 \\
\hline
\end{tabular}




$\begin{array}{lc}\text { Thermal correction to Energy }= & 0.339982 \\ \text { Thermal correction to Enthalpy= } & 0.340926 \\ \text { Thermal correction to Gibbs Free Energy= } & 0.266329 \\ \text { Sum of electronic and zero-point Energies }= & -1046.384959 \\ \text { Sum of electronic and thermal Energies }= & -1046.364057 \\ \text { Sum of electronic and thermal Enthalpies }= & -1046.363113 \\ \text { Sum of electronic and thermal Free Energies }= & -1046.437710\end{array}$<smiles>CCOC(=O)CCC1=CCCC2(OC)C1=CC=CC2OC</smiles>

\begin{tabular}{|c|c|c|c|c|c|}
\hline \multirow{2}{*}{$\begin{array}{l}\text { Center } \\
\text { Number }\end{array}$} & \multirow{2}{*}{$\begin{array}{l}\text { Atomic } \\
\text { Number }\end{array}$} & \multirow{2}{*}{$\begin{array}{l}\text { Atomic } \\
\text { Type }\end{array}$} & \multicolumn{3}{|c|}{ Coordinates (Angstroms) } \\
\hline & & & $X$ & Y & 2 \\
\hline 1 & 6 & 0 & -3.722029 & 0.756101 & 1.308456 \\
\hline 2 & 6 & 0 & -2.663331 & 0.715673 & 2.261171 \\
\hline 3 & 6 & 0 & -1.405071 & 0.216931 & 1.917934 \\
\hline 4 & 6 & 0 & -1.118746 & -0.248902 & 0.642089 \\
\hline 5 & 6 & 0 & -2.160886 & -0.138161 & -0.458552 \\
\hline 6 & 6 & 0 & -3.503493 & 0.339625 & 0.030096 \\
\hline 7 & 6 & 0 & 0.144483 & -0.865592 & 0.271594 \\
\hline 8 & 6 & 0 & 0.271902 & -1.533793 & -0.903655 \\
\hline 9 & 6 & 0 & -0.859096 & -1.759154 & -1.868605 \\
\hline 10 & 6 & 0 & -2.229091 & -1.462970 & -1.255537 \\
\hline 11 & 6 & 0 & 1.291221 & -0.754785 & 1.267570 \\
\hline 12 & 6 & 0 & 2.700714 & -0.941838 & 0.736041 \\
\hline 13 & 9 & 0 & 3.585973 & -0.672540 & 1.766416 \\
\hline 14 & 9 & 0 & 2.934508 & -2.235567 & 0.373838 \\
\hline 15 & 6 & 0 & 3.113738 & -0.027948 & -0.446291 \\
\hline 16 & 8 & 0 & 3.610446 & -0.422804 & -1.465131 \\
\hline 17 & 8 & 0 & -4.421113 & 0.355908 & -0.970951 \\
\hline 18 & 6 & 0 & -5.733790 & 0.826562 & -0.685127 \\
\hline 19 & 8 & 0 & 2.855634 & 1.246016 & -0.141064 \\
\hline 20 & 6 & 0 & 2.849825 & 3.599427 & -0.589362 \\
\hline 21 & 6 & 0 & 3.231955 & 2.240404 & -1.134859 \\
\hline 22 & 1 & 0 & -4.691283 & 1.125299 & 1.617228 \\
\hline 23 & 1 & 0 & -2.851717 & 1.054258 & 3.272536 \\
\hline 24 & 1 & 0 & -0.651632 & 0.161818 & 2.694663 \\
\hline 25 & 1 & 0 & -1.809575 & 0.625513 & -1.178104 \\
\hline 26 & 1 & 0 & 1.220990 & -1.979311 & -1.174302 \\
\hline 27 & 1 & 0 & -0.705344 & -1.136669 & -2.762495 \\
\hline 28 & 1 & 0 & -0.822637 & -2.793748 & -2.228146 \\
\hline
\end{tabular}




$\begin{array}{llrrrr}29 & 1 & 0 & -2.995299 & -1.396901 & -2.029105 \\ 30 & 1 & 0 & -2.516047 & -2.268674 & -0.571293 \\ 31 & 1 & 0 & 1.284358 & 0.235099 & 1.726676 \\ 32 & 1 & 0 & 1.175443 & -1.484671 & 2.076802 \\ 33 & 1 & 0 & -6.289691 & 0.747979 & -1.617760 \\ 34 & 1 & 0 & -6.213899 & 0.210452 & 0.081918 \\ 35 & 1 & 0 & -5.713981 & 1.870492 & -0.355475 \\ 36 & 1 & 0 & 3.121494 & 4.371836 & -1.313669 \\ 37 & 1 & 0 & 1.774681 & 3.661747 & -0.408448 \\ 38 & 1 & 0 & 3.372945 & 3.807673 & 0.346331 \\ 39 & 1 & 0 & 4.305456 & 2.152841 & -1.314437 \\ 40 & 1 & 0 & 2.711835 & 2.005480 & -2.065804\end{array}$

Zero-point correction=

Thermal correction to Energy=

Thermal correction to Enthalpy=

Thermal correction to Gibbs Free Energy=

Sum of electronic and zero-point Energies=

Sum of electronic and thermal Energies=

Sum of electronic and thermal Enthalpies=

Sum of electronic and thermal Free Energies=

$$
\begin{aligned}
& 0.322771 \text { (Hartree/Particle) } \\
& 0.343367 \\
& 0.344311 \\
& 0.270940 \\
& -1046.425387 \\
& -1046.404792 \\
& -1046.403848 \\
& -1046.477219
\end{aligned}
$$

\begin{tabular}{|c|c|c|c|c|c|}
\hline \multirow{2}{*}{$\begin{array}{l}\text { Center } \\
\text { Number }\end{array}$} & \multirow{2}{*}{$\begin{array}{l}\text { Atomic } \\
\text { Number }\end{array}$} & \multirow{2}{*}{$\begin{array}{l}\text { Atomic } \\
\text { Type }\end{array}$} & \multicolumn{3}{|c|}{ Coordinates (Angstroms) } \\
\hline & & & $\mathrm{X}$ & Y & Z \\
\hline 1 & 6 & 0 & -4.109643 & 0.126225 & 0.768211 \\
\hline 2 & 6 & 0 & -3.399076 & -0.904239 & 0.068223 \\
\hline 3 & 6 & 0 & -2.081041 & -0.704207 & -0.337384 \\
\hline 4 & 6 & 0 & -1.390674 & 0.473016 & -0.039010 \\
\hline 5 & 6 & 0 & -2.032753 & 1.523423 & 0.852366 \\
\hline 6 & 6 & 0 & -3.490882 & 1.272596 & 1.115762 \\
\hline 7 & 6 & 0 & -0.059906 & 0.760658 & -0.532831 \\
\hline 8 & 6 & 0 & 0.483043 & 2.001091 & -0.390721 \\
\hline 9 & 6 & 0 & -0.245761 & 3.175647 & 0.202678 \\
\hline 10 & 6 & 0 & -1.754055 & 2.939257 & 0.301662 \\
\hline 11 & 6 & 0 & 0.684843 & -0.369456 & -1.230649 \\
\hline 12 & 6 & 0 & 2.189229 & -0.237260 & -1.385103 \\
\hline 13 & 9 & 0 & 2.665034 & -1.415614 & -1.937330 \\
\hline
\end{tabular}<smiles>CCOC(=O)CCC1=CCCC2C=C(OC)C=CC12</smiles> 


\begin{tabular}{|c|c|c|c|c|c|}
\hline 14 & 9 & 0 & 2.518815 & 0.747091 & -2.268147 \\
\hline 15 & 6 & 0 & 2.998328 & -0.008615 & -0.082396 \\
\hline 16 & 8 & 0 & 3.809759 & 0.863448 & 0.064673 \\
\hline 17 & 8 & 0 & -4.137244 & -2.021319 & -0.187974 \\
\hline 18 & 6 & 0 & -3.532539 & -3.097062 & -0.893254 \\
\hline 19 & 8 & 0 & 2.672224 & -0.937665 & 0.819600 \\
\hline 20 & 6 & 0 & 2.883412 & -2.033566 & 2.939860 \\
\hline 21 & 6 & 0 & 3.382712 & -0.885918 & 2.088900 \\
\hline 22 & 1 & 0 & -5.155669 & -0.047088 & 0.994803 \\
\hline 23 & 1 & 0 & -1.598266 & -1.462182 & -0.938783 \\
\hline 24 & 1 & 0 & -1.515191 & 1.481161 & 1.831484 \\
\hline 25 & 1 & 0 & -4.039732 & 2.049081 & 1.639979 \\
\hline 26 & 1 & 0 & 1.483593 & 2.200740 & -0.752506 \\
\hline 27 & 1 & 0 & 0.167175 & 3.397040 & 1.198090 \\
\hline 28 & 1 & 0 & -0.040722 & 4.067659 & -0.399965 \\
\hline 29 & 1 & 0 & -2.222002 & 3.691098 & 0.944966 \\
\hline 30 & 1 & 0 & -2.213557 & 3.028469 & -0.688391 \\
\hline 31 & 1 & 0 & 0.532852 & -1.301884 & -0.683600 \\
\hline 32 & 1 & 0 & 0.294757 & -0.523101 & -2.243430 \\
\hline 33 & 1 & 0 & -4.291334 & -3.875088 & -0.957502 \\
\hline 34 & 1 & 0 & -3.236295 & -2.795433 & -1.903715 \\
\hline 35 & 1 & 0 & -2.659231 & -3.483515 & -0.356750 \\
\hline 36 & 1 & 0 & 3.398185 & -2.022317 & 3.904150 \\
\hline 37 & 1 & 0 & 1.810219 & -1.948733 & 3.123431 \\
\hline 38 & 1 & 0 & 3.079971 & -2.993433 & 2.457625 \\
\hline 39 & 1 & 0 & 4.452679 & -0.956914 & 1.883574 \\
\hline 40 & 1 & 0 & 3.188599 & 0.085886 & 2.547558 \\
\hline oin & & & \multicolumn{3}{|c|}{0.322193 (Hartree/Particle) } \\
\hline nal & to & & \multicolumn{3}{|c|}{0.342933} \\
\hline mal & to & & \multicolumn{3}{|c|}{0.343878} \\
\hline cmal & to & & \multicolumn{3}{|c|}{0.269903} \\
\hline of $\mathrm{e}$ & and & & \multicolumn{3}{|c|}{-1046.421793} \\
\hline & & & \multicolumn{3}{|c|}{-1046.401052} \\
\hline $\mathrm{e}$ & d & & \multicolumn{3}{|c|}{-1046.400108} \\
\hline of $\mathrm{e}$ & & & \multicolumn{3}{|c|}{-1046.474083} \\
\hline
\end{tabular}




\section{Copies of ${ }^{1} \mathrm{H}$ NMR and ${ }^{13} \mathrm{C}$ NMR Spectra for the substrates:}

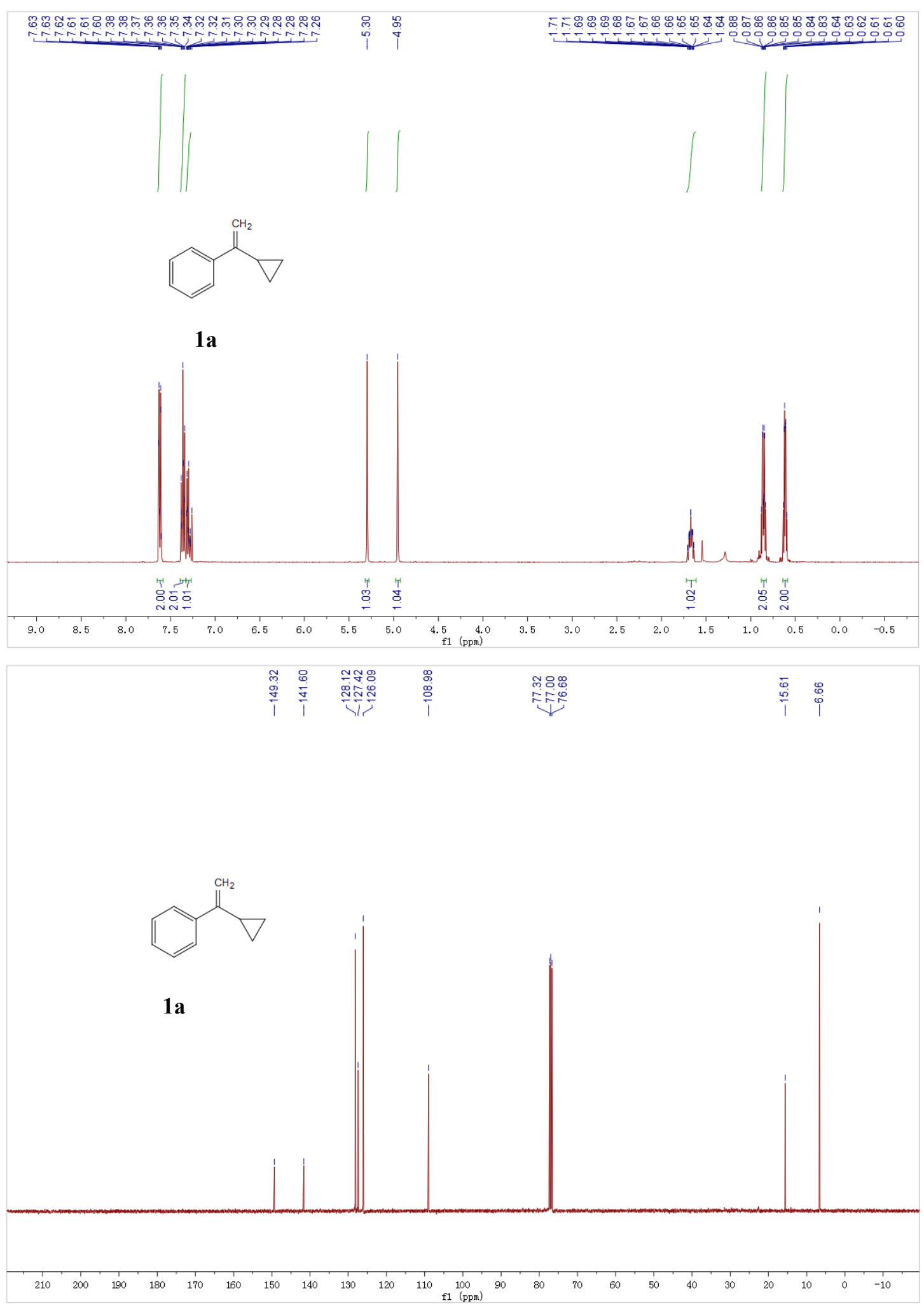



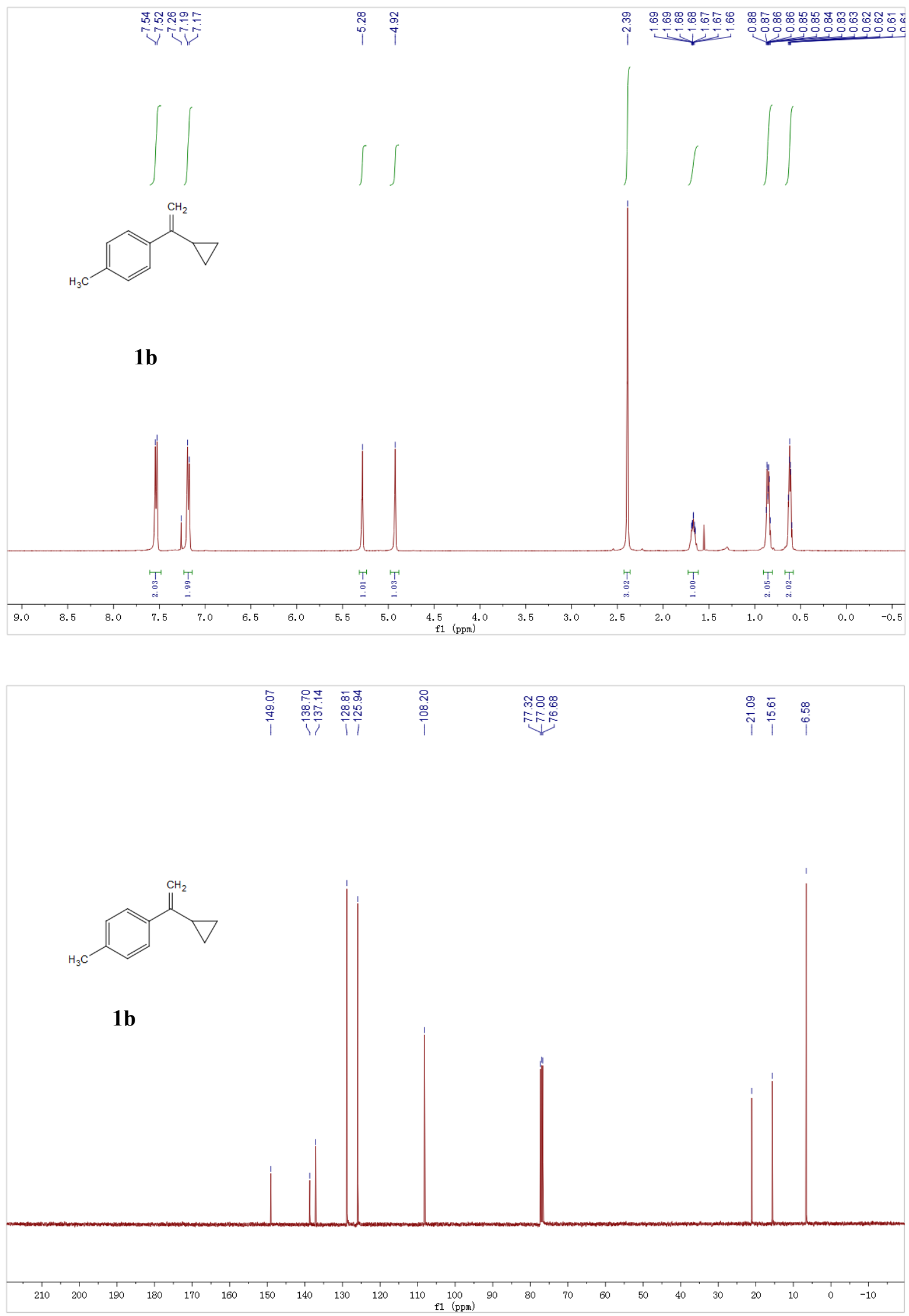

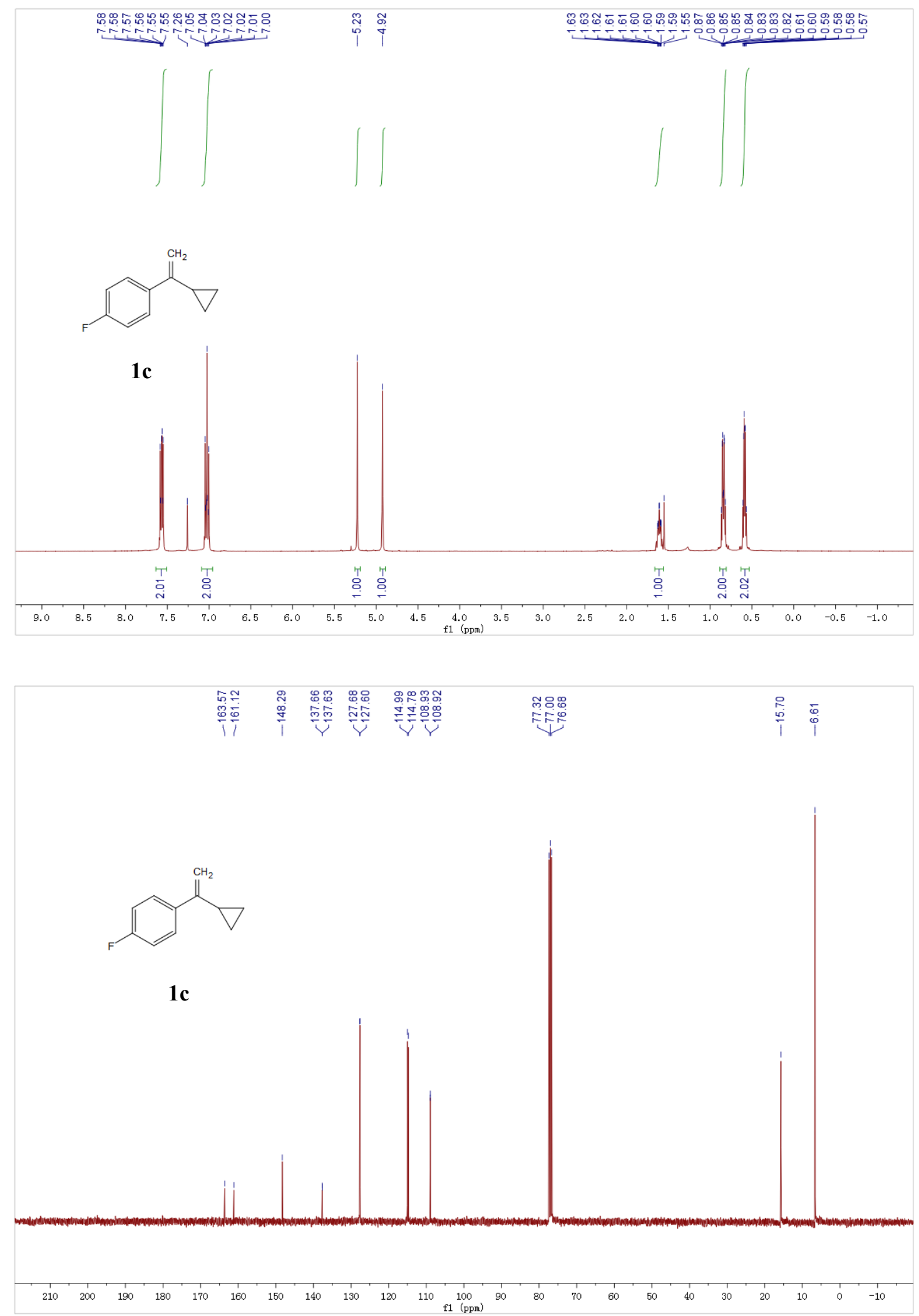

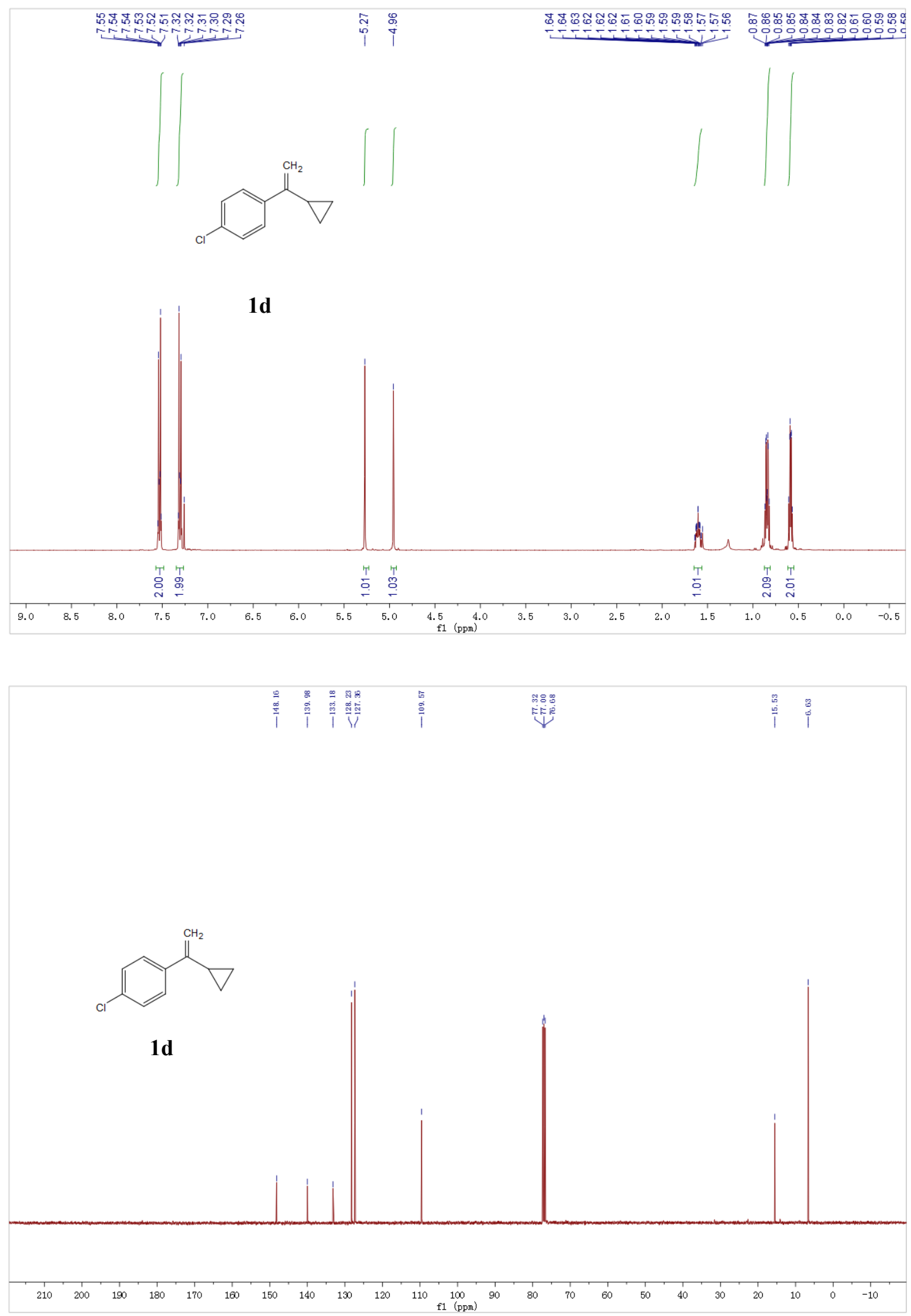

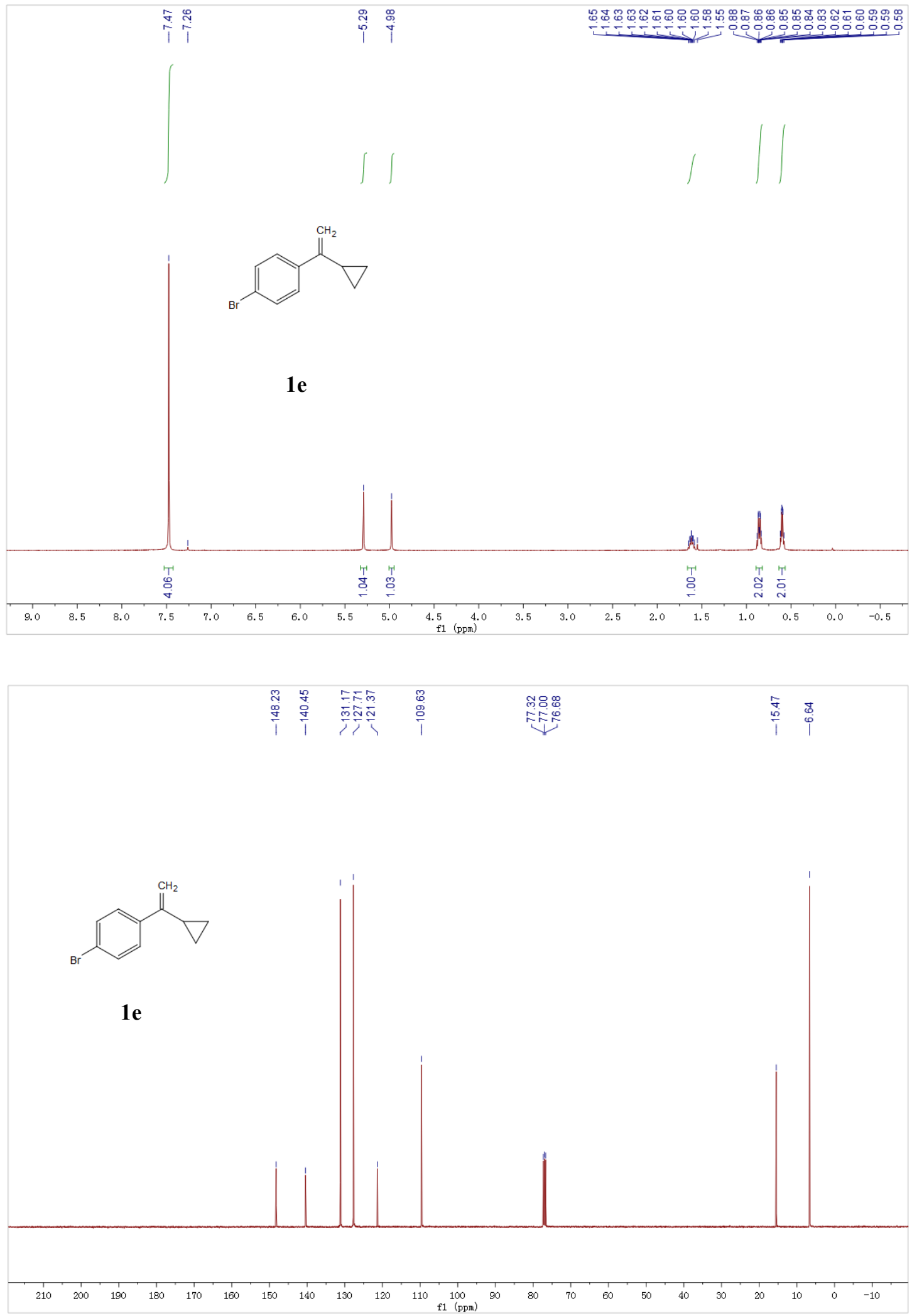

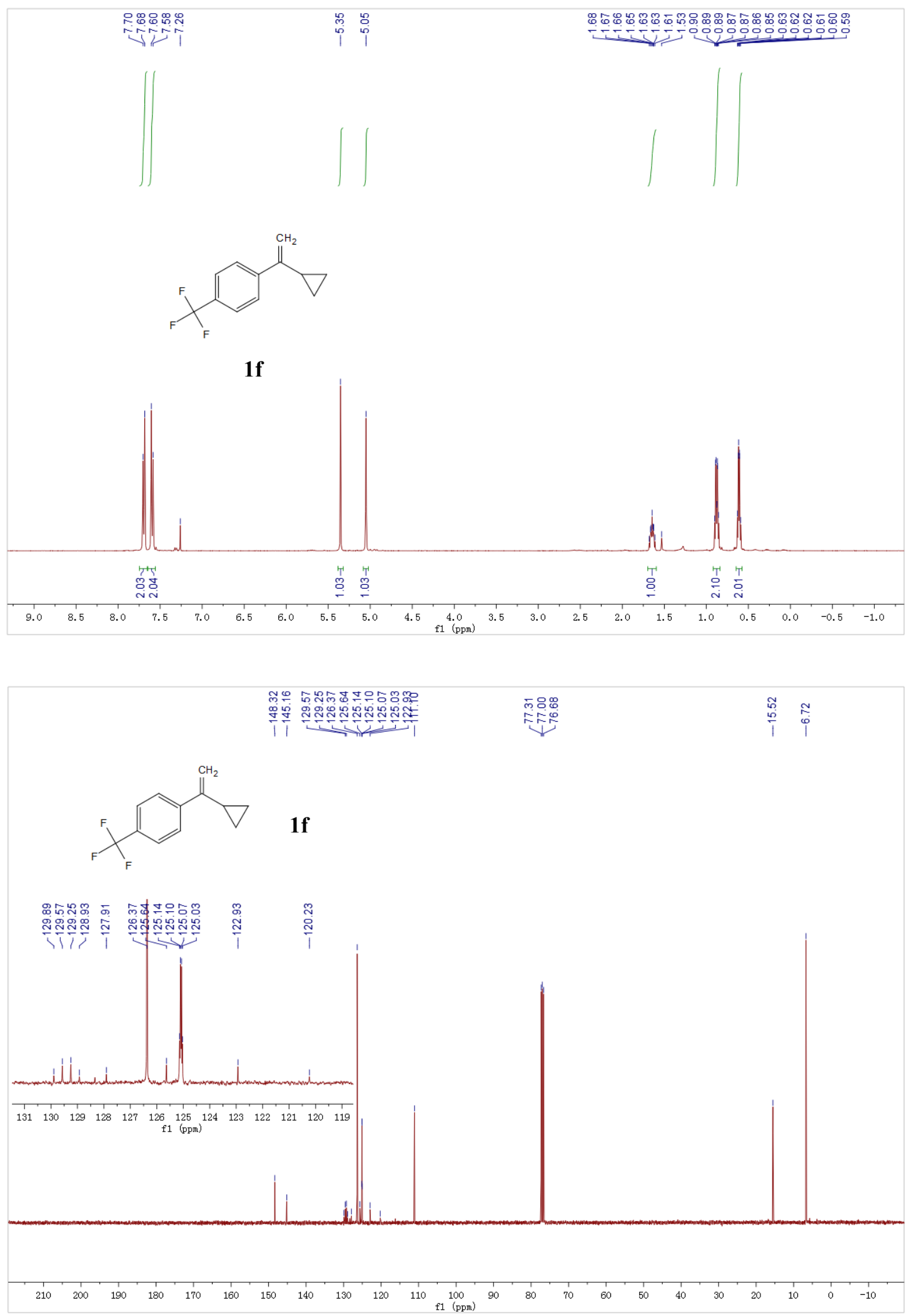

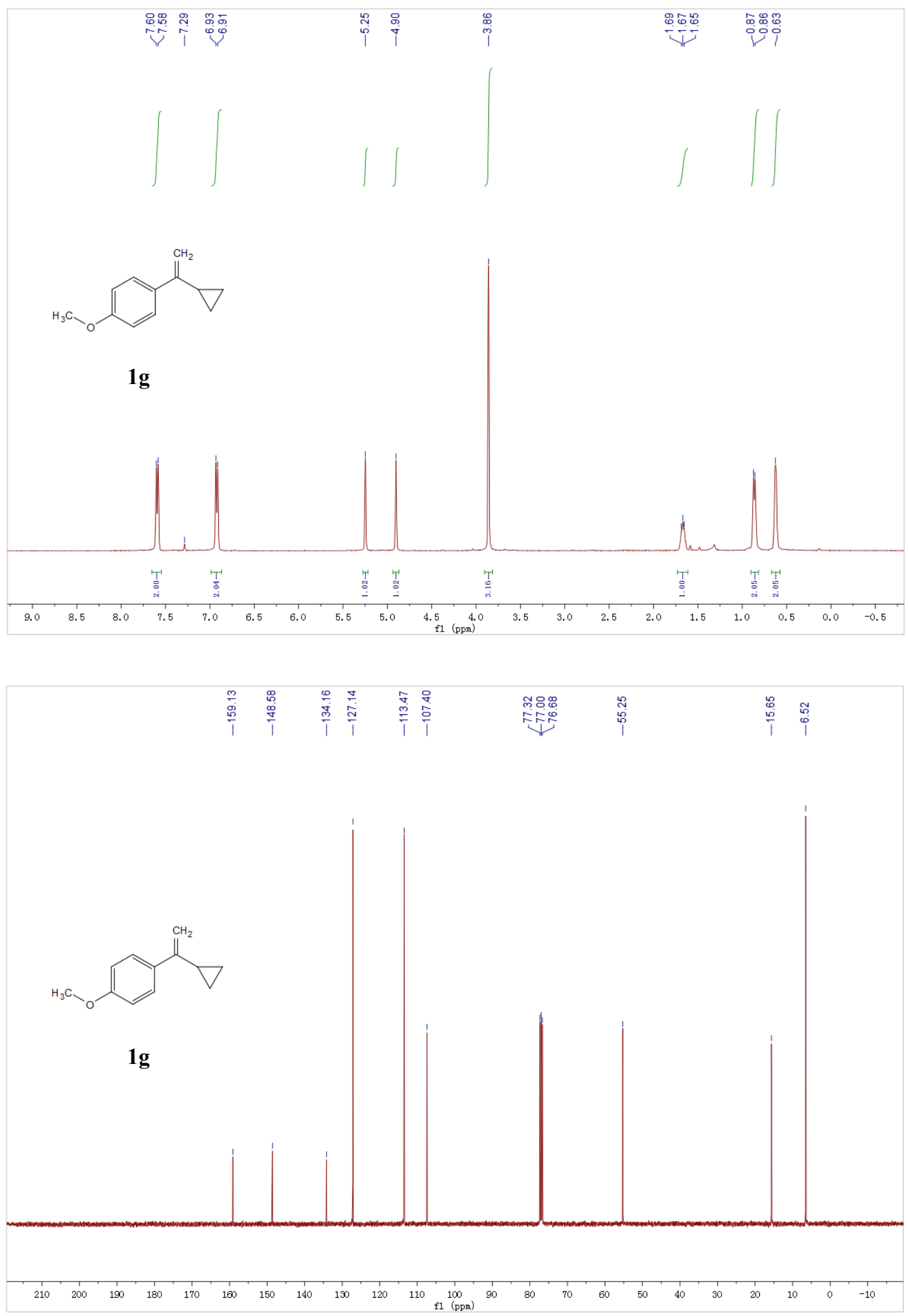

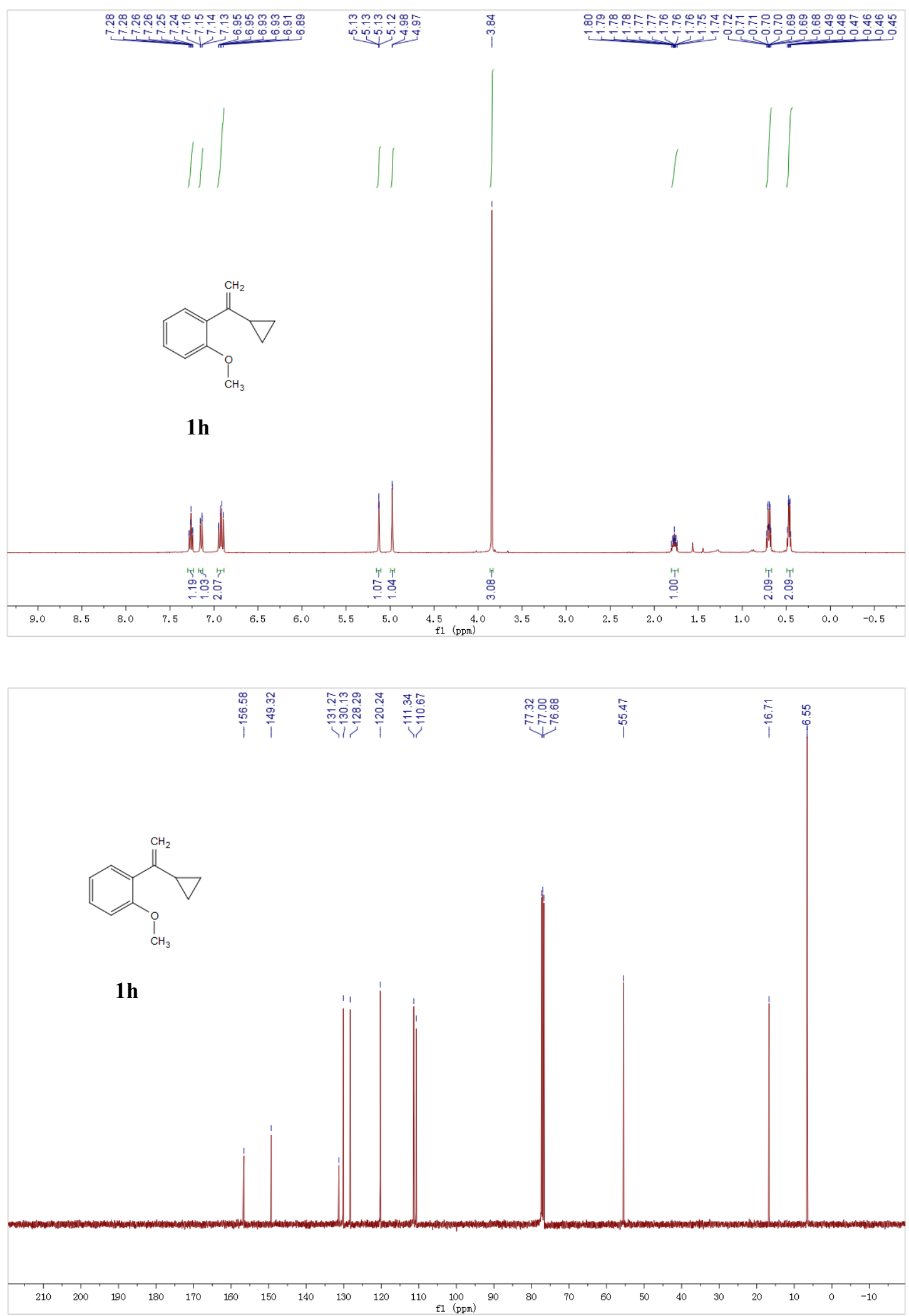

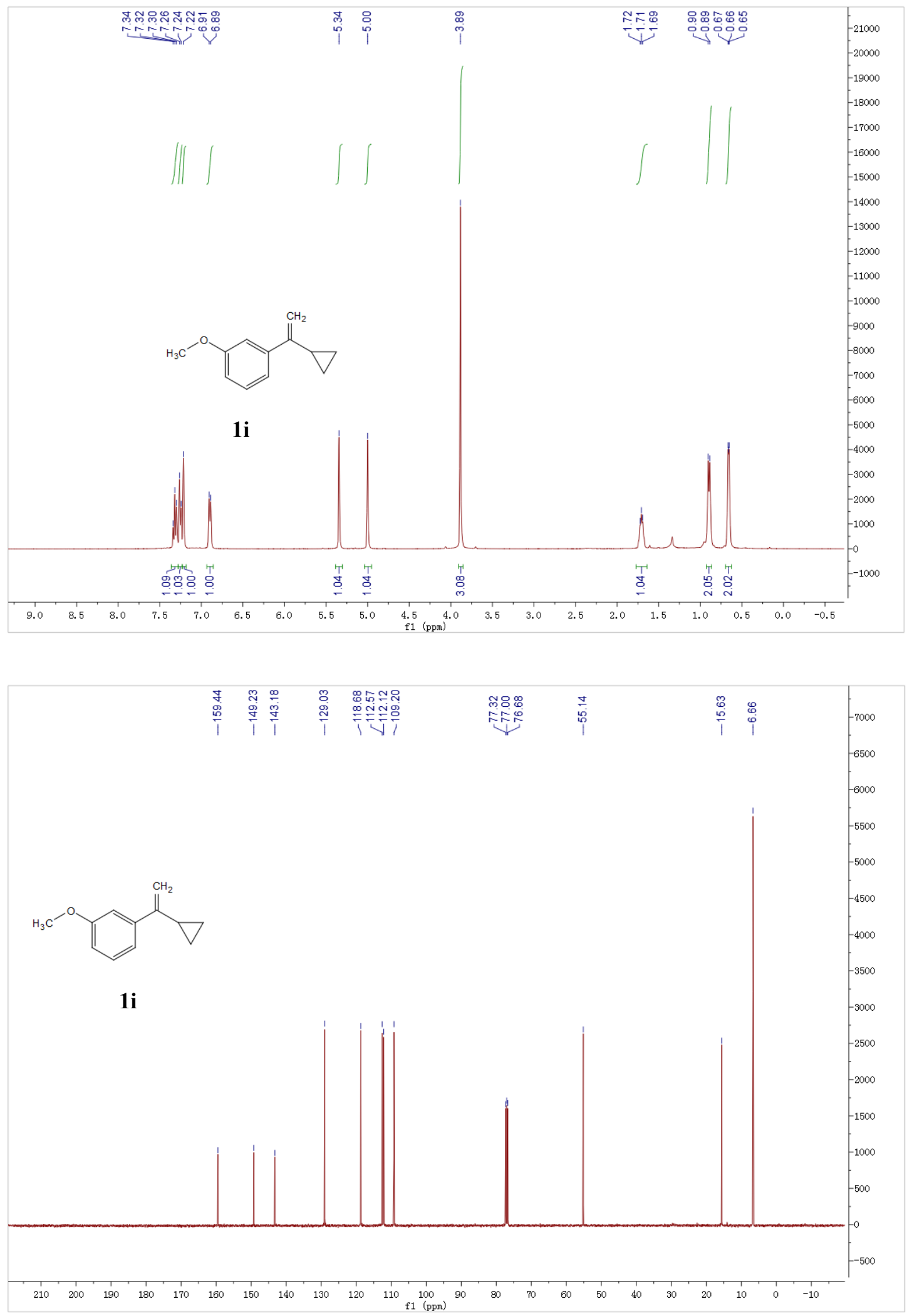

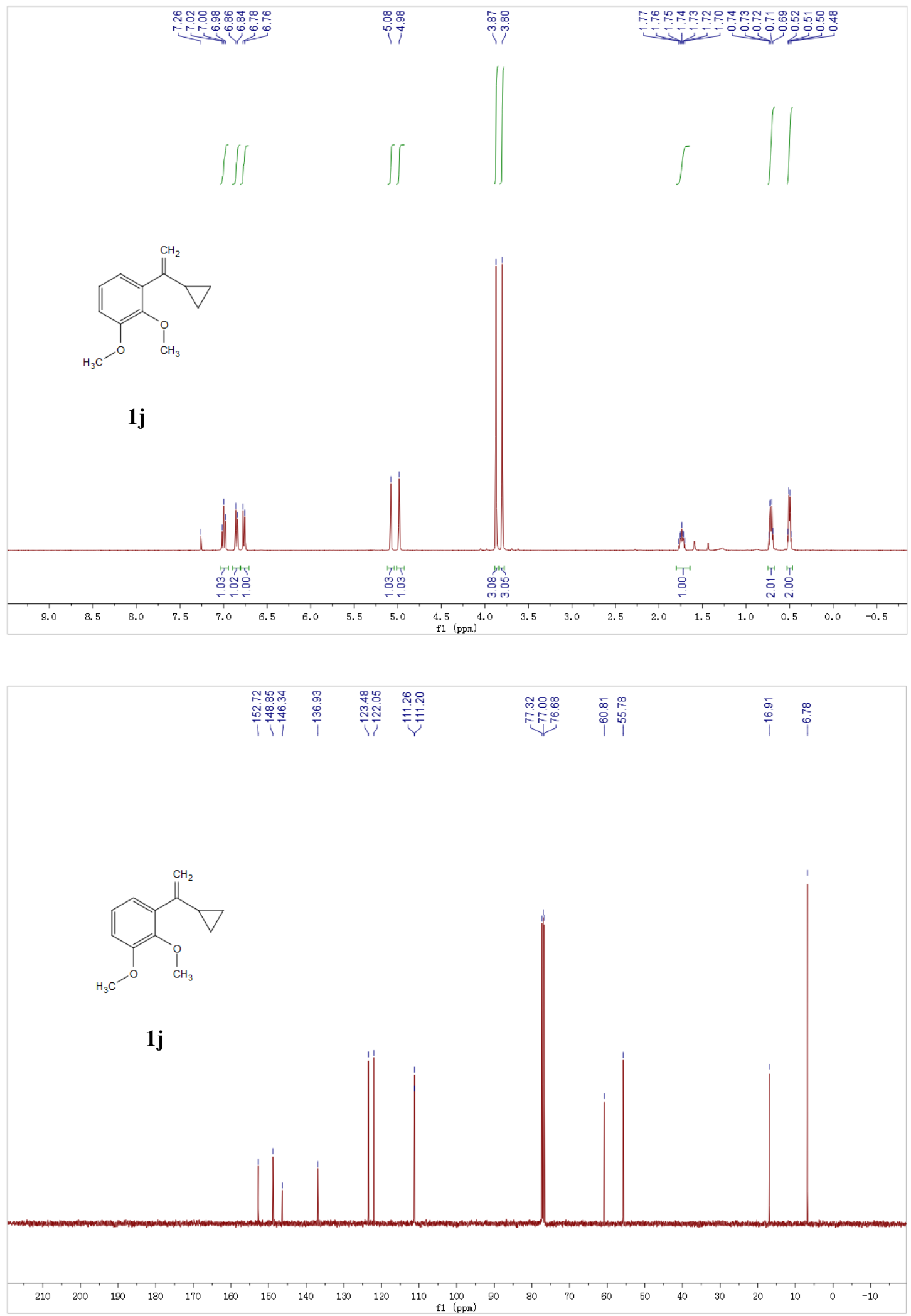

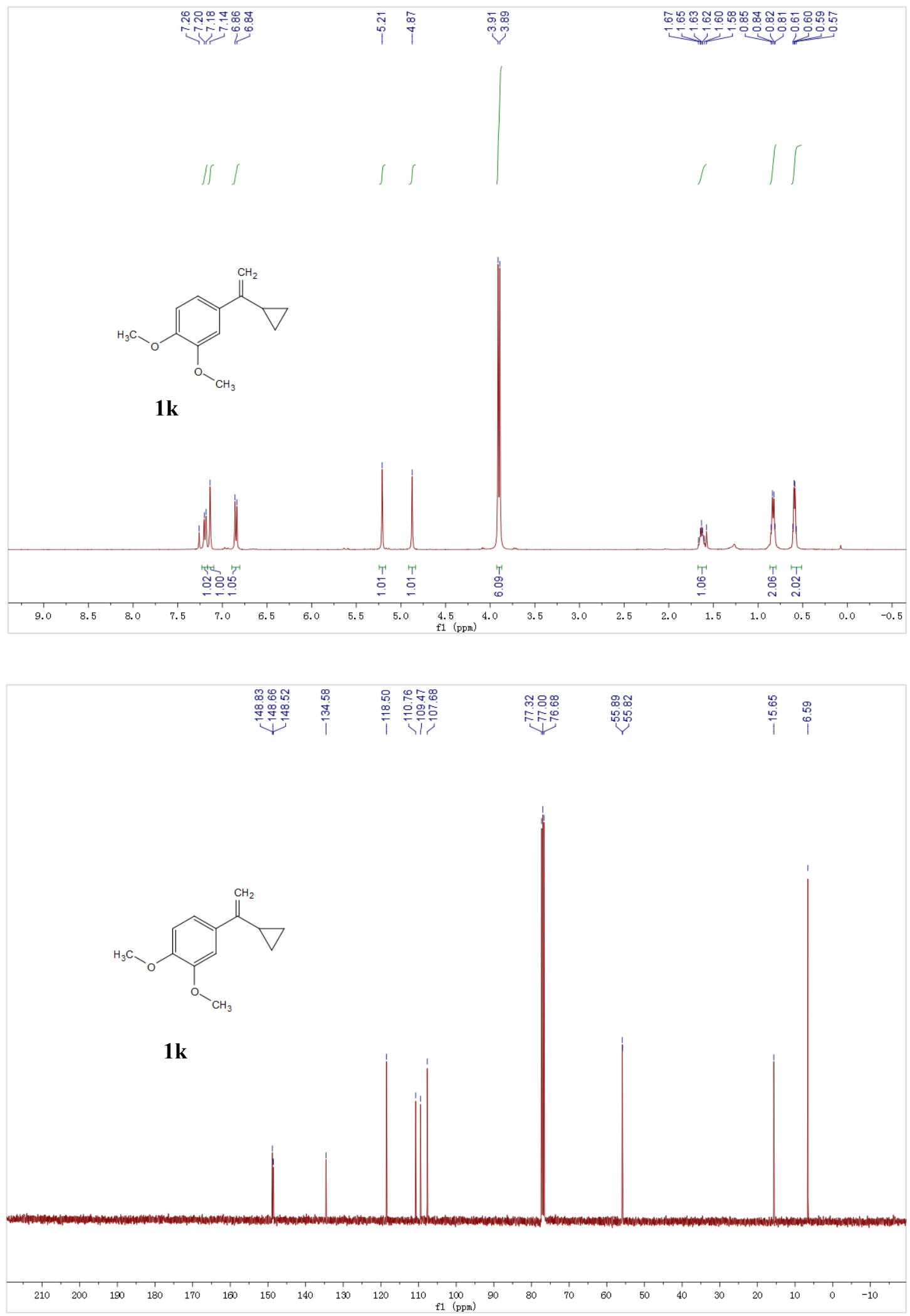

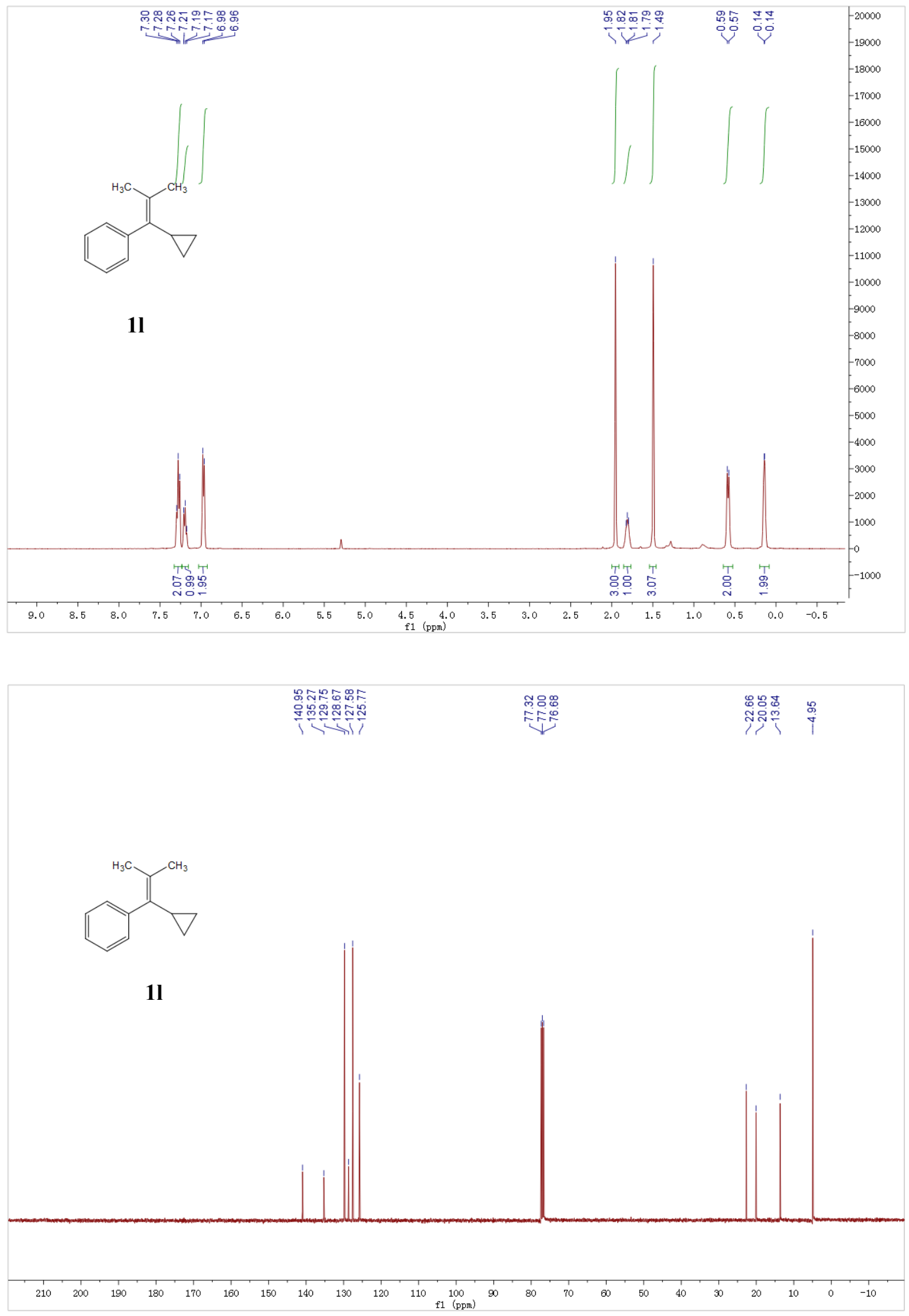

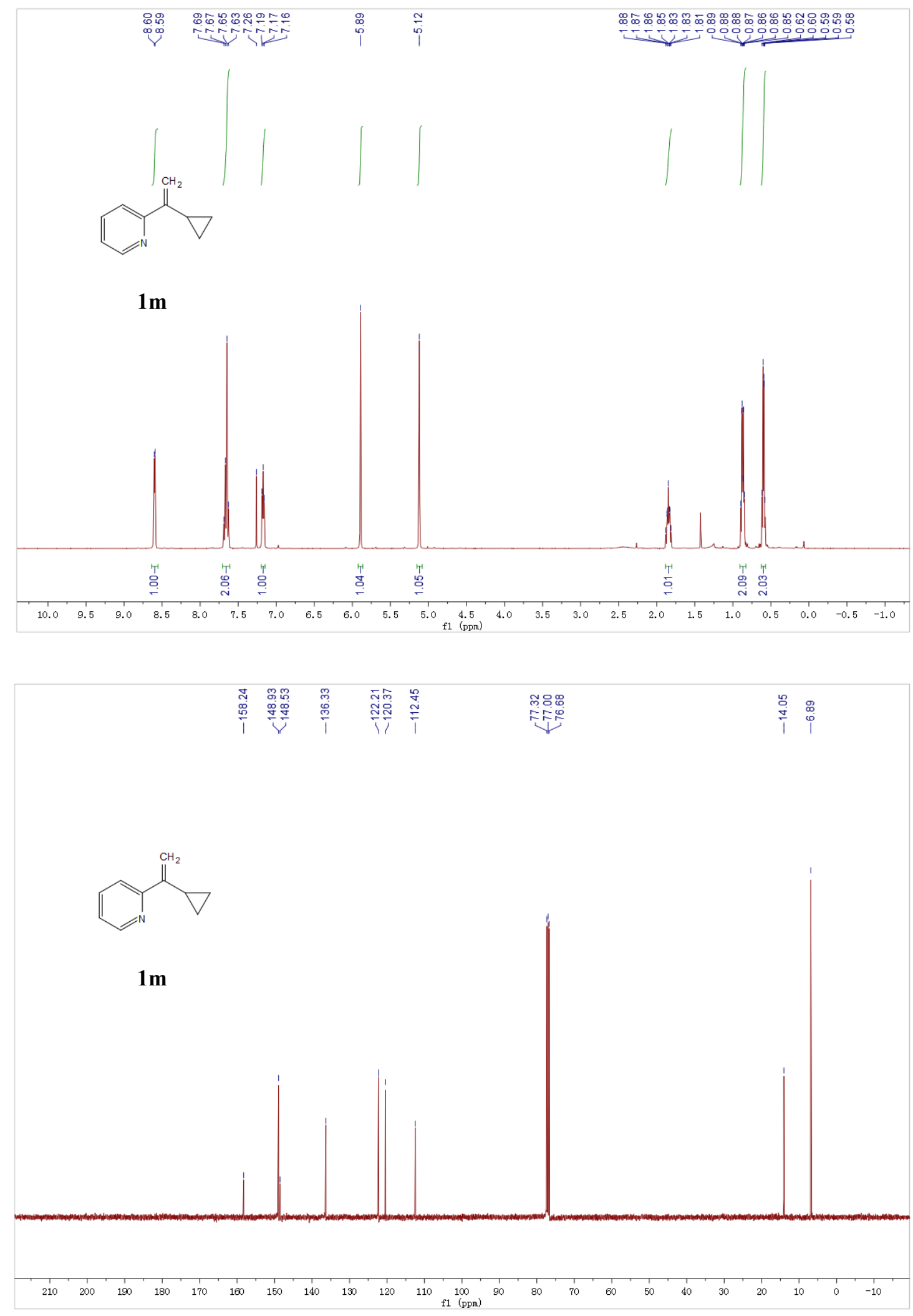

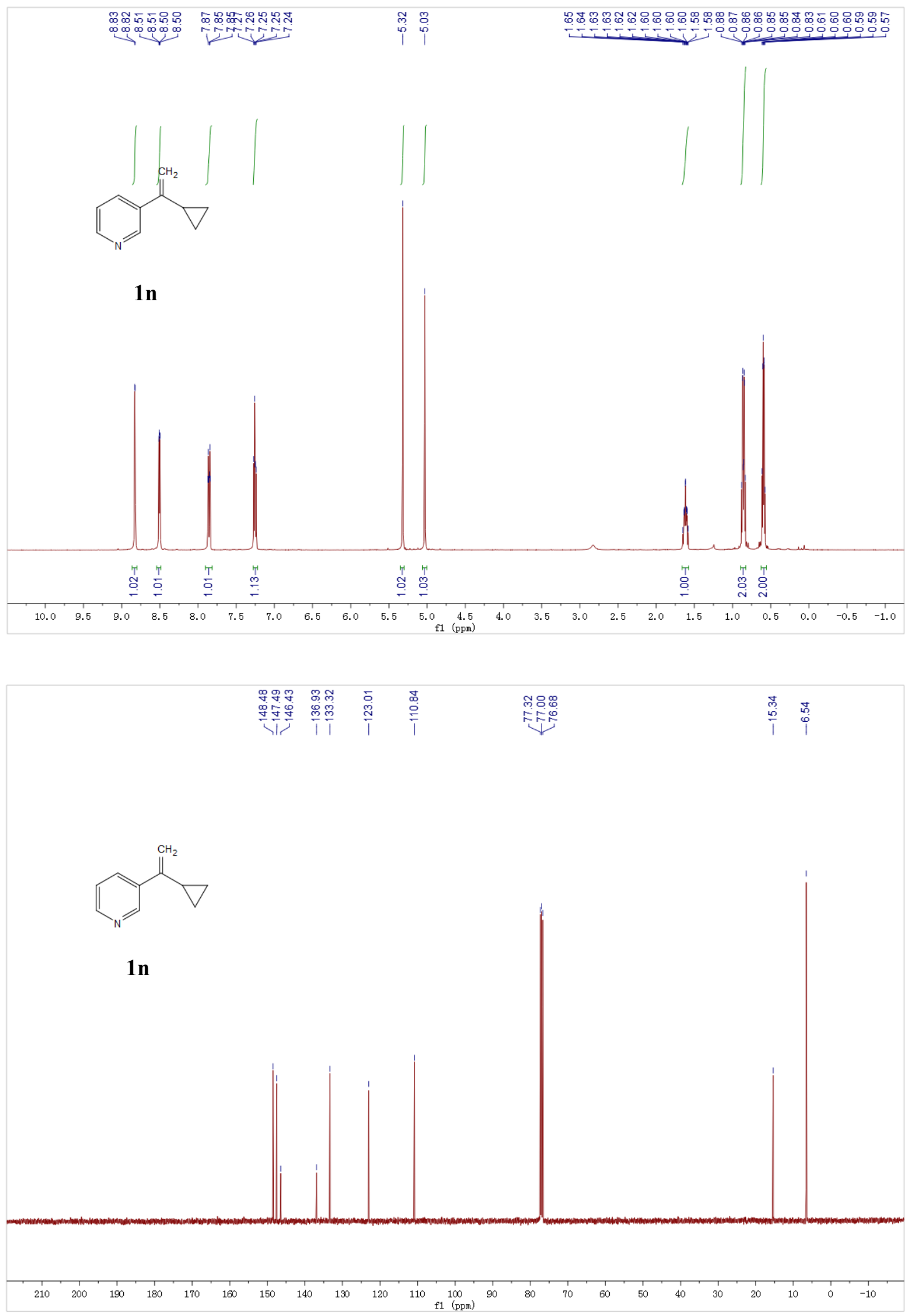

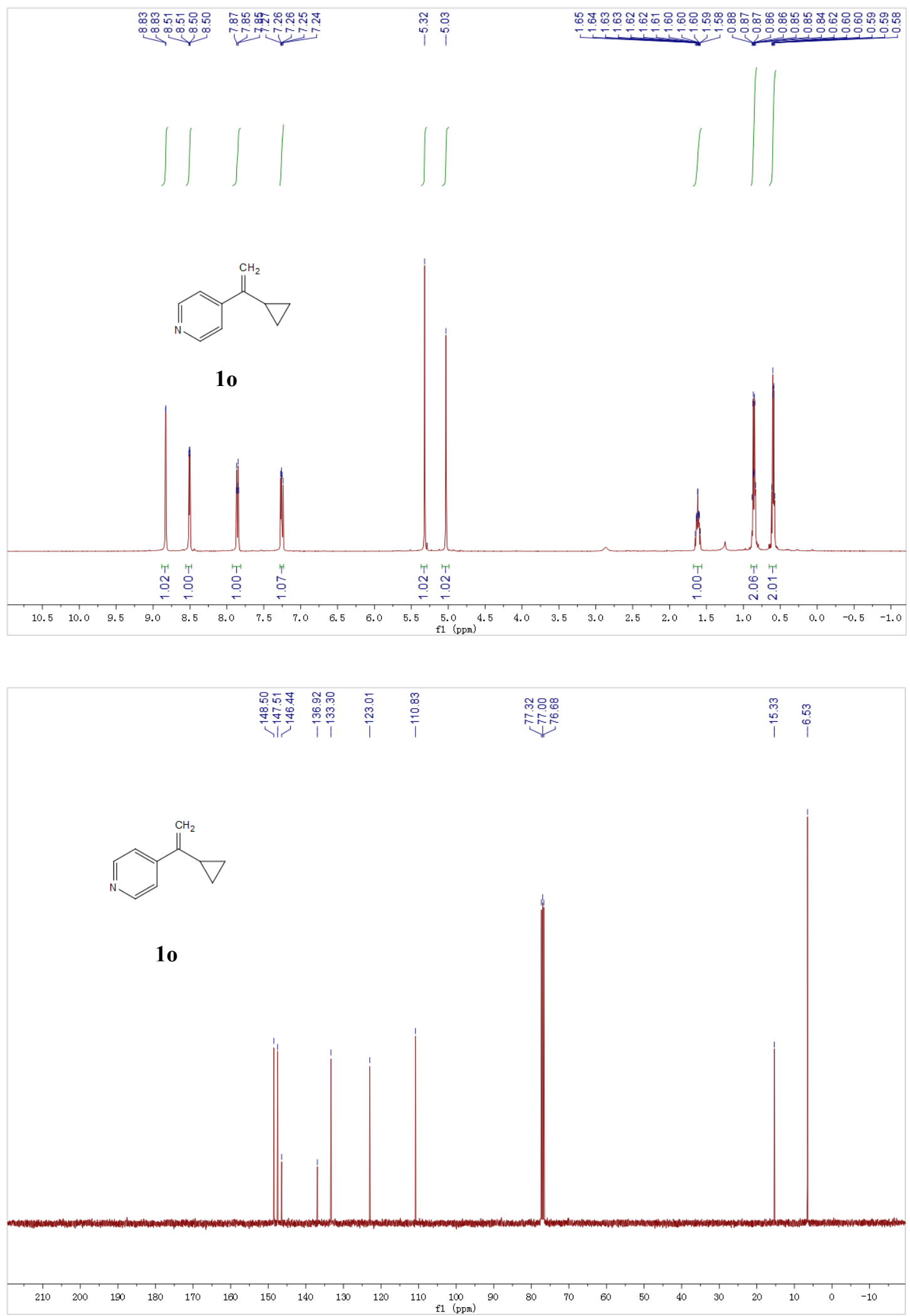

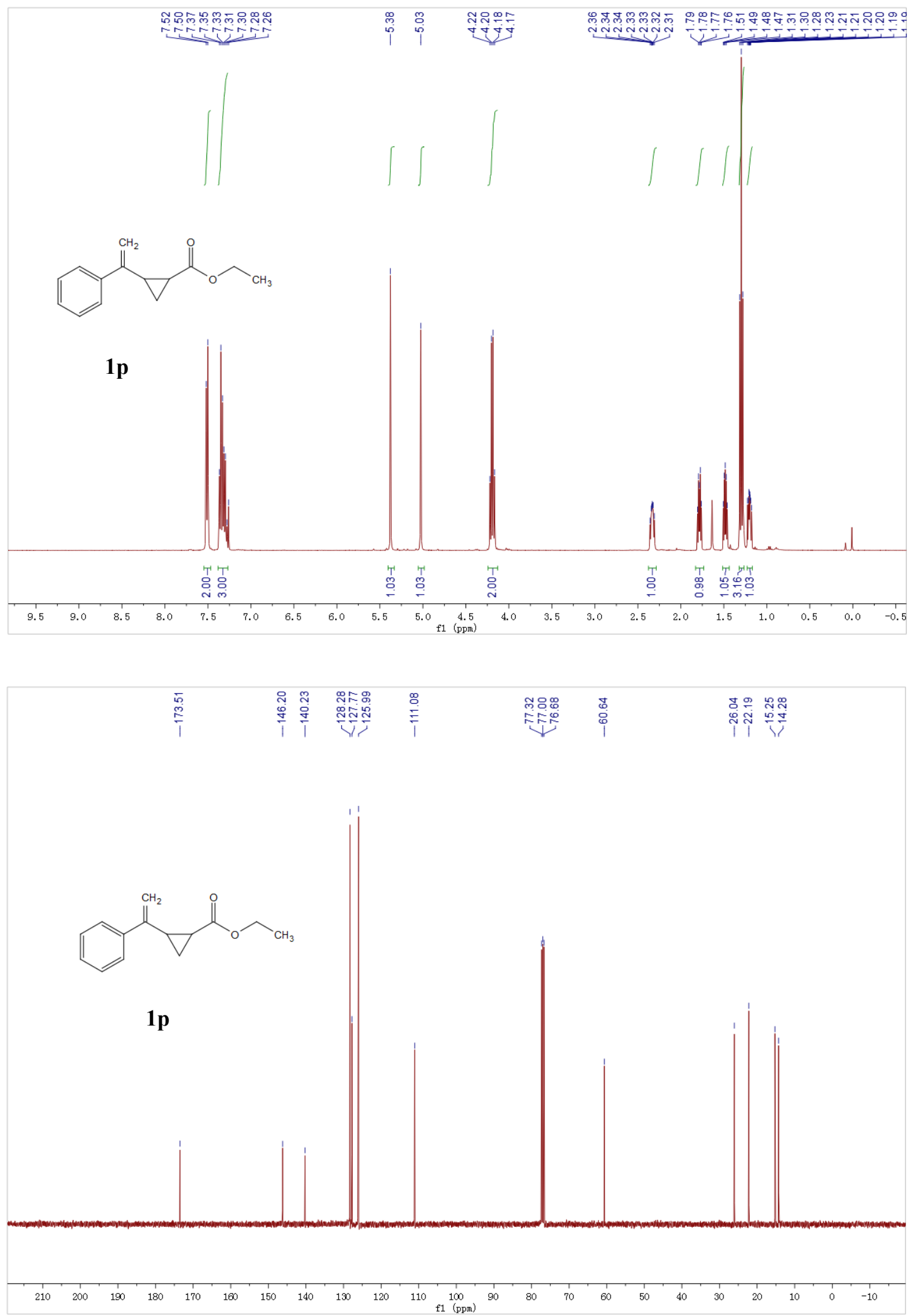

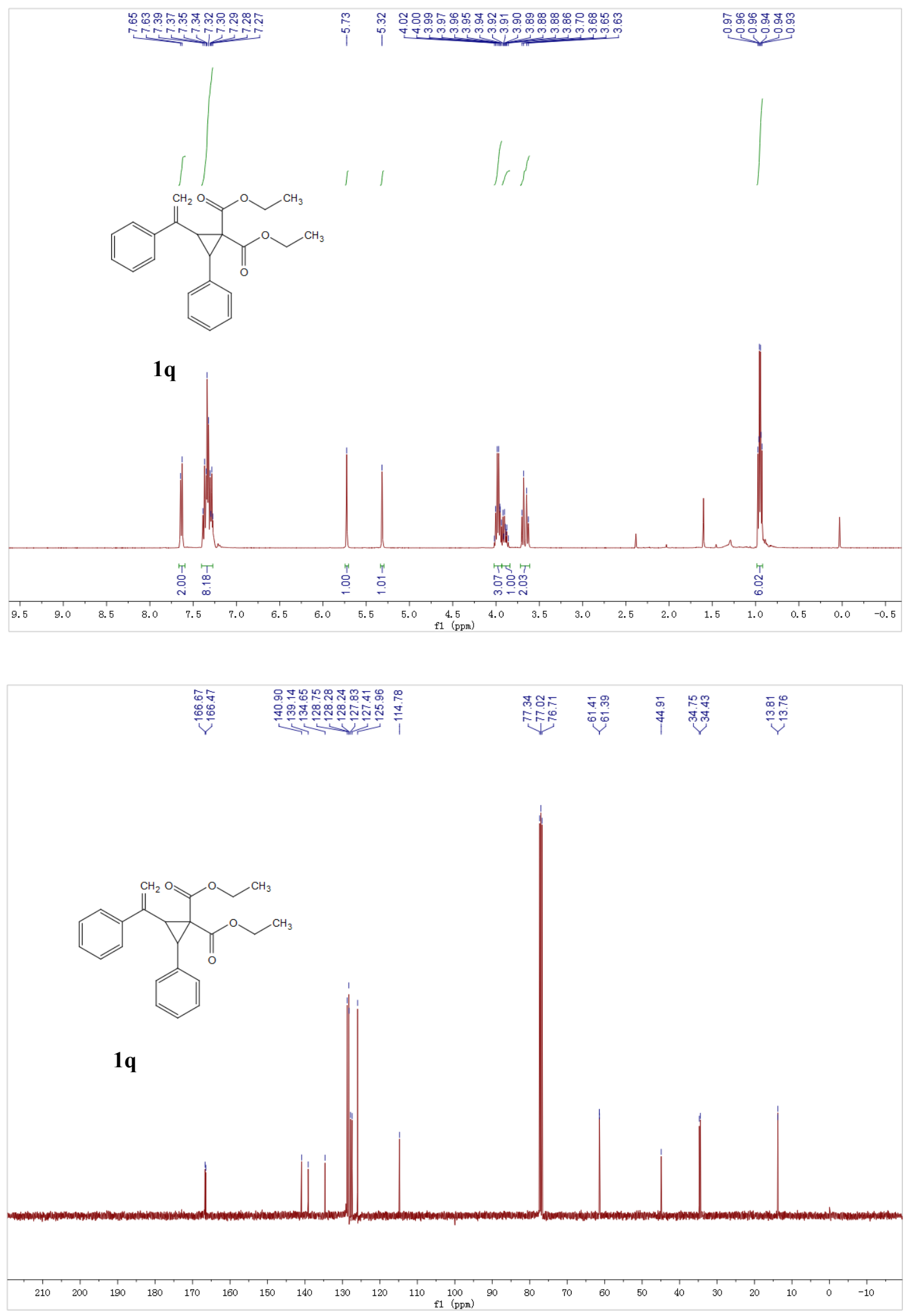

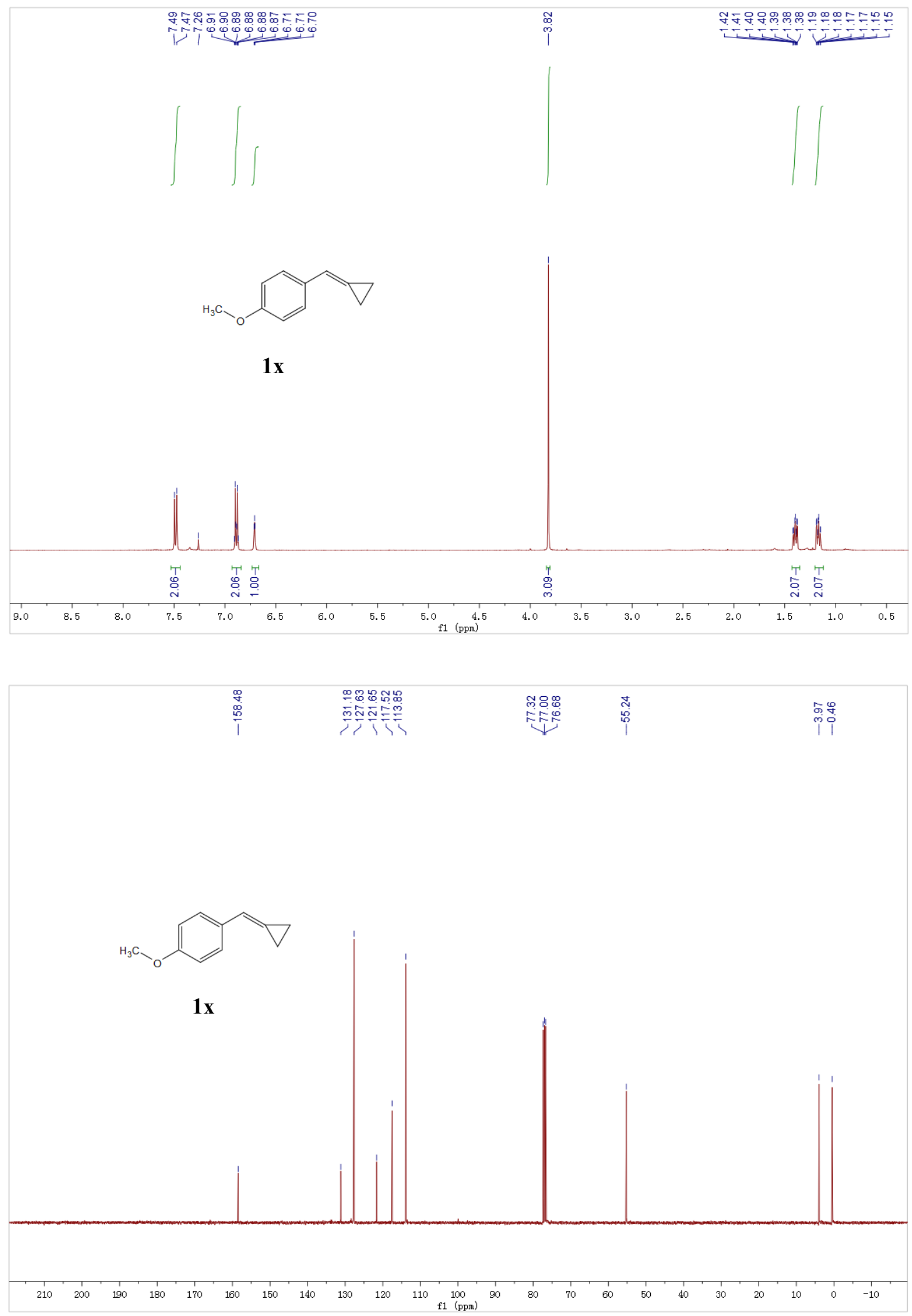


\section{Copies of ${ }^{1} \mathrm{H}$ NMR and ${ }^{13} \mathrm{C}$ NMR and ${ }^{19} \mathrm{~F}$ Spectra for the Products}

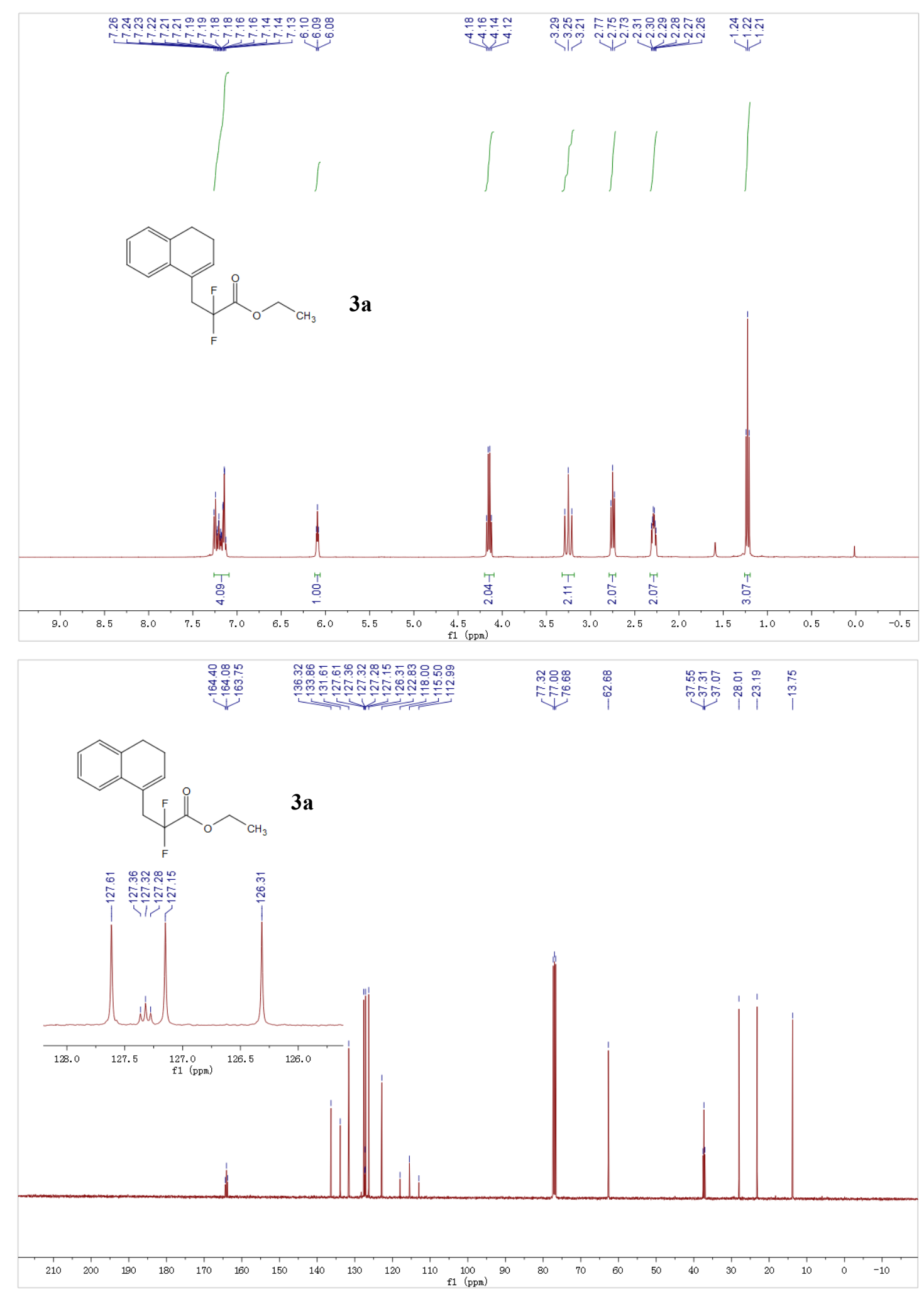



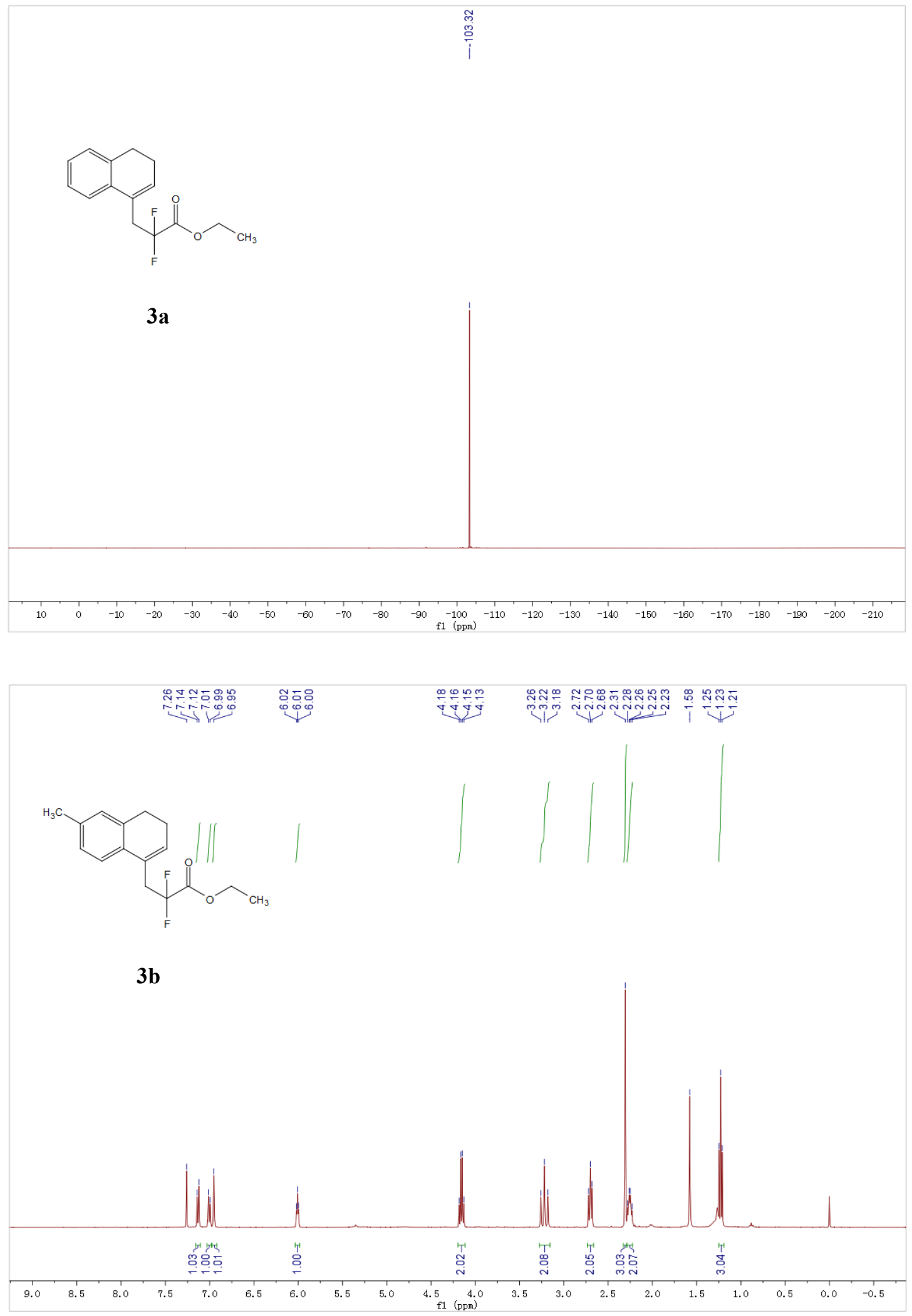

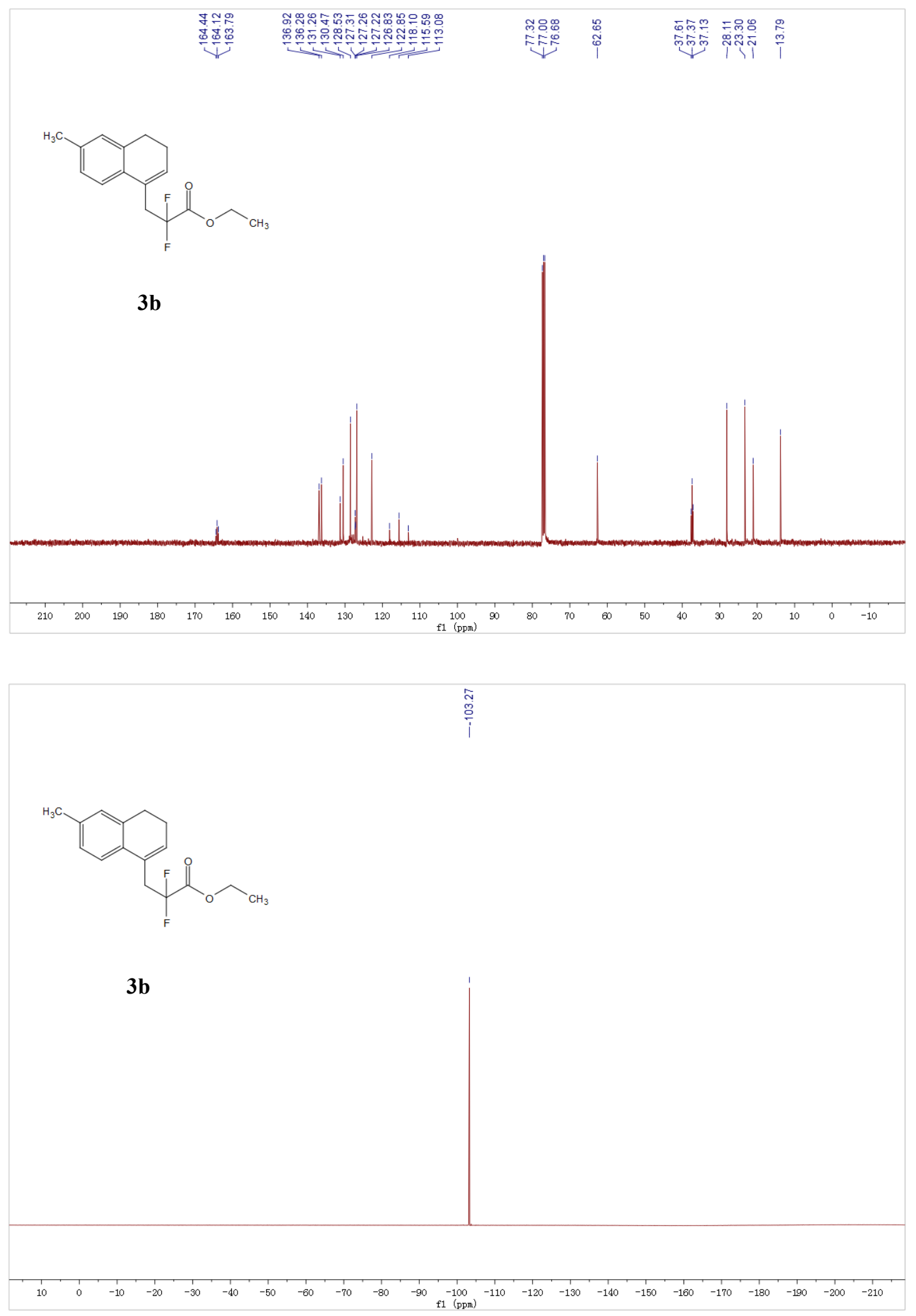

S29 

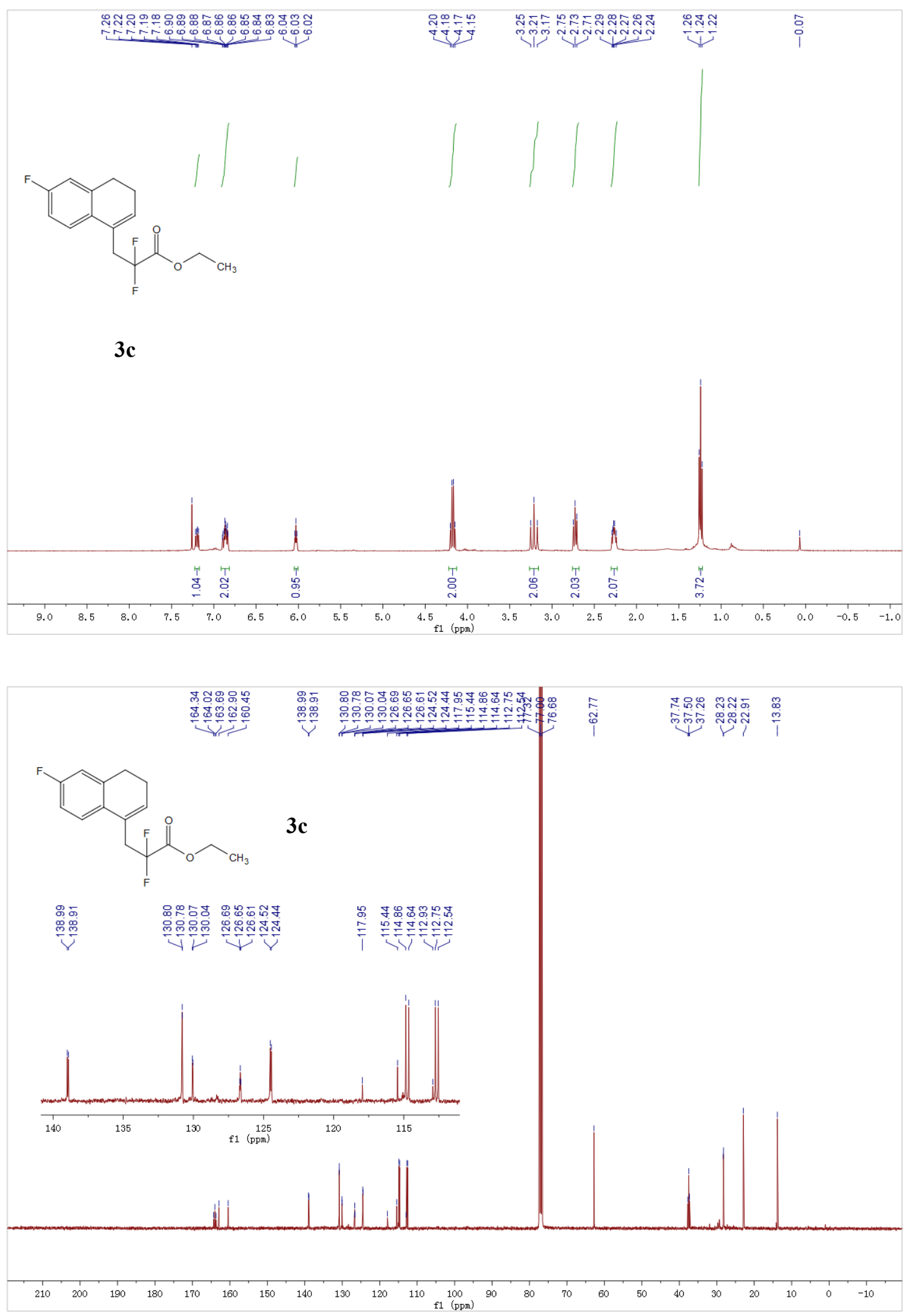

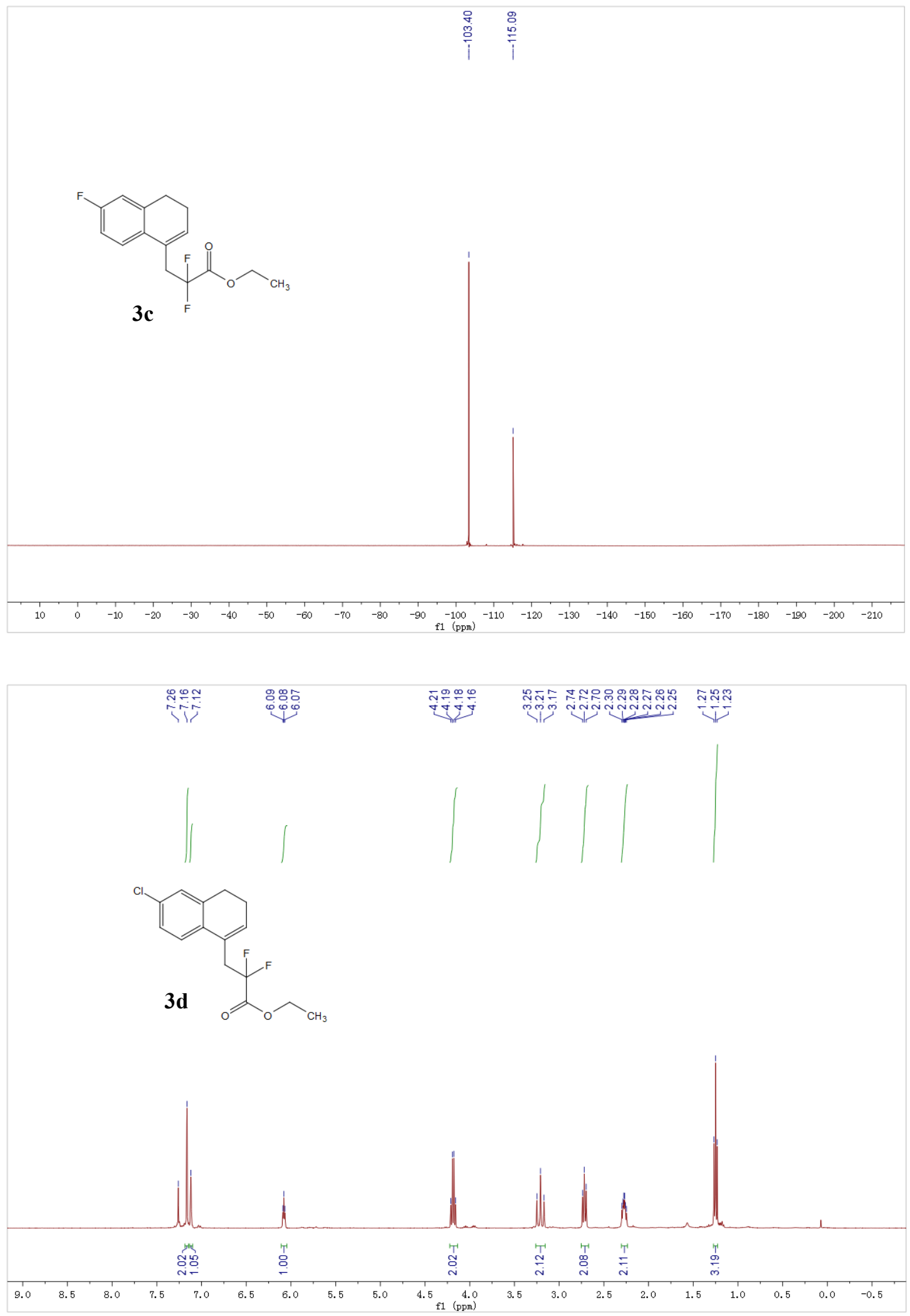

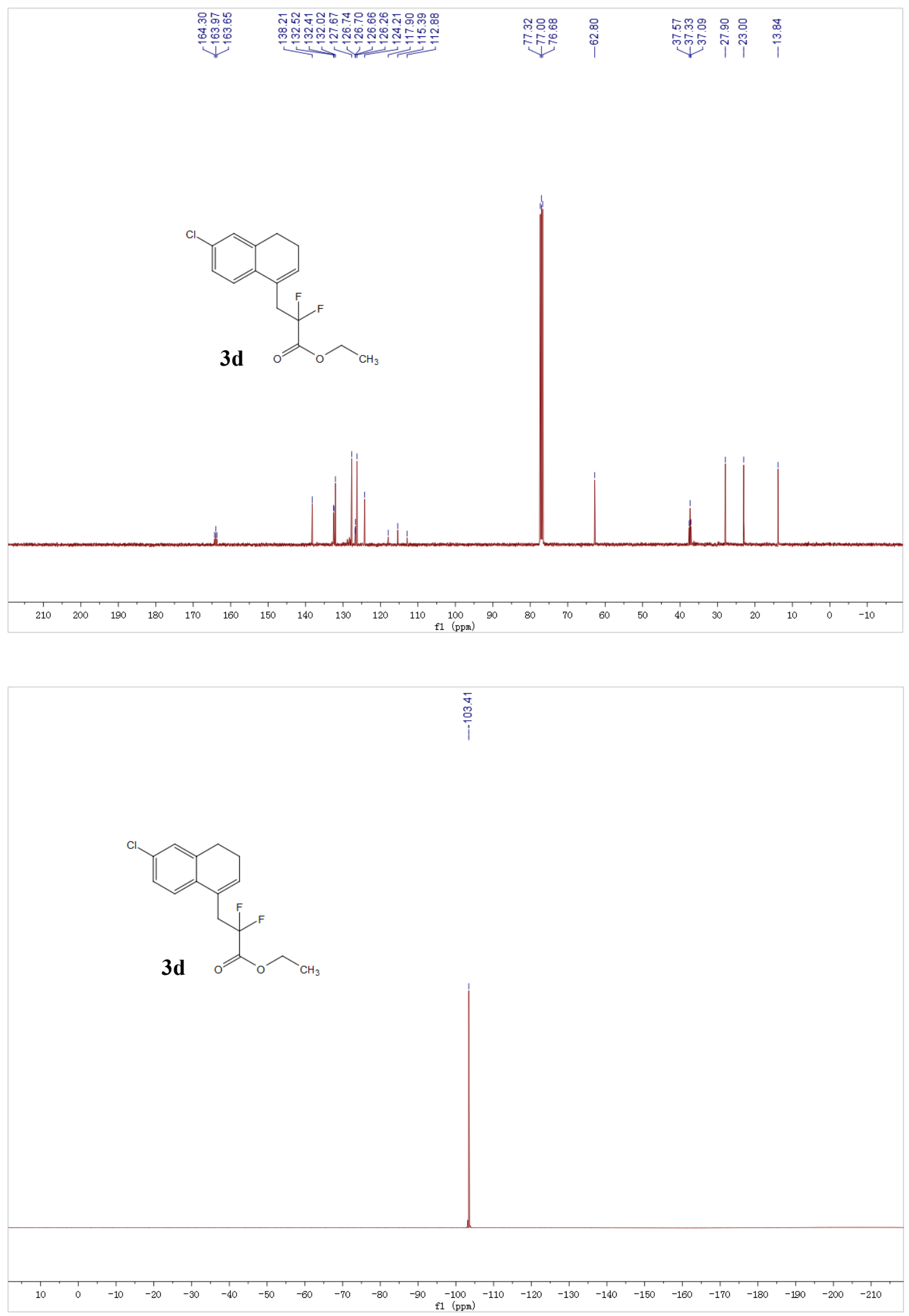

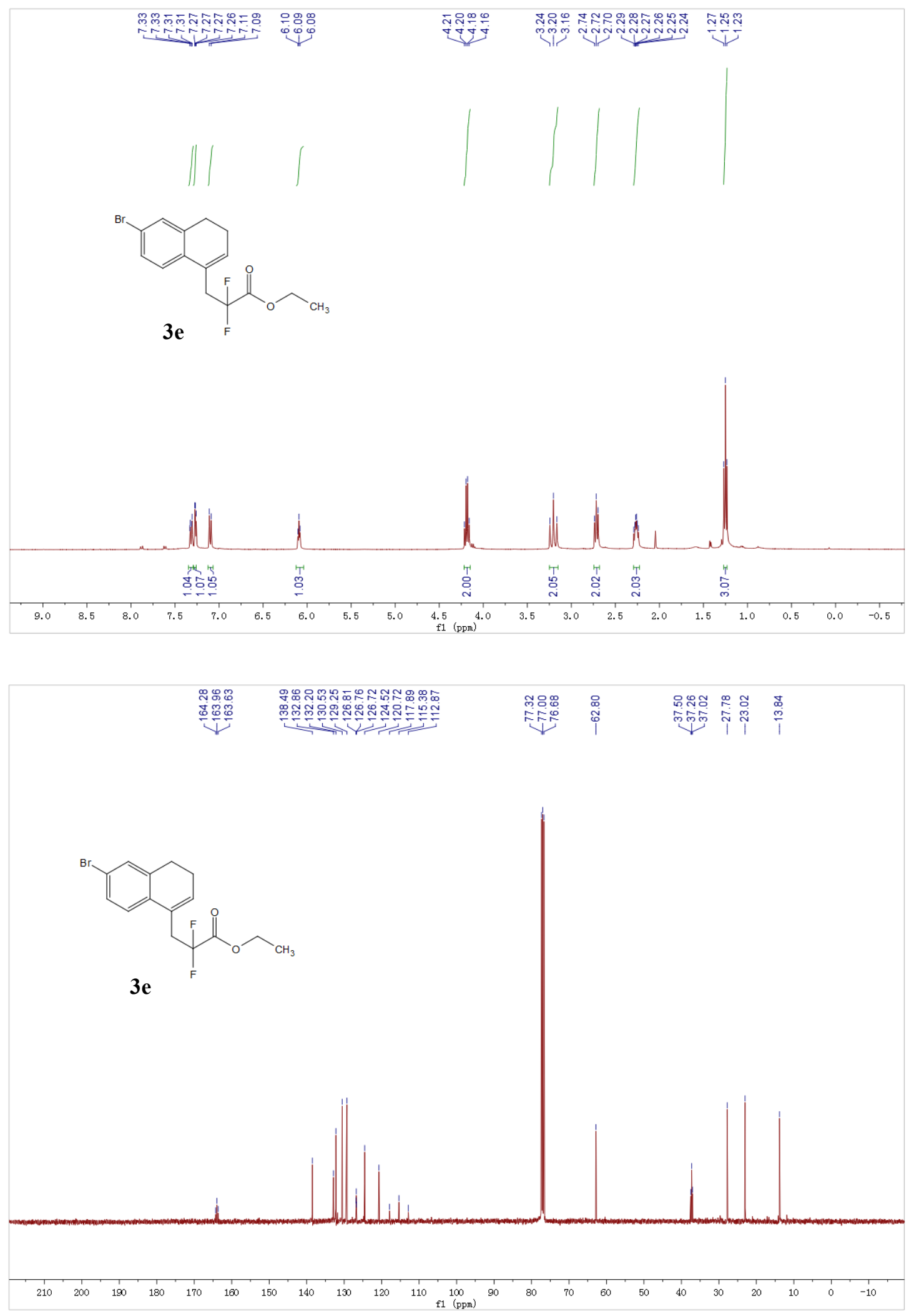

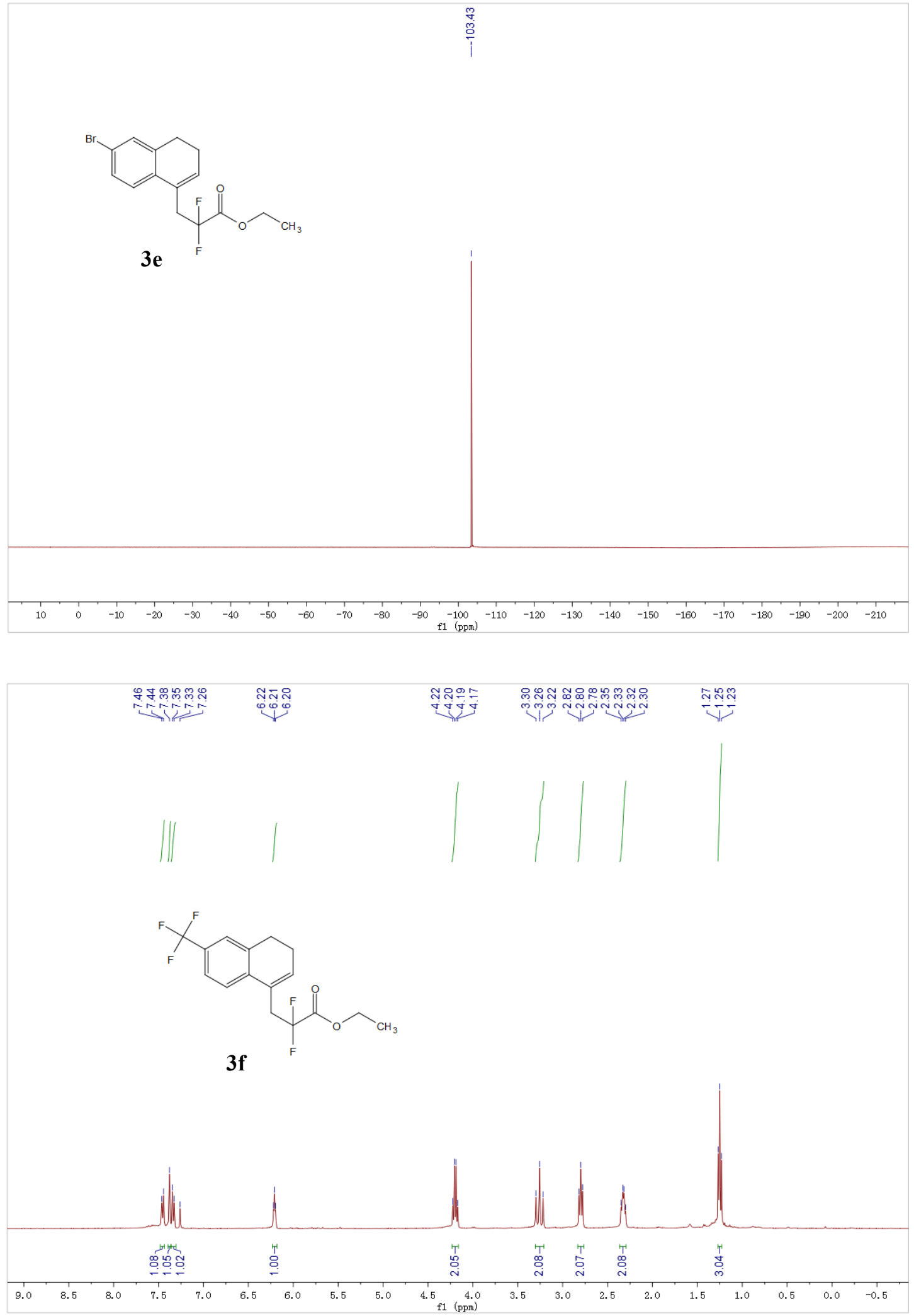

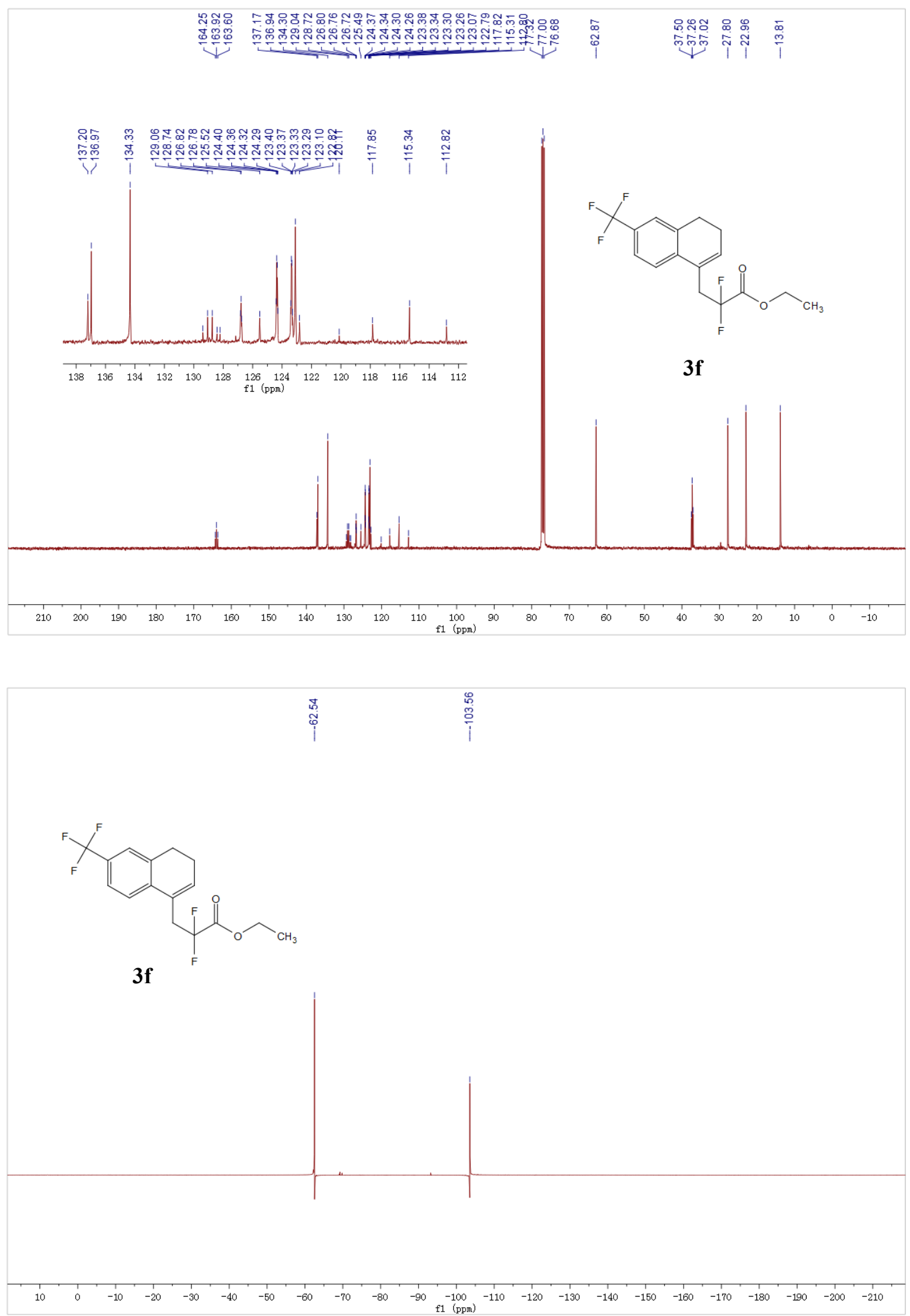

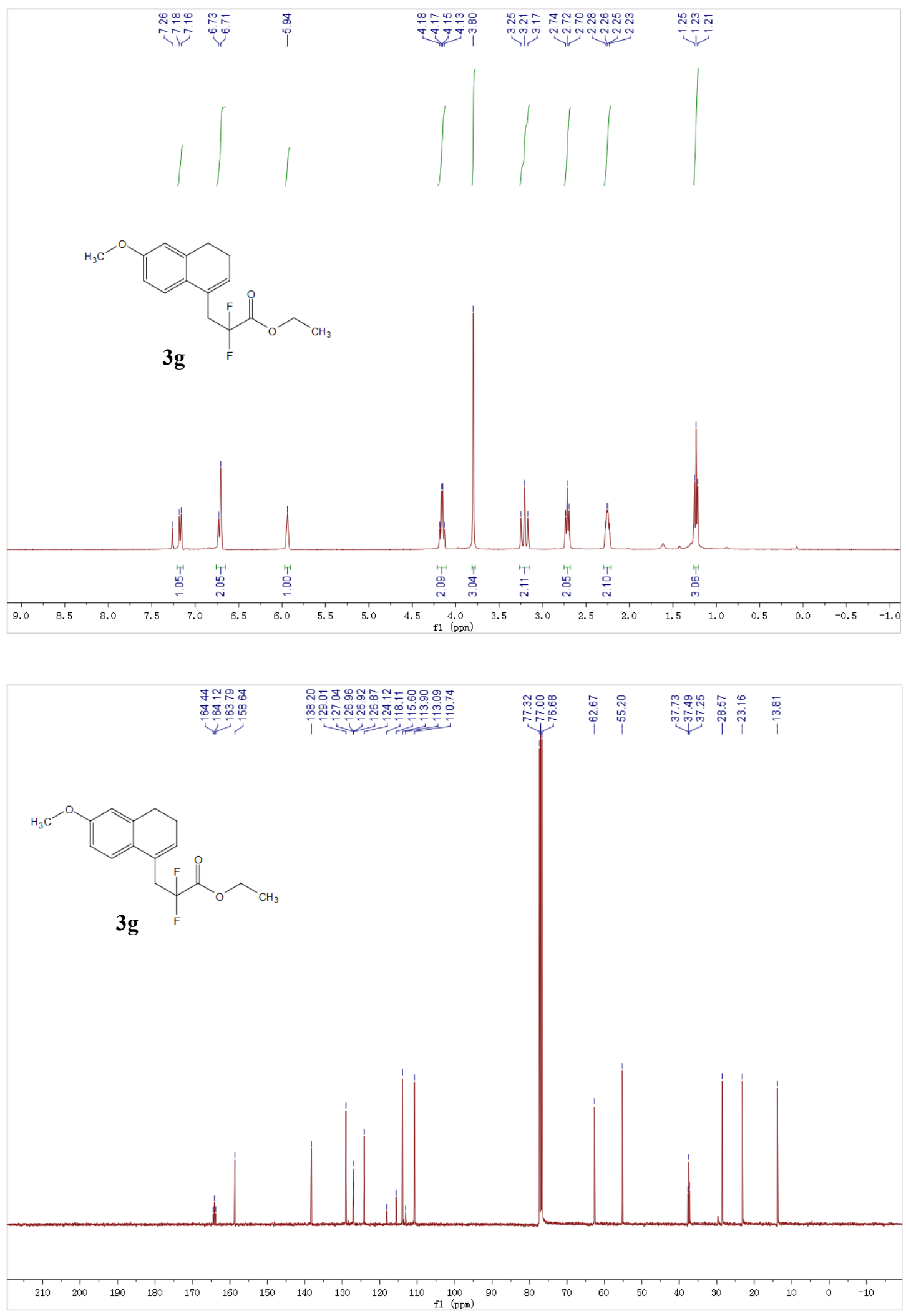

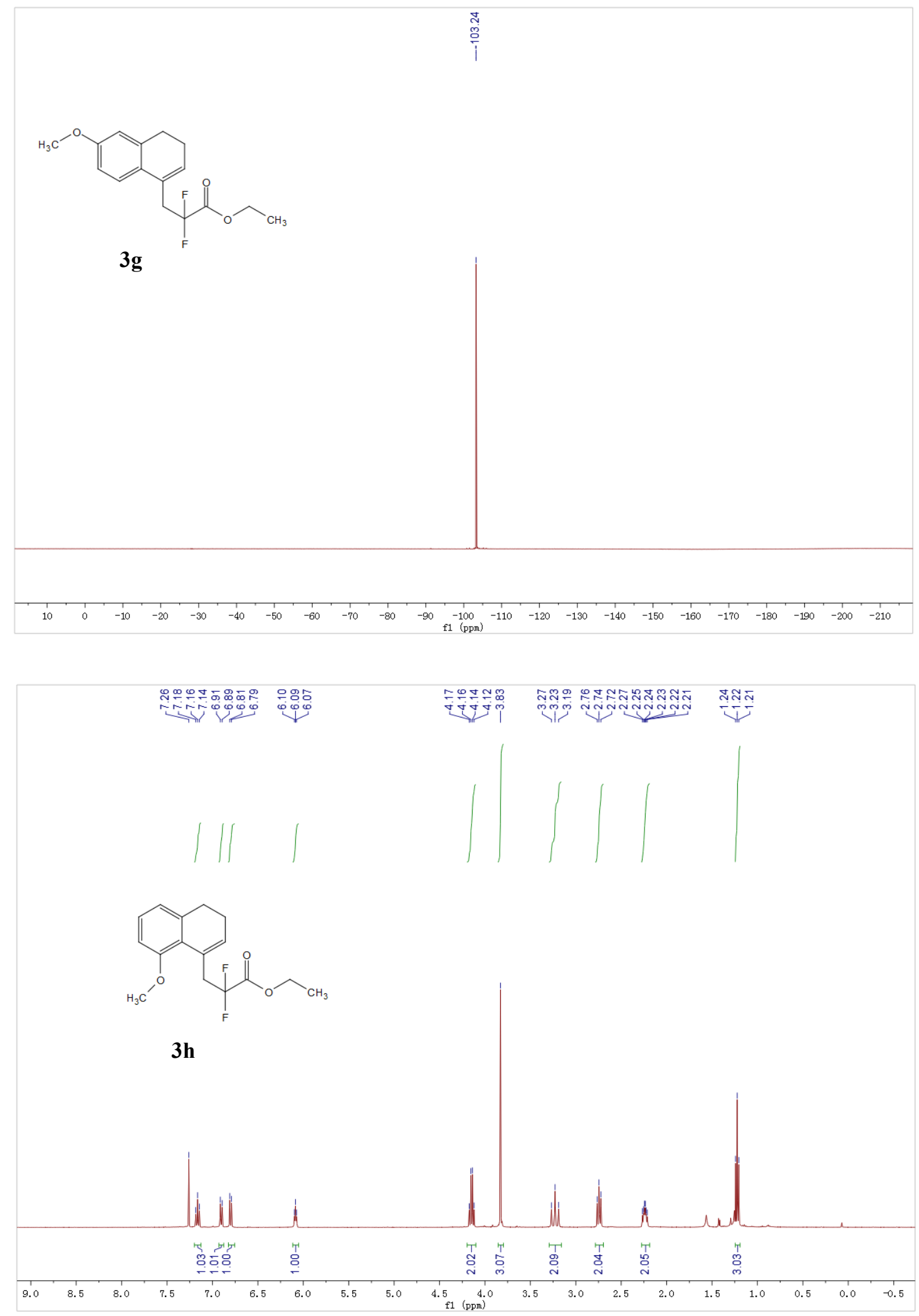

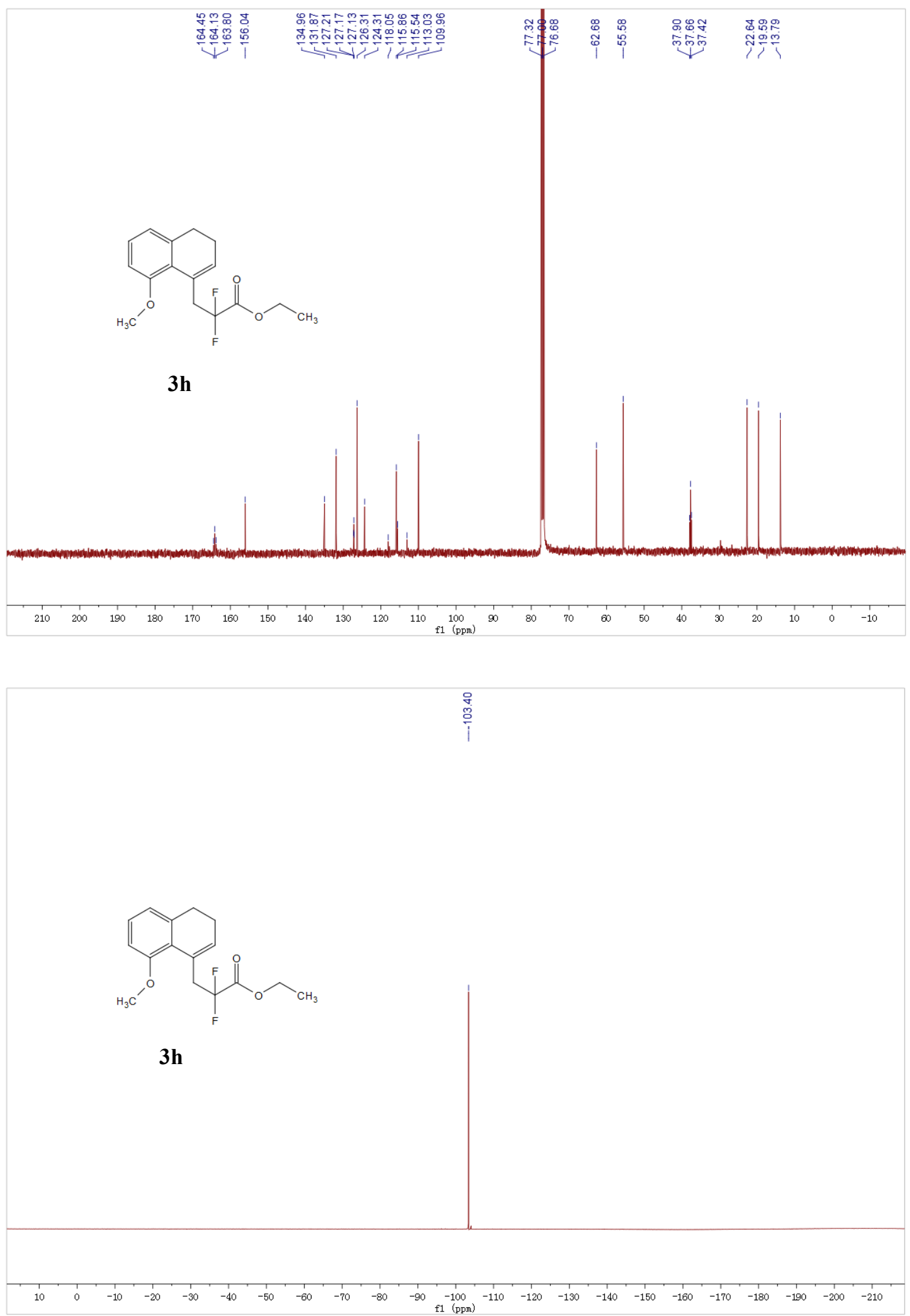

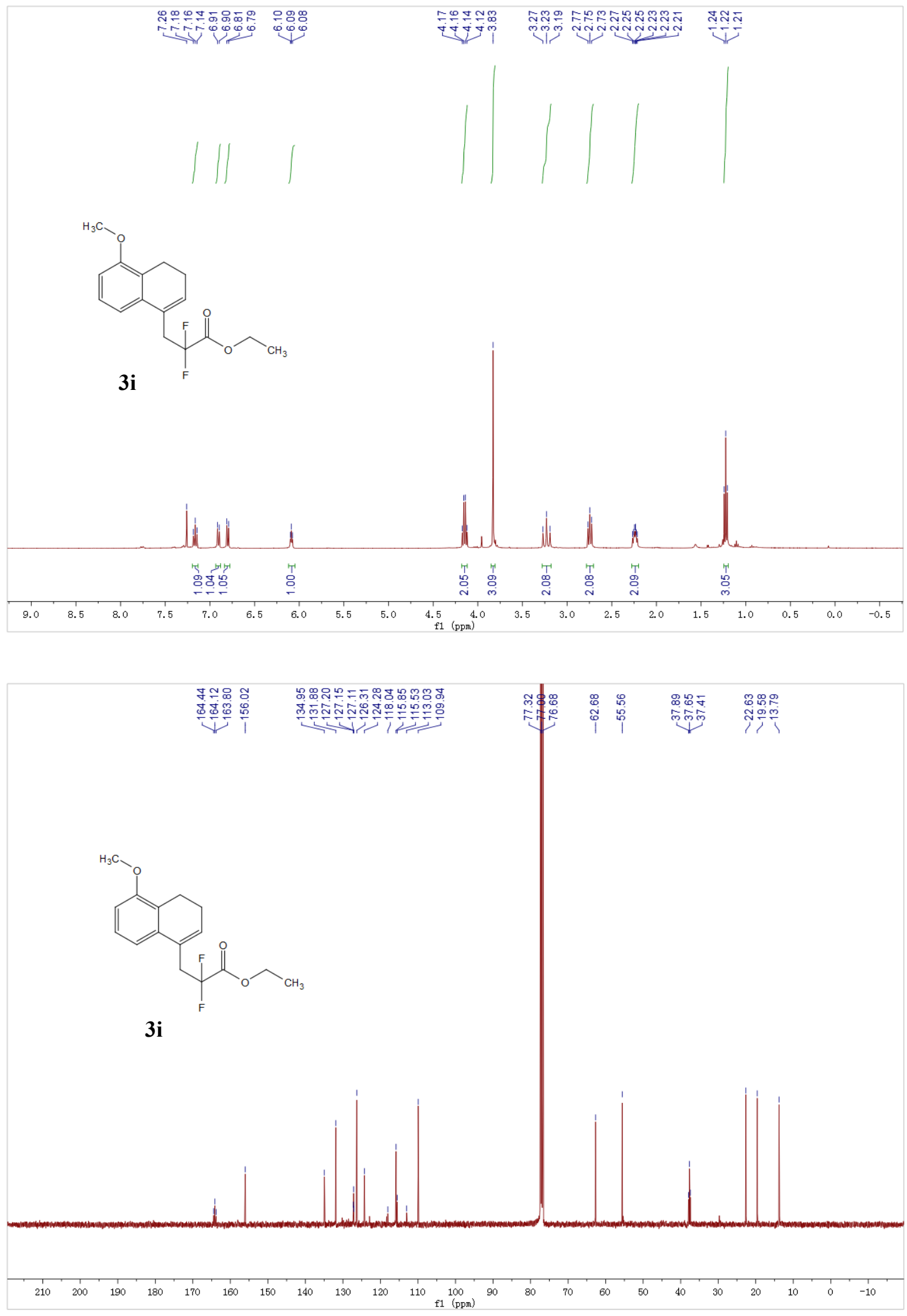


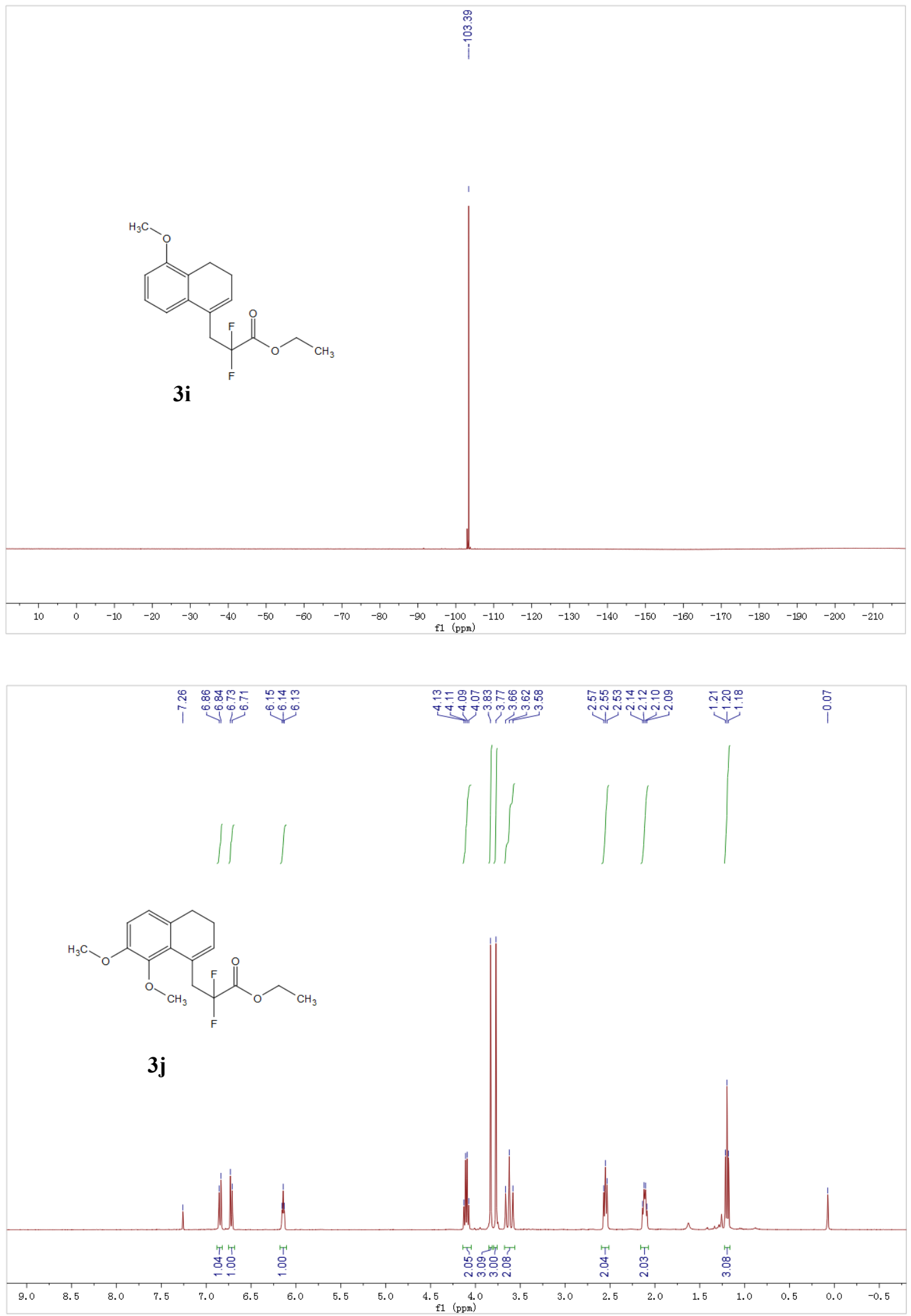



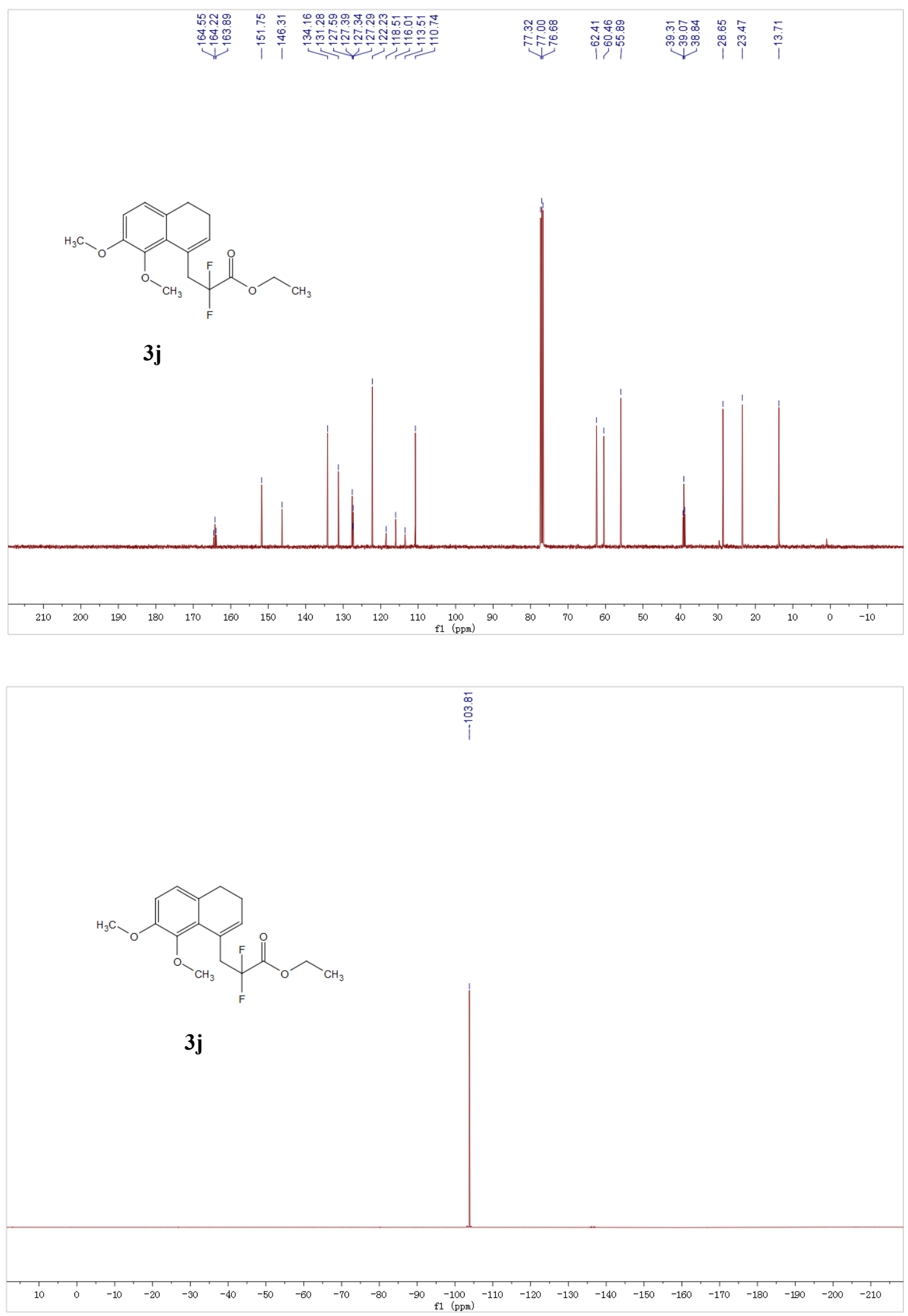

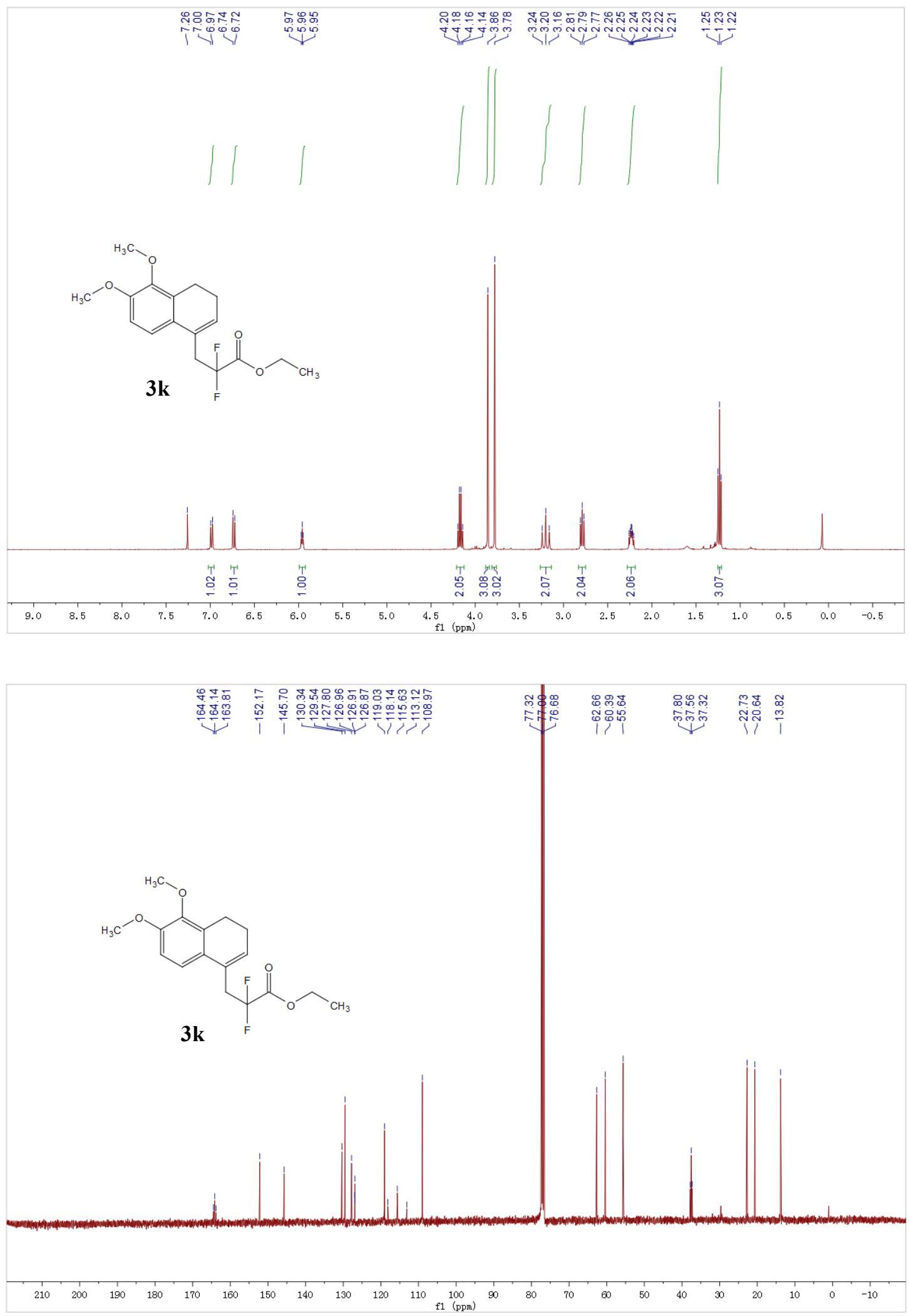

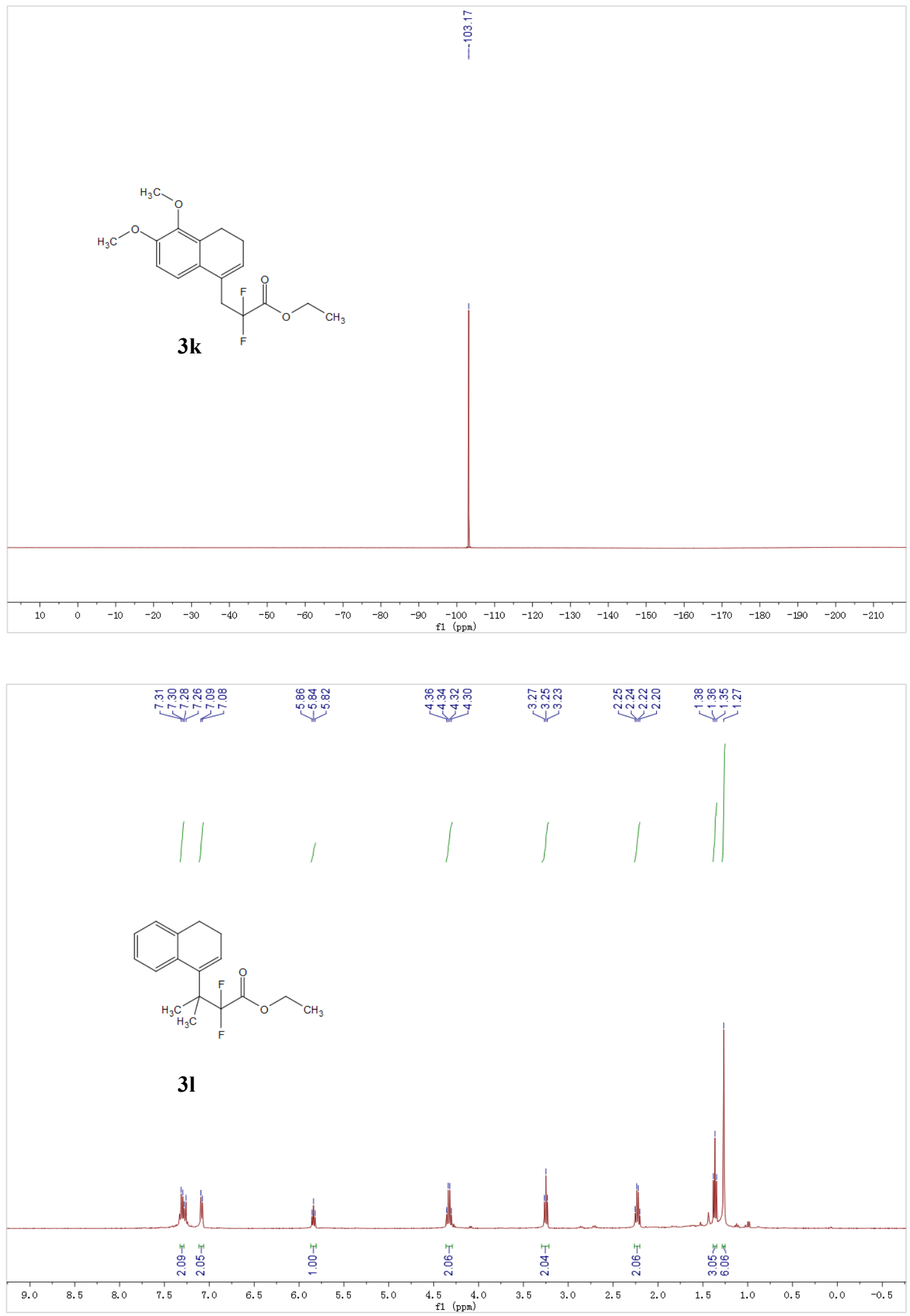

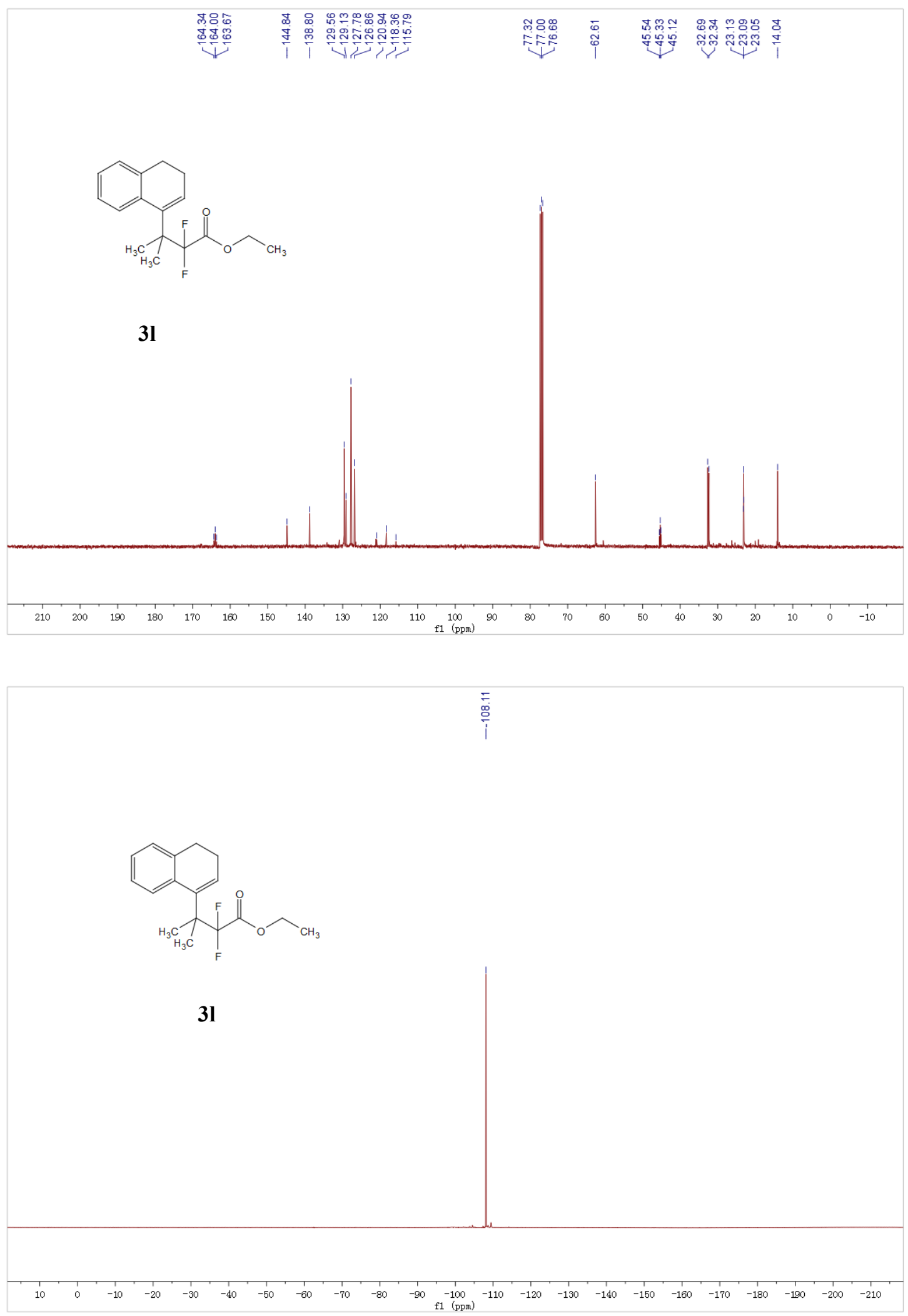

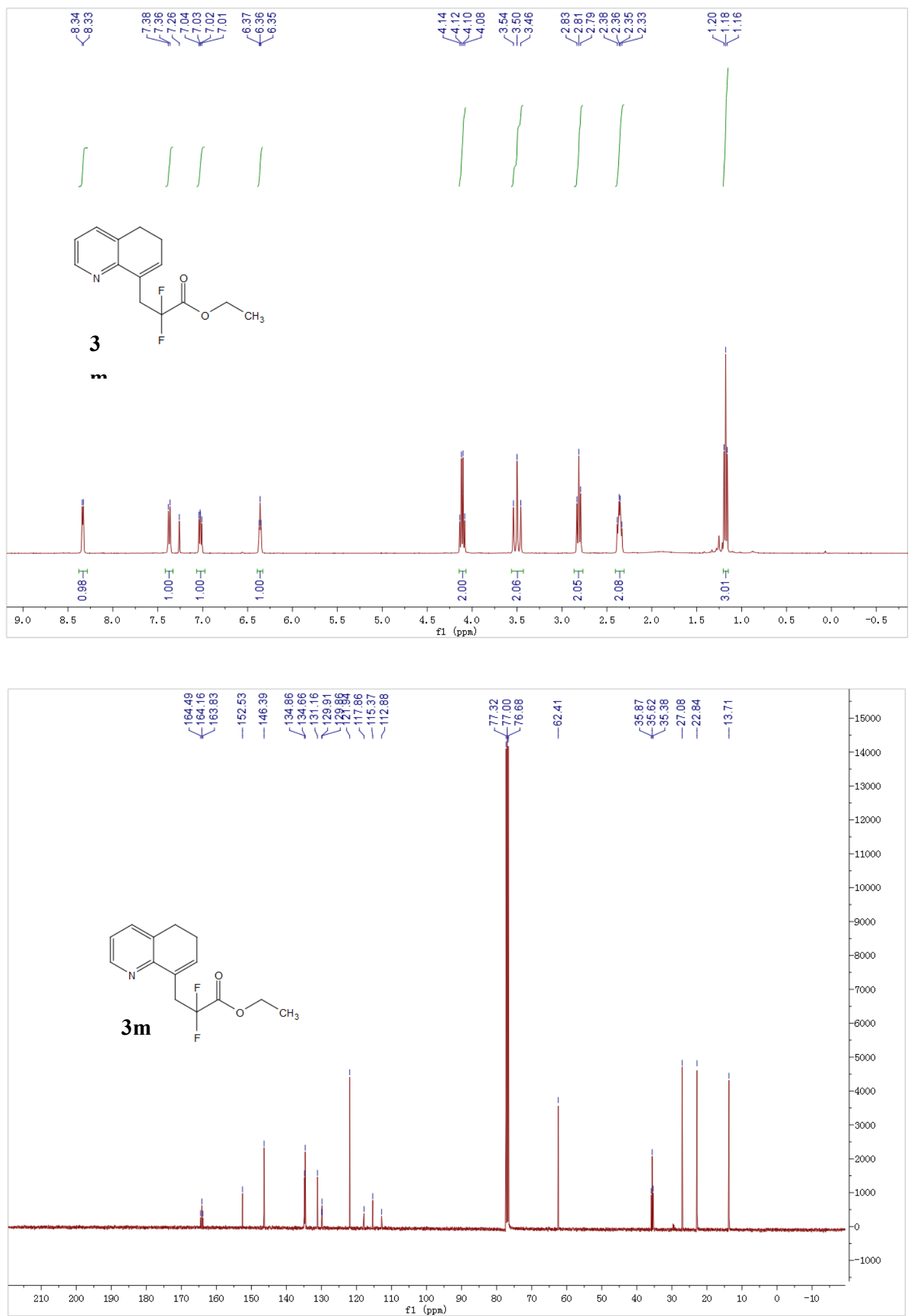

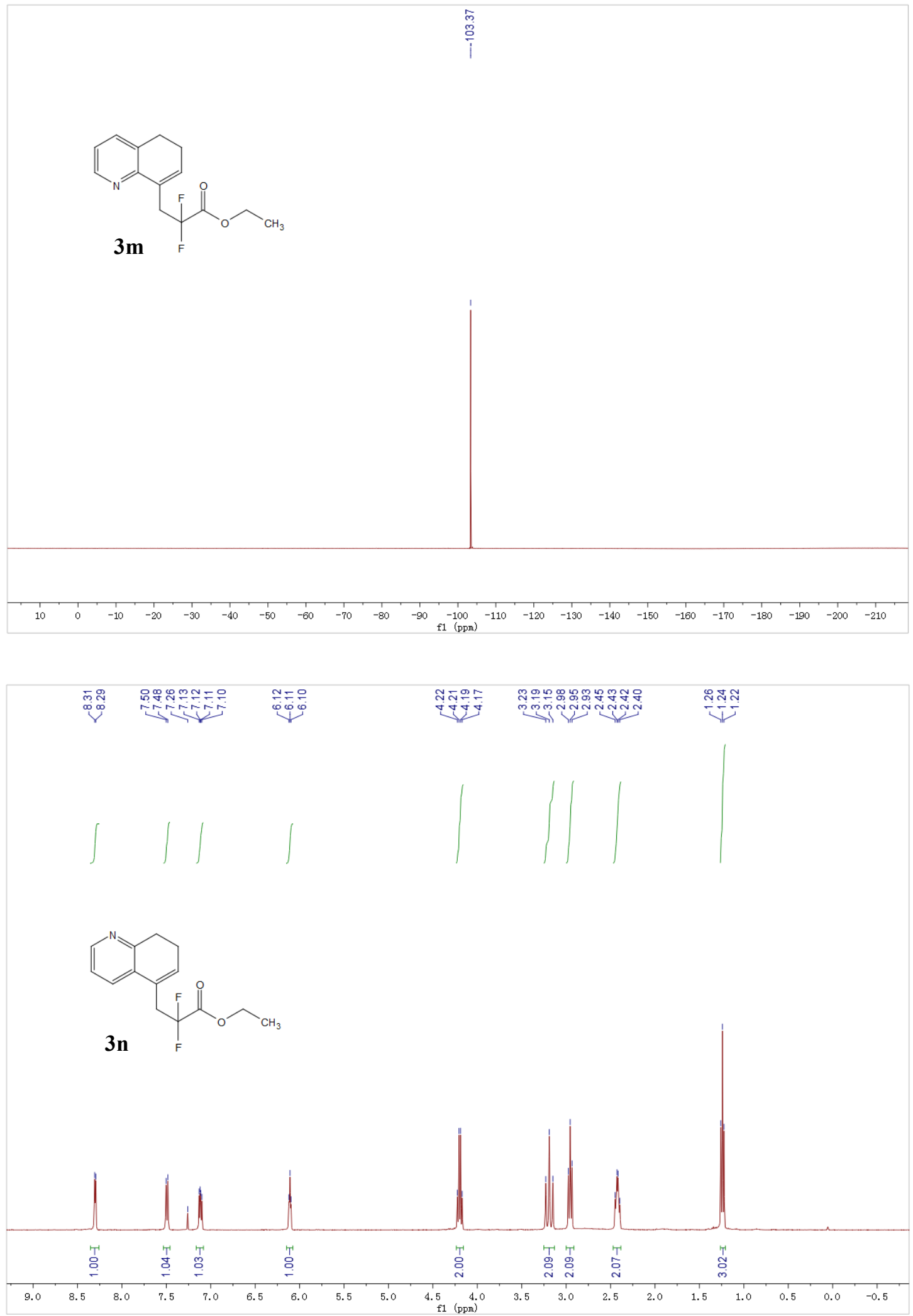

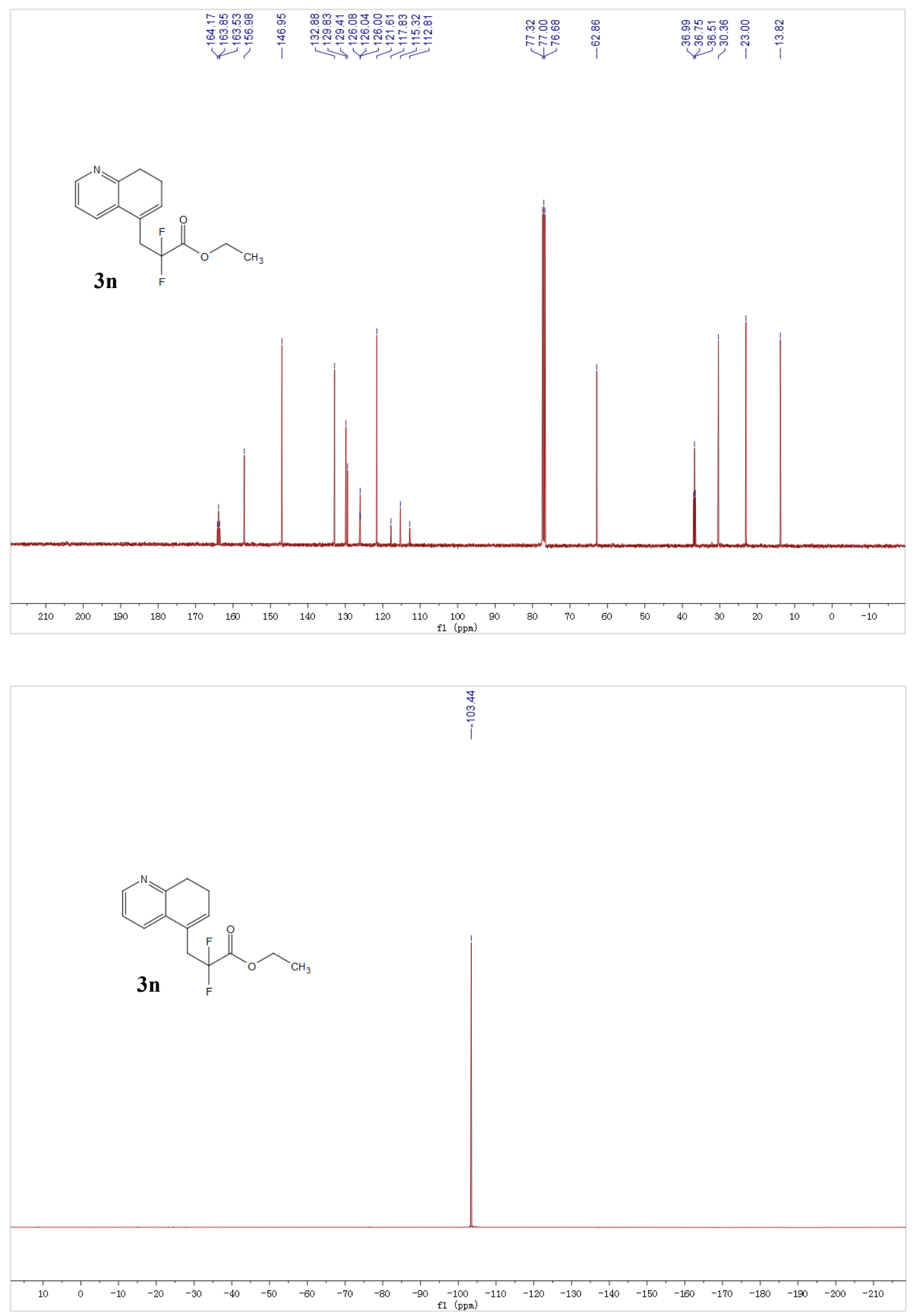

S47 

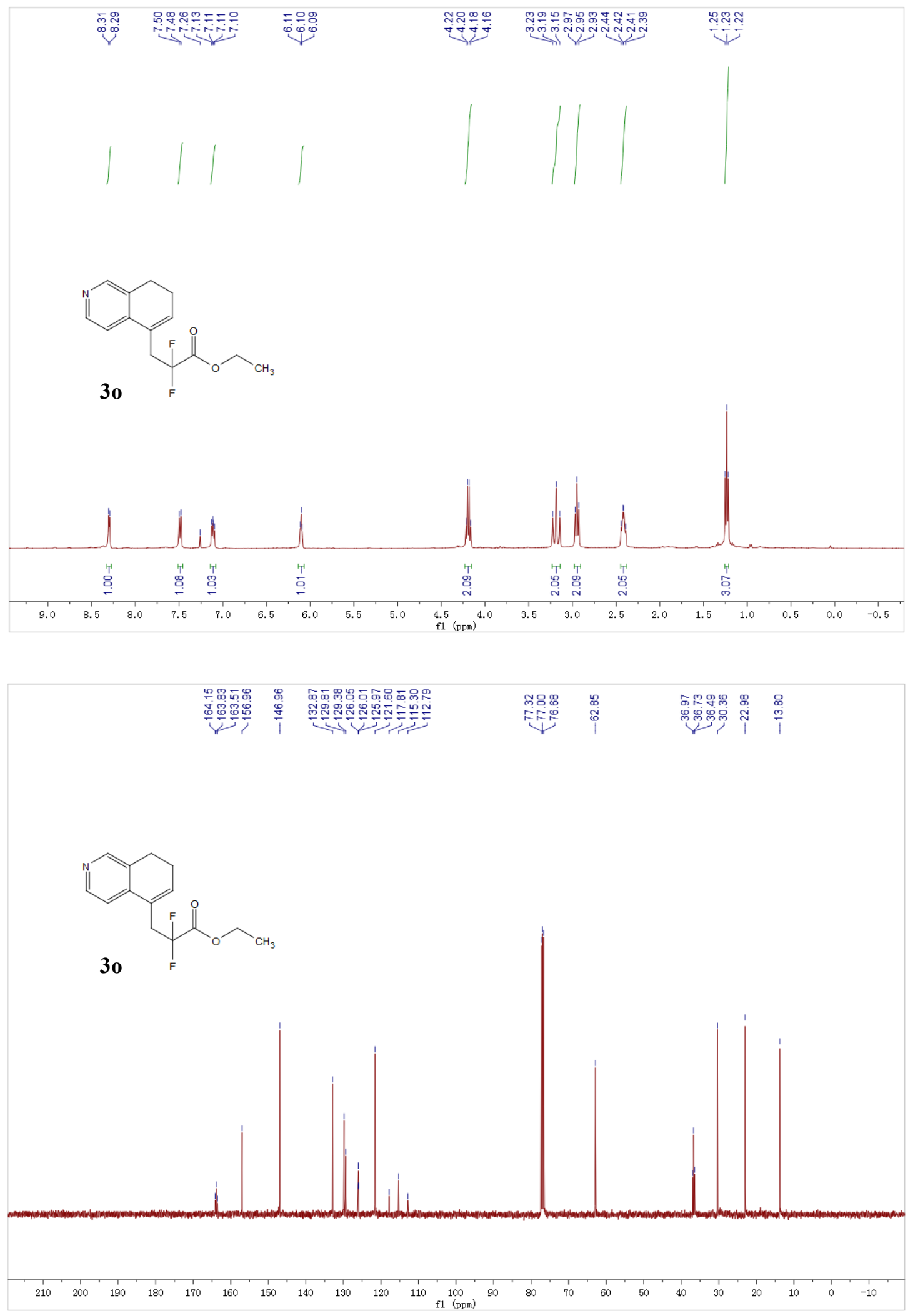

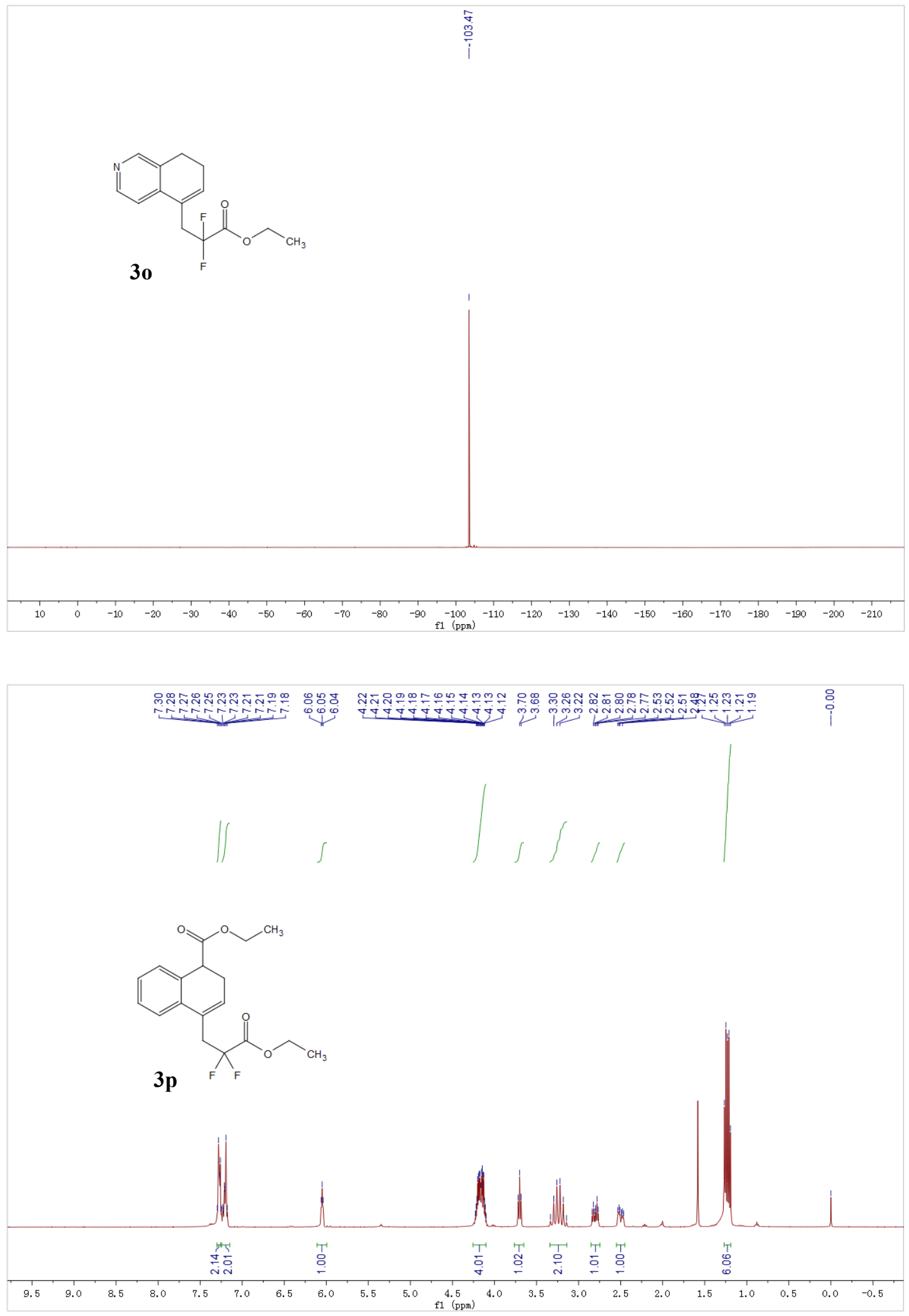

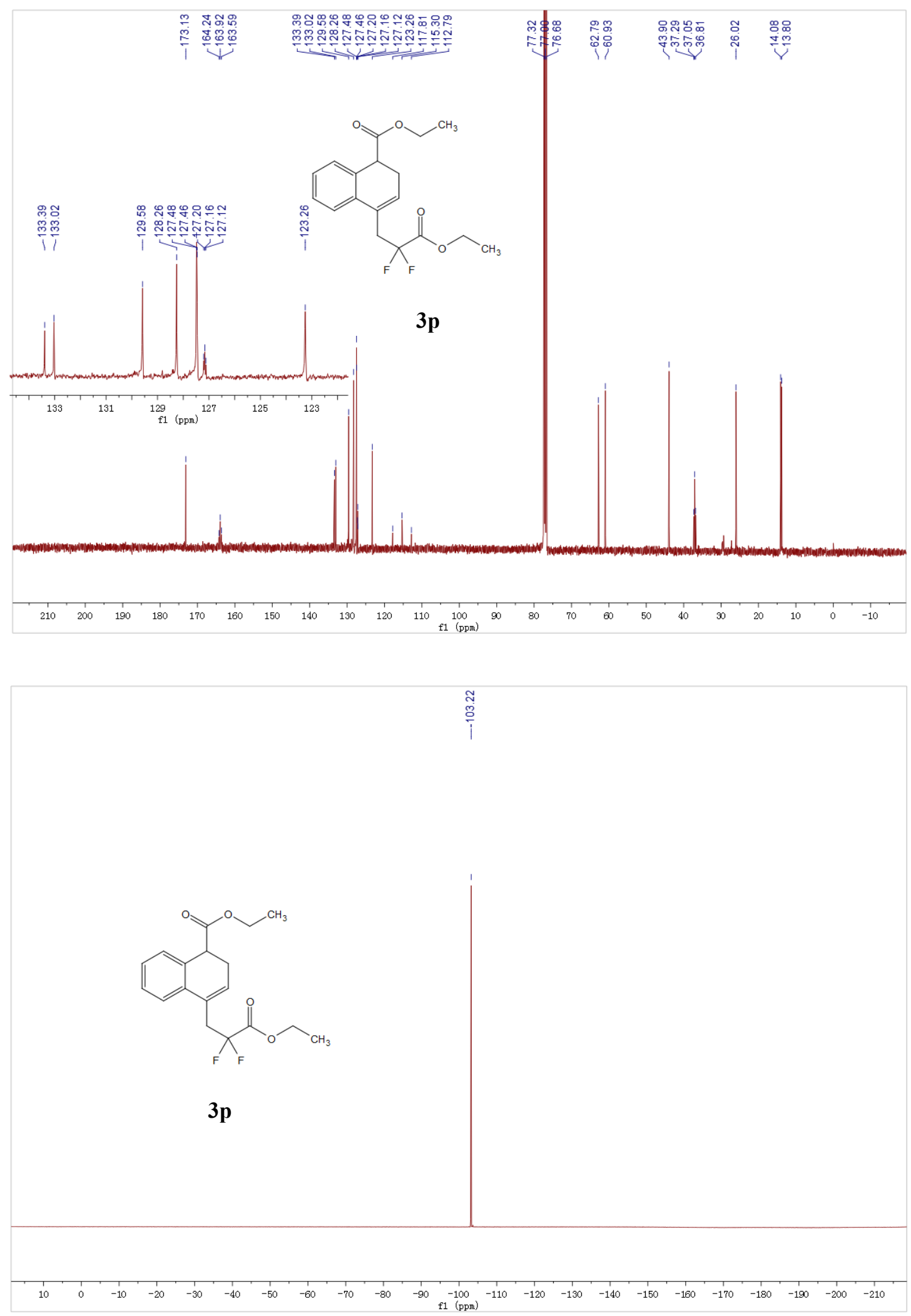

S50 

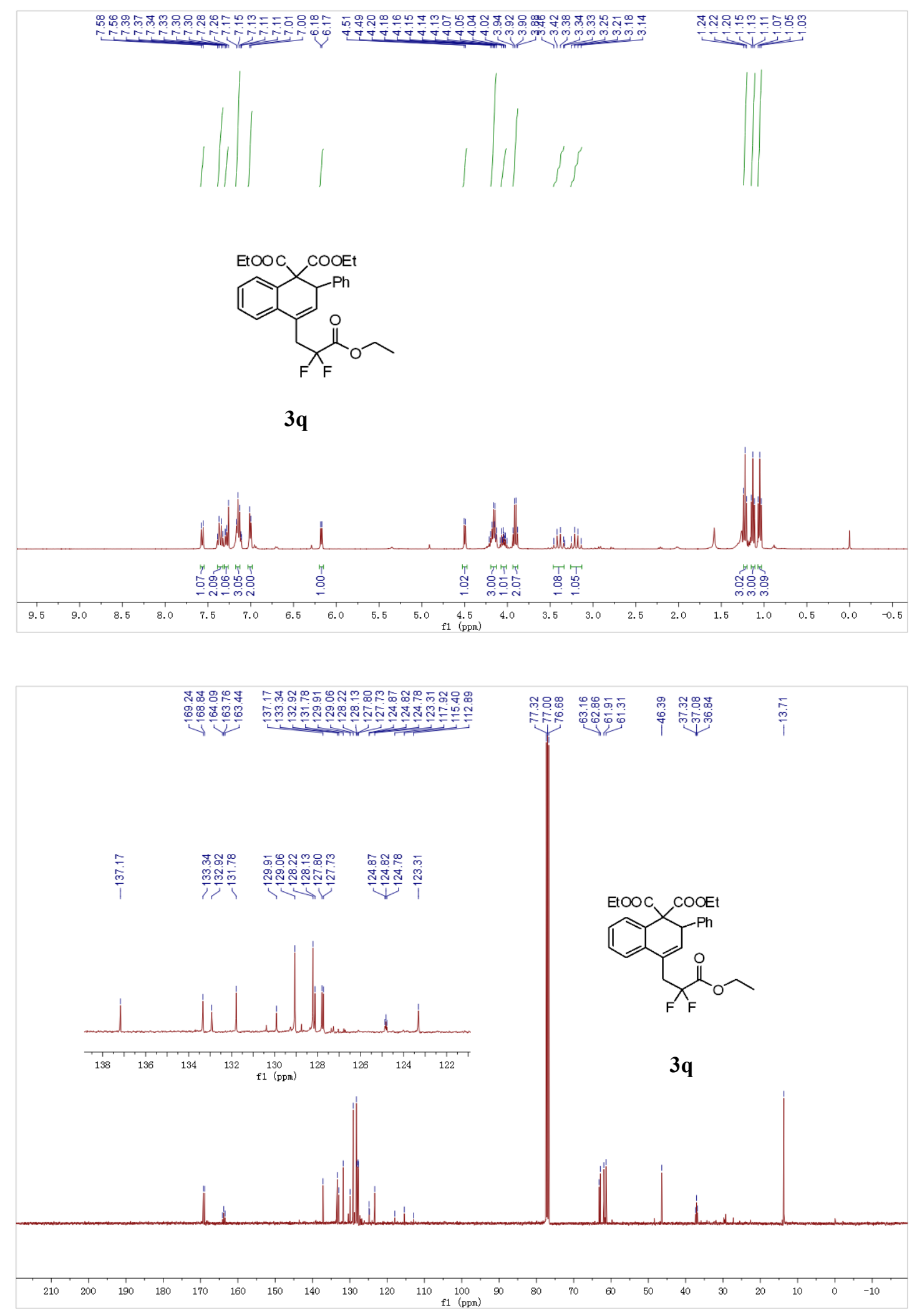

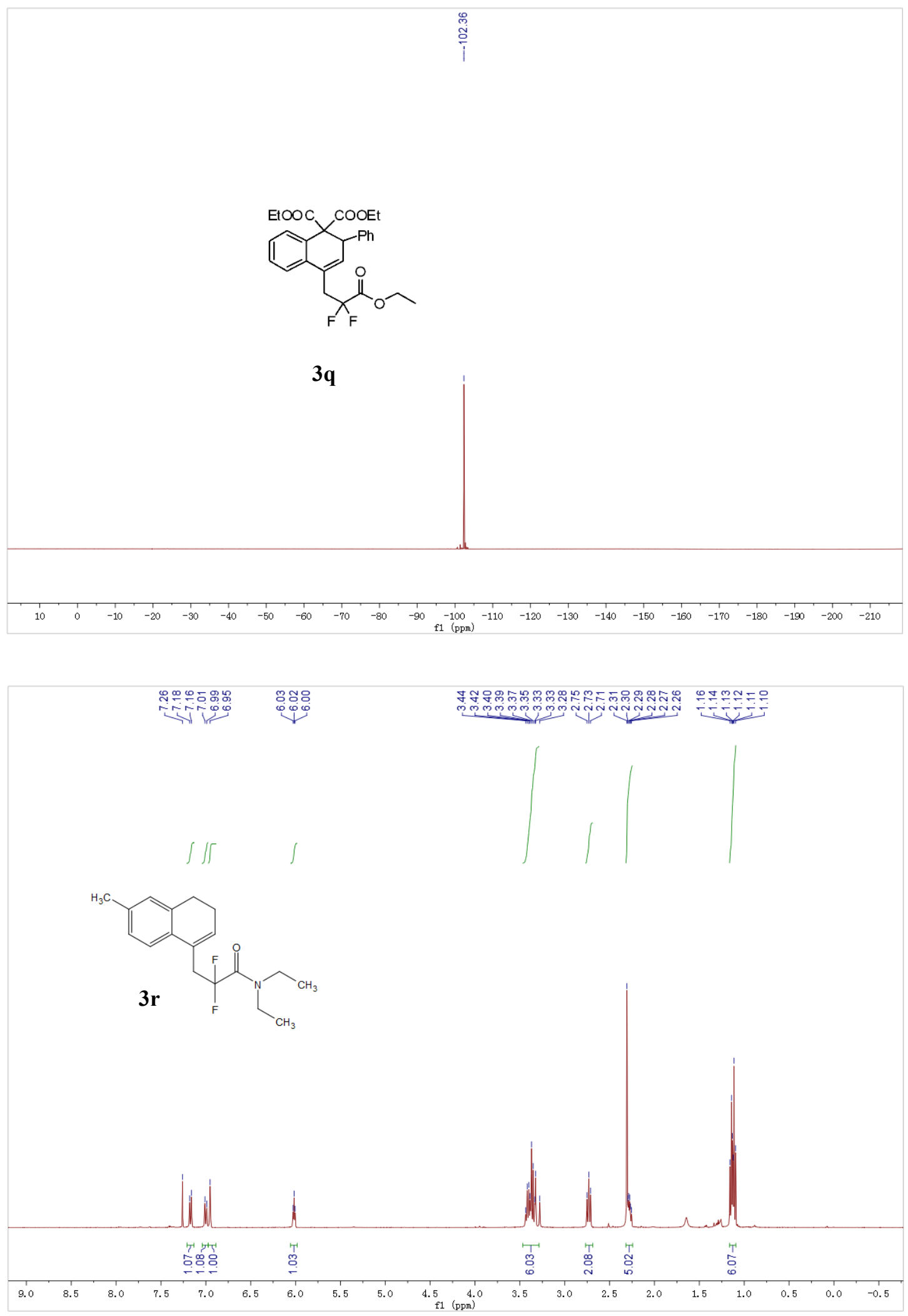

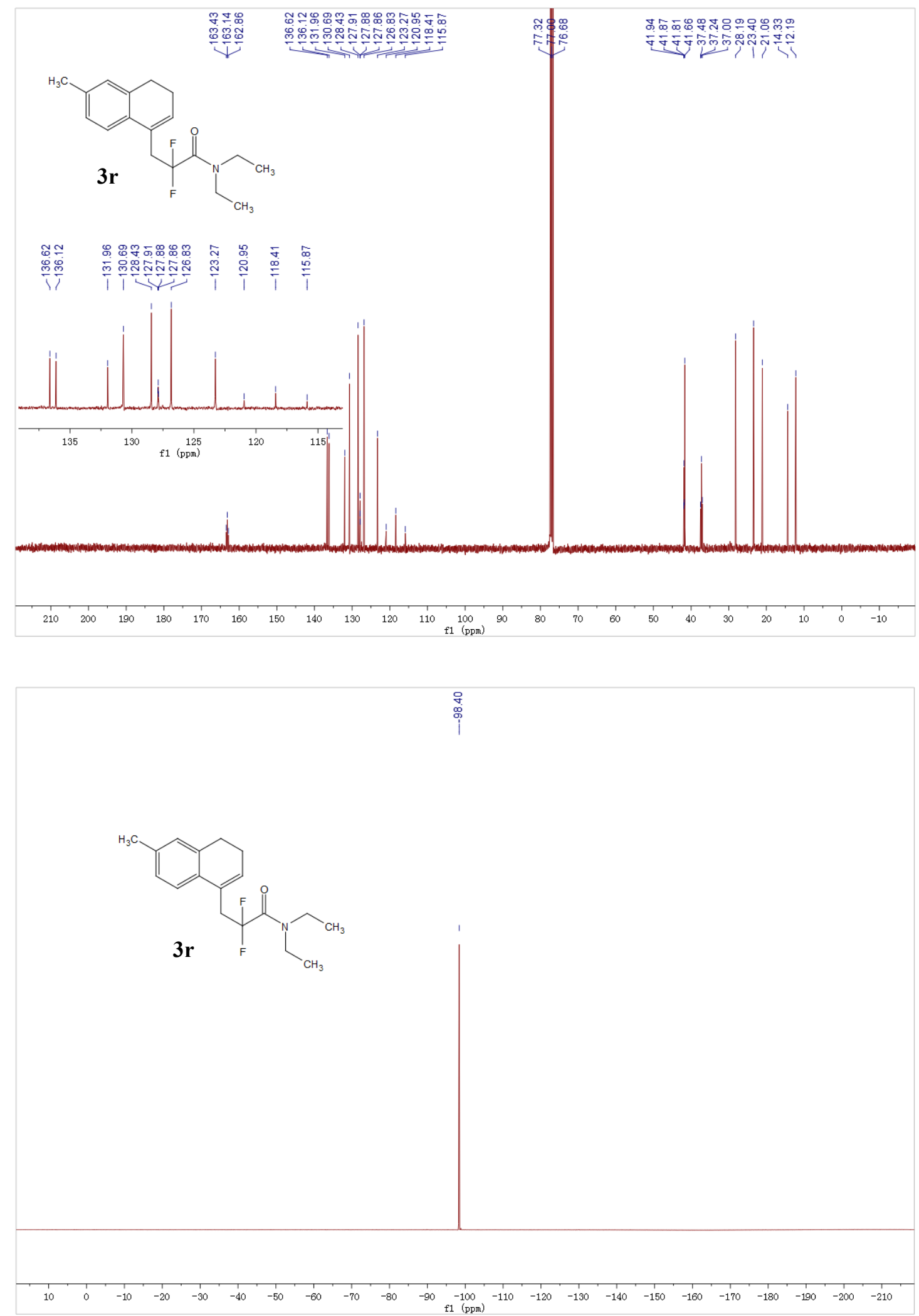

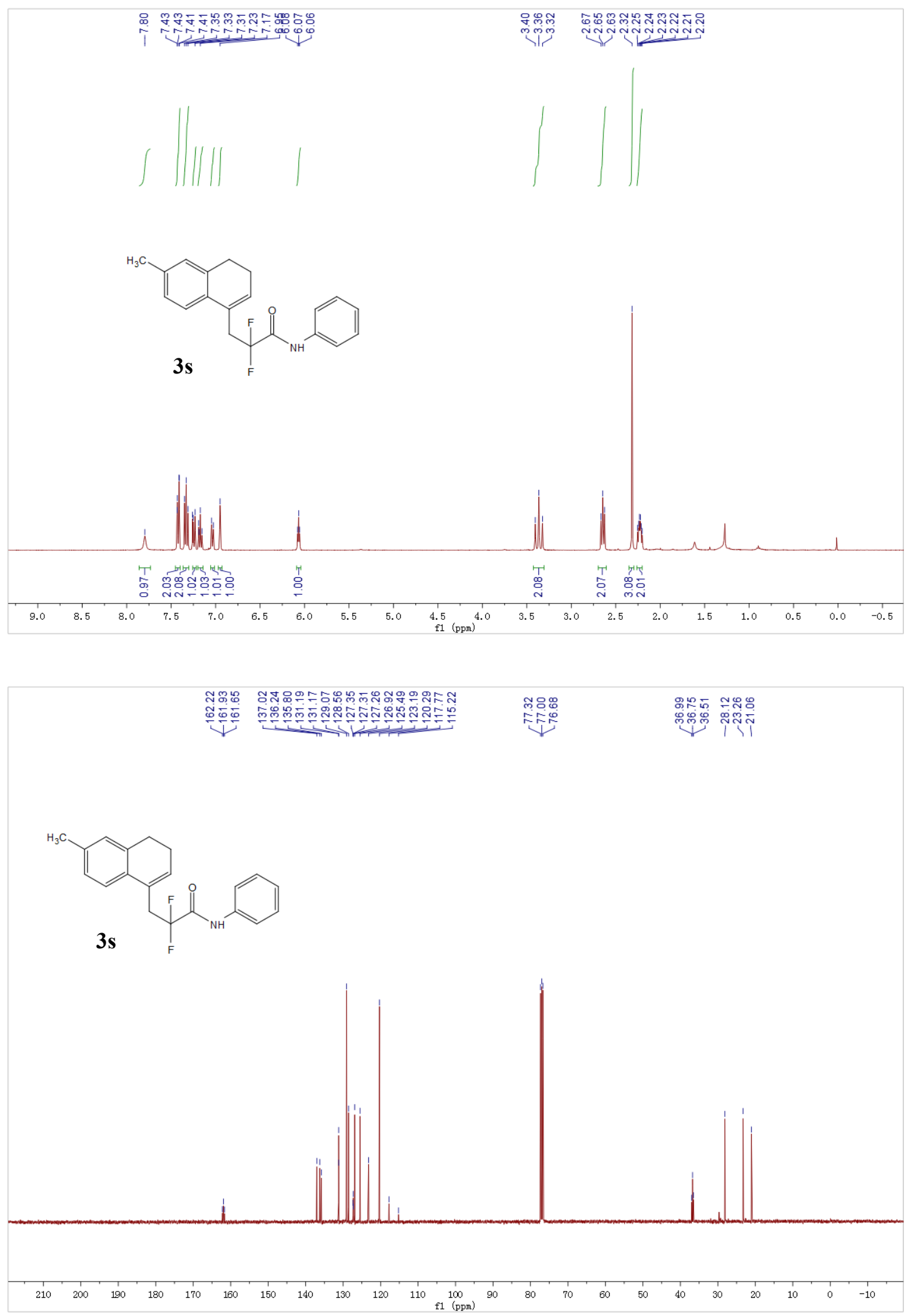

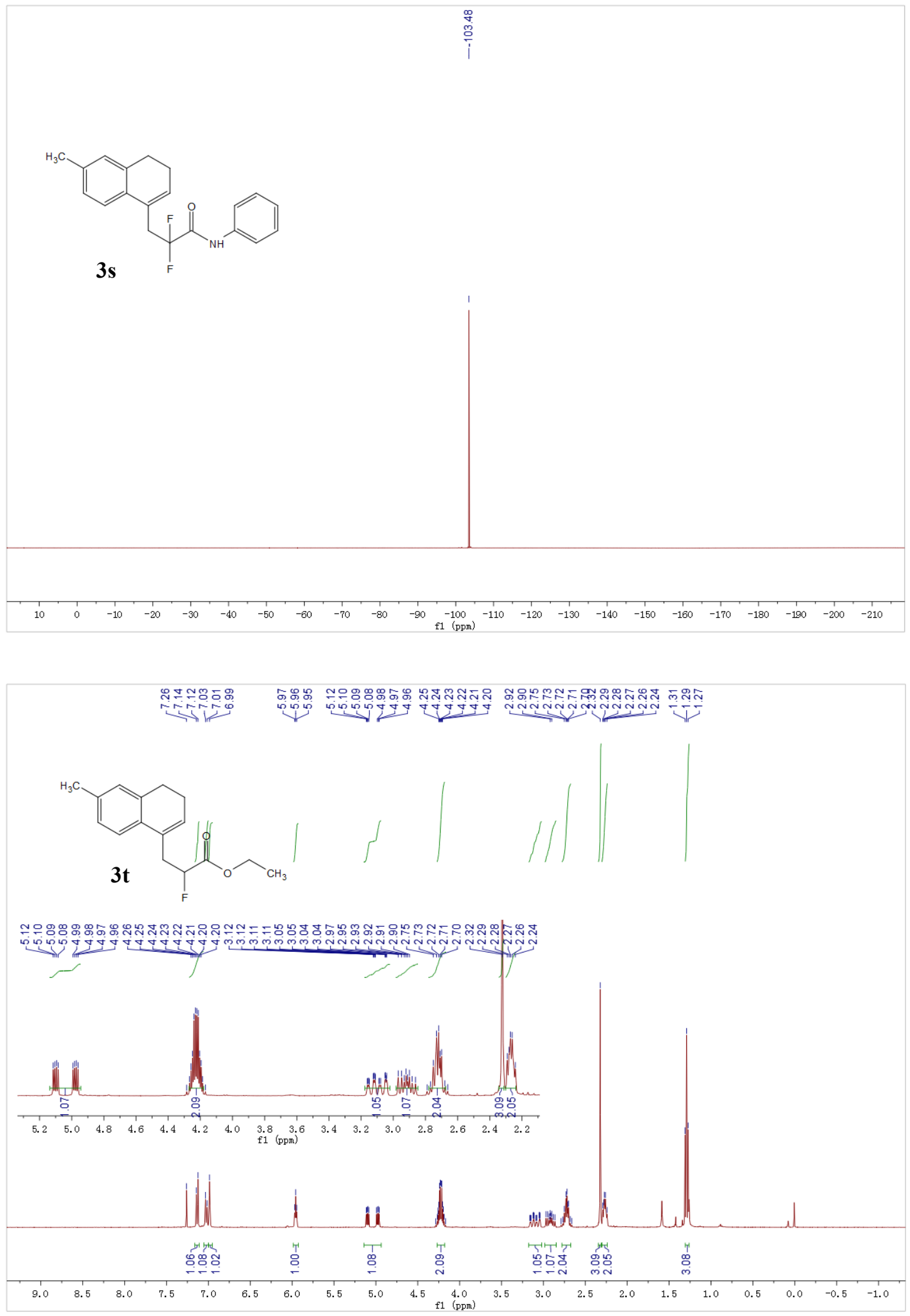

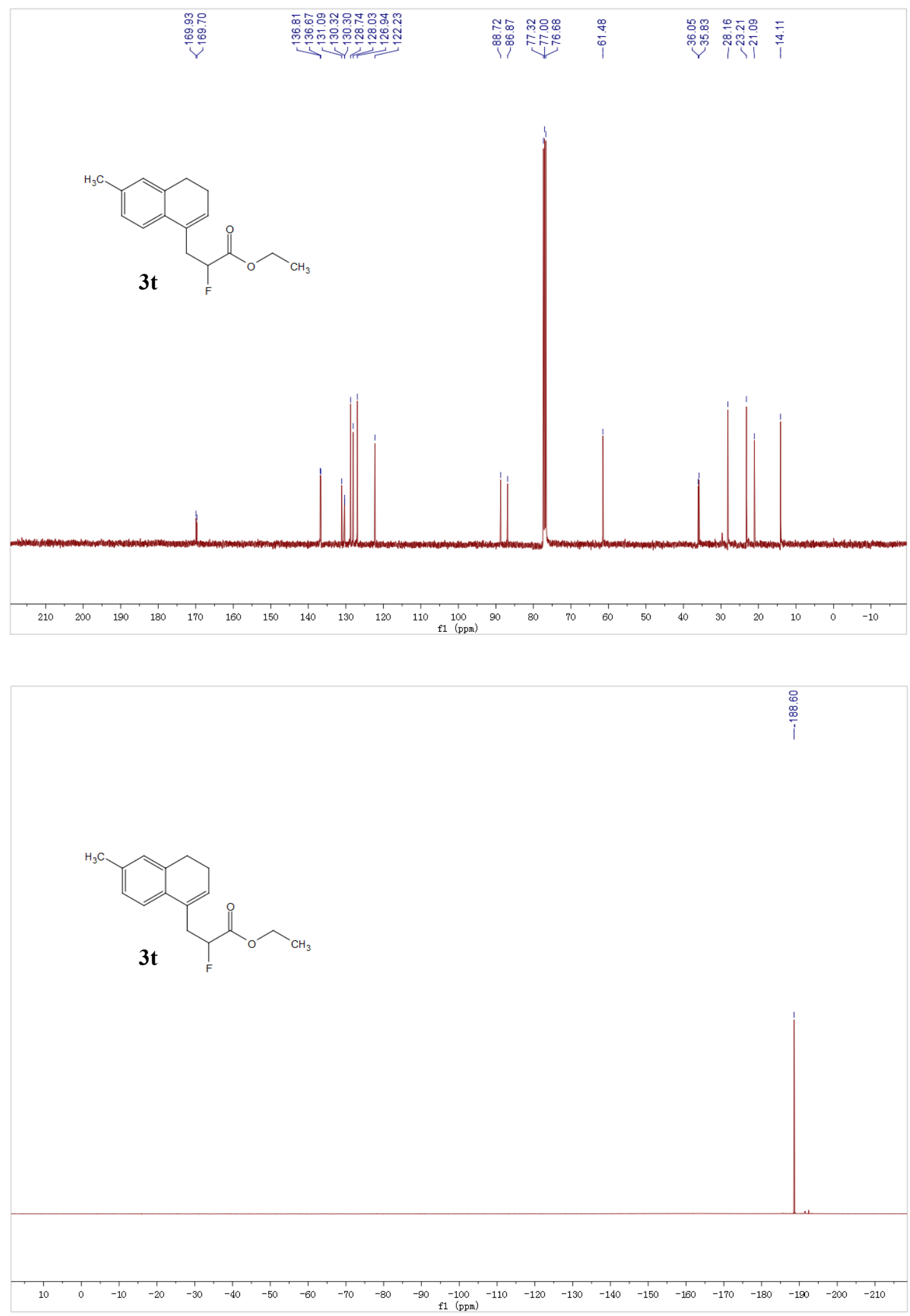

S56 

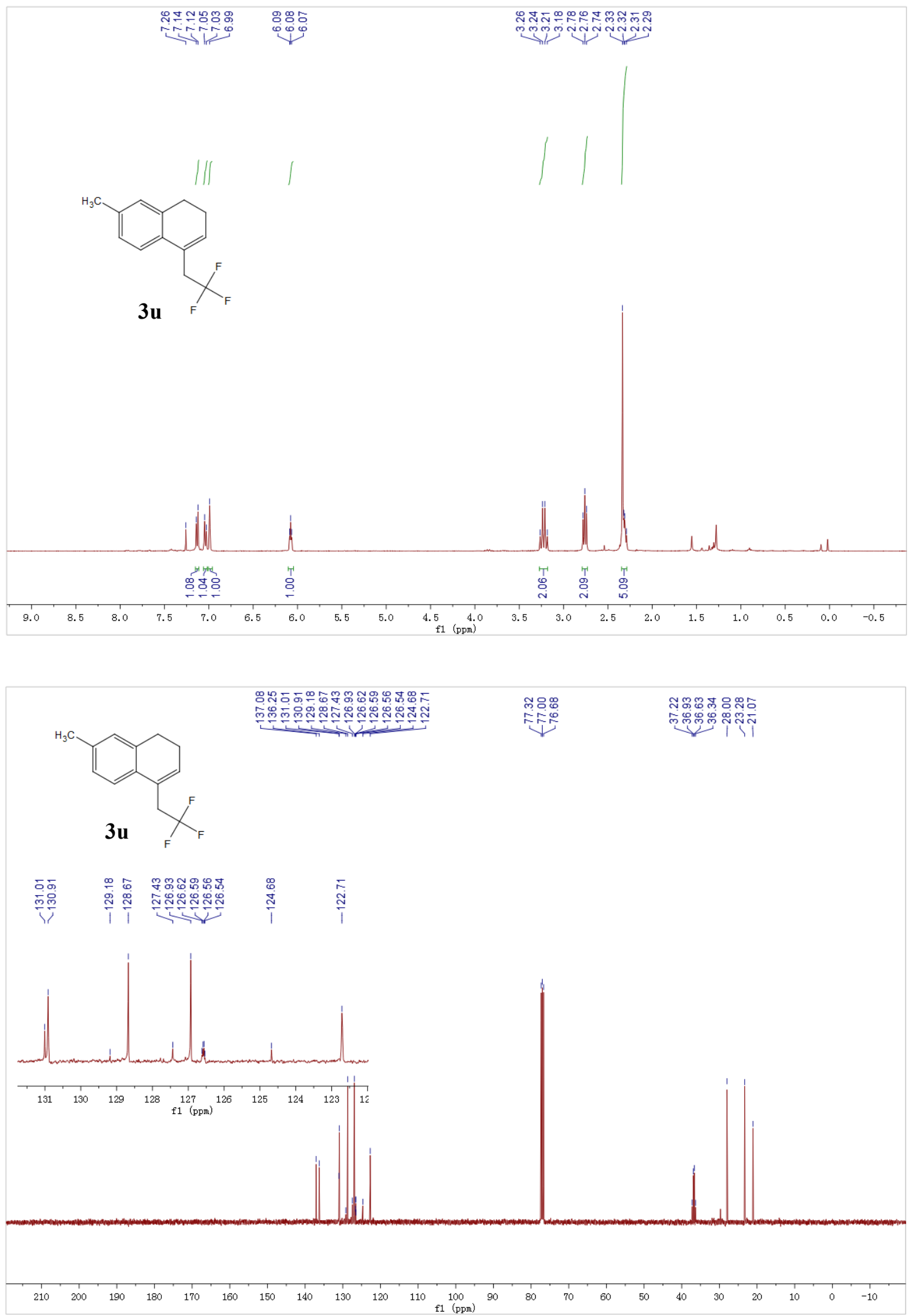

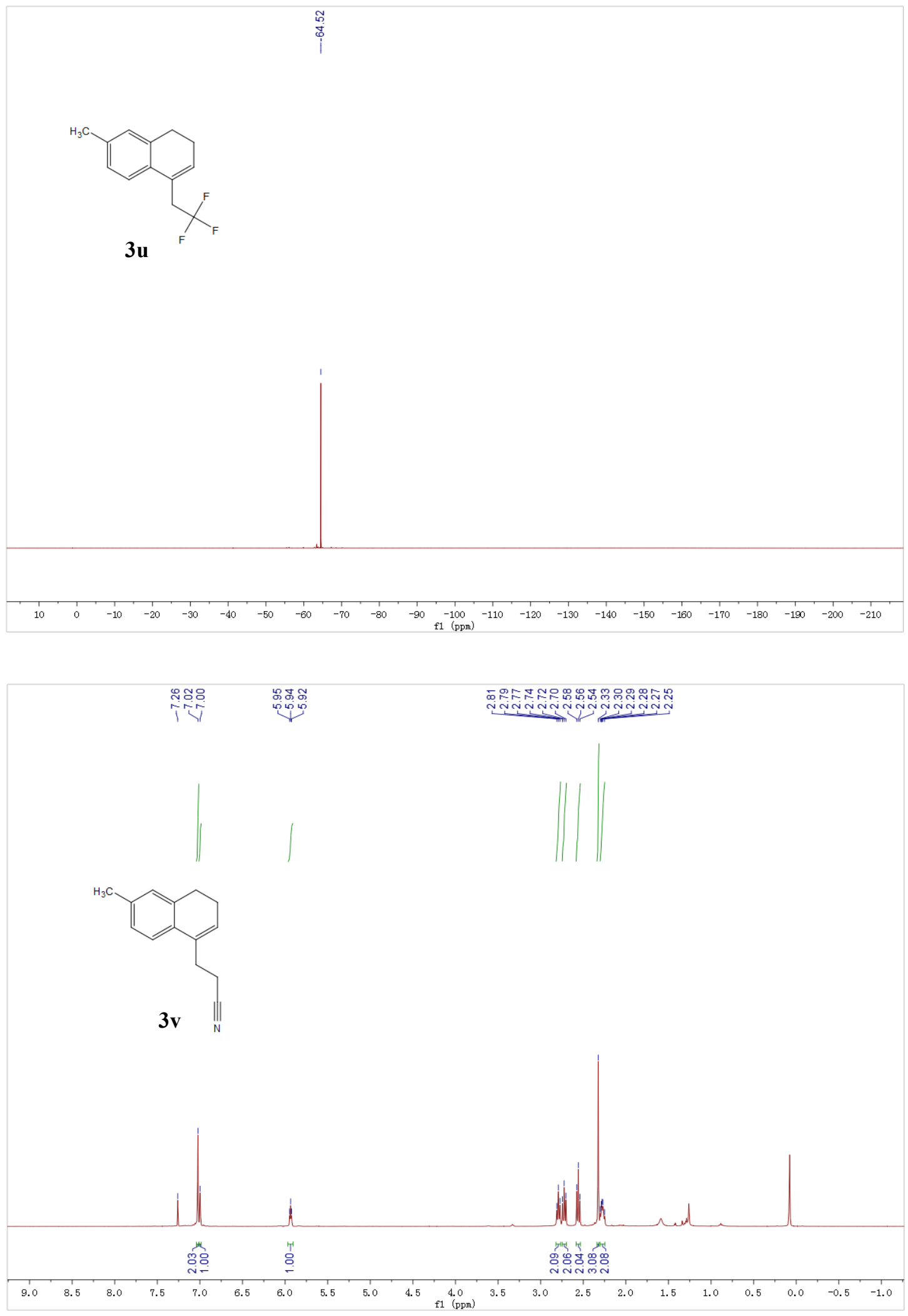

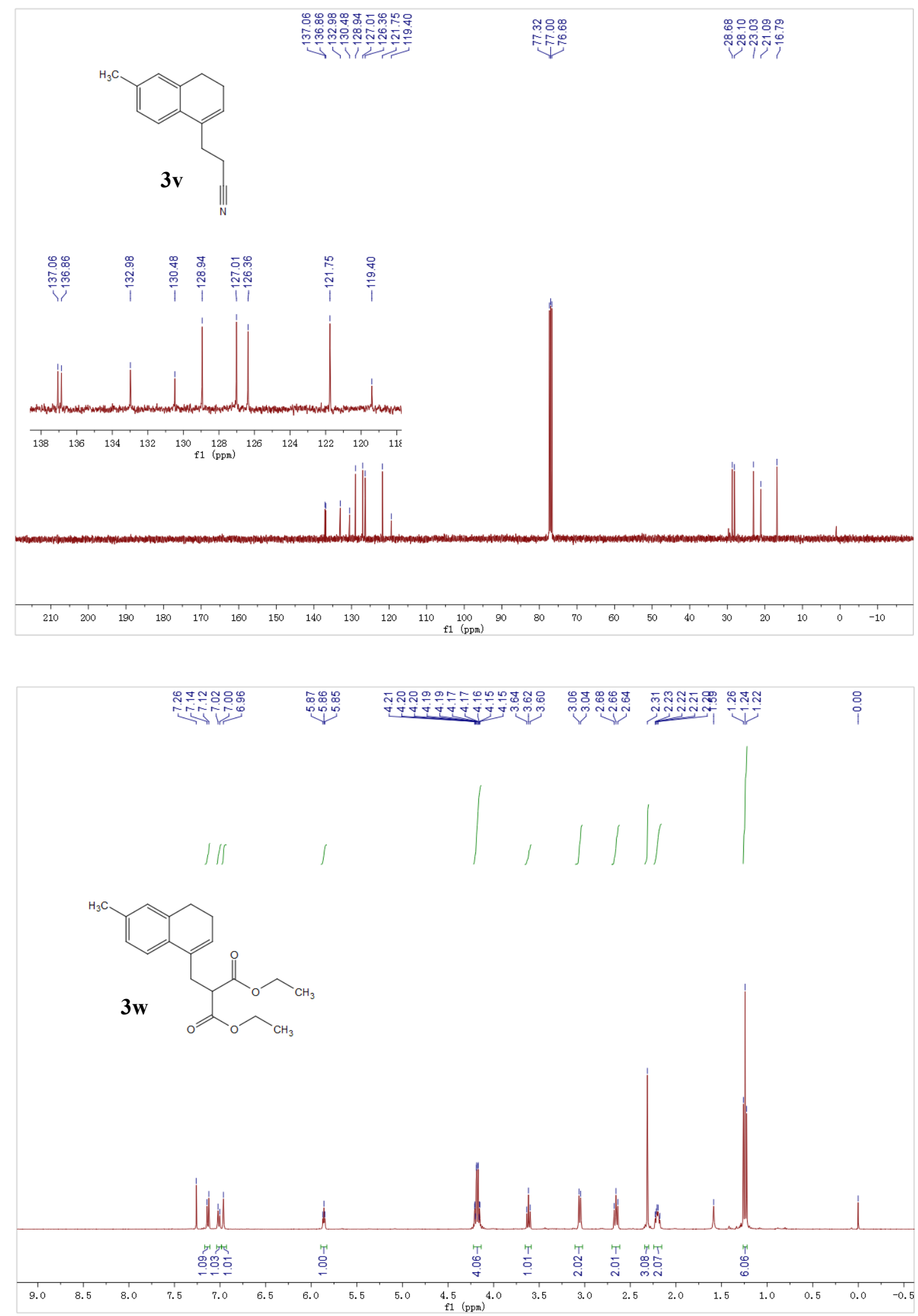

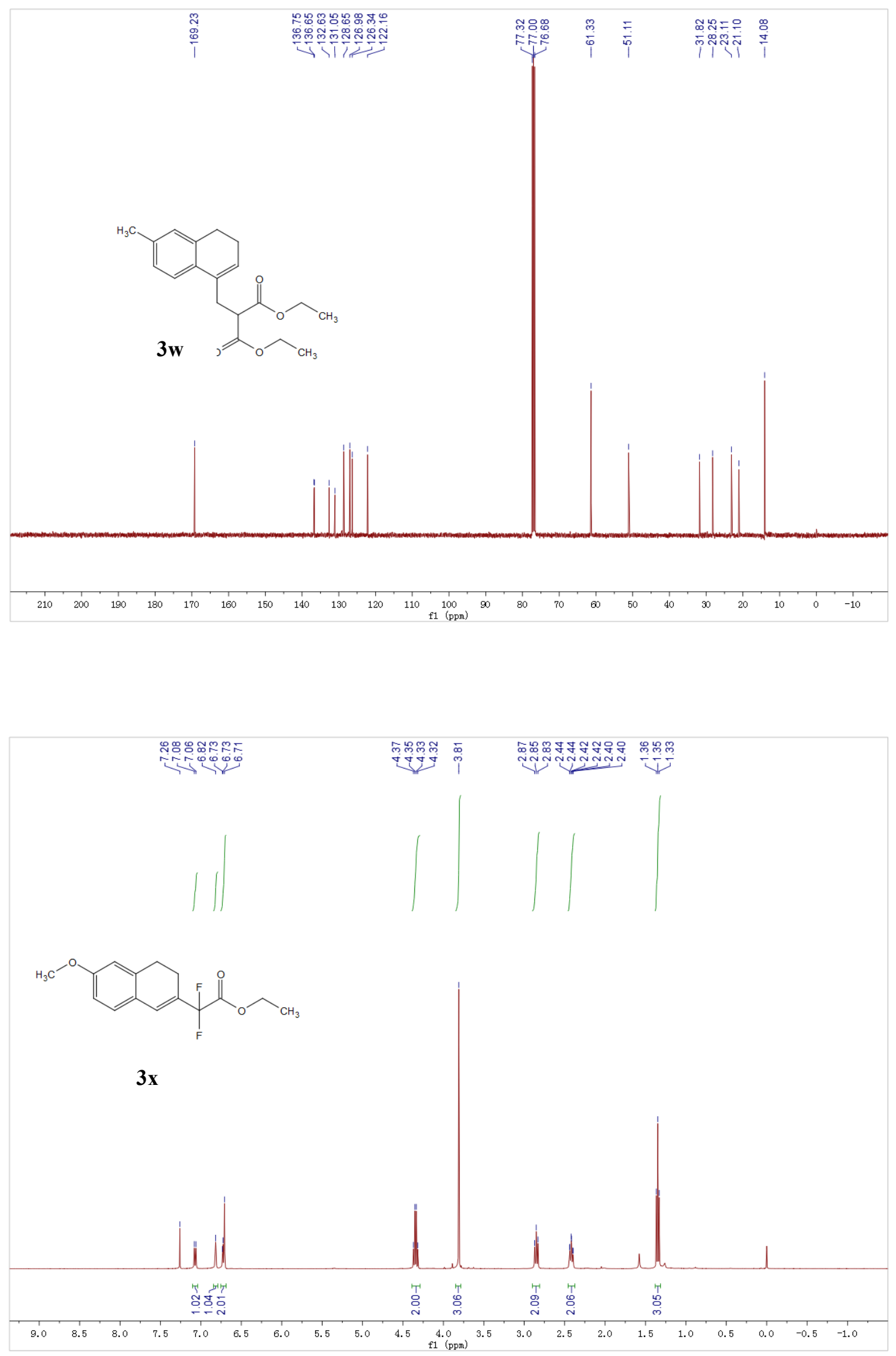

S60 

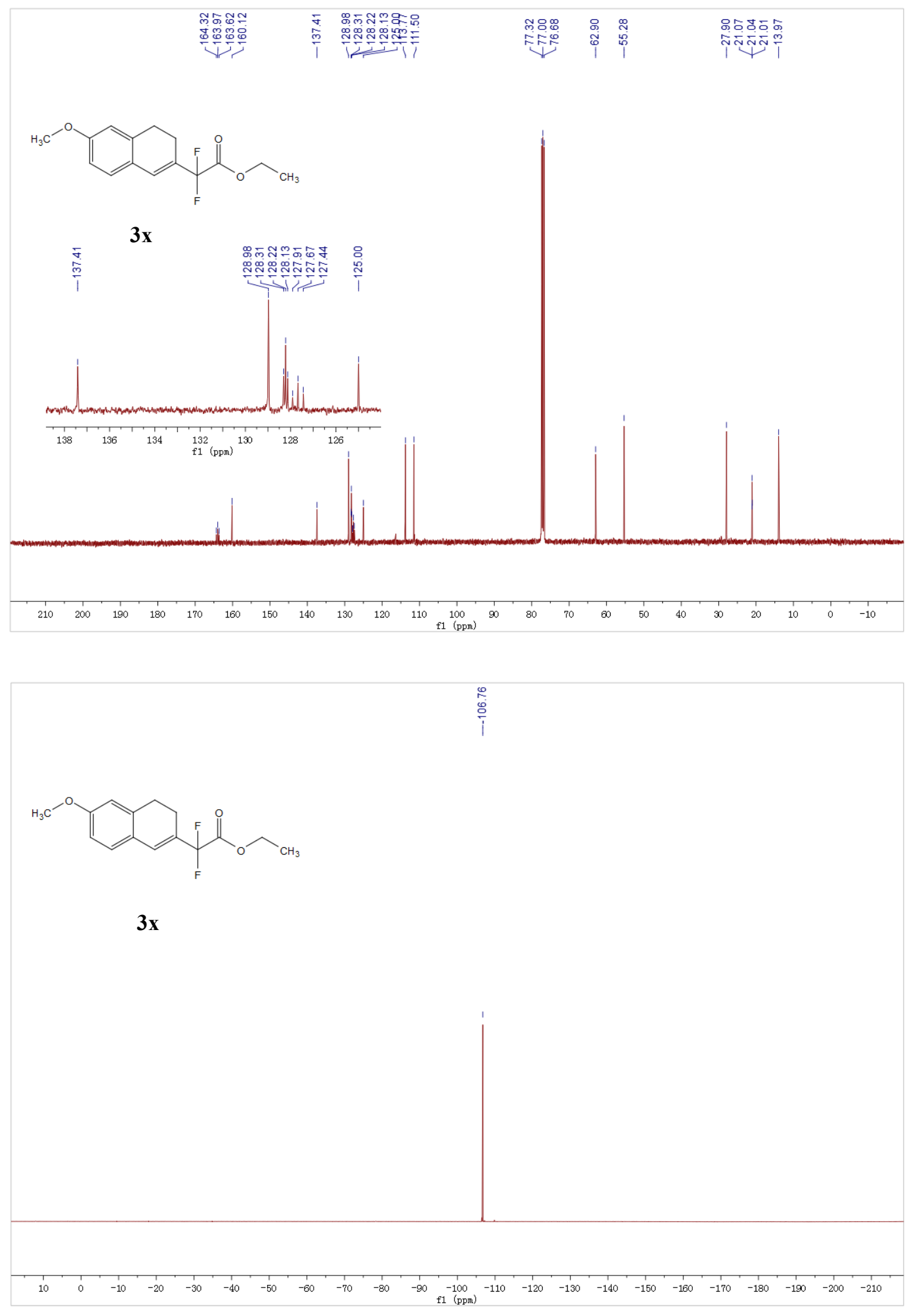

S61 

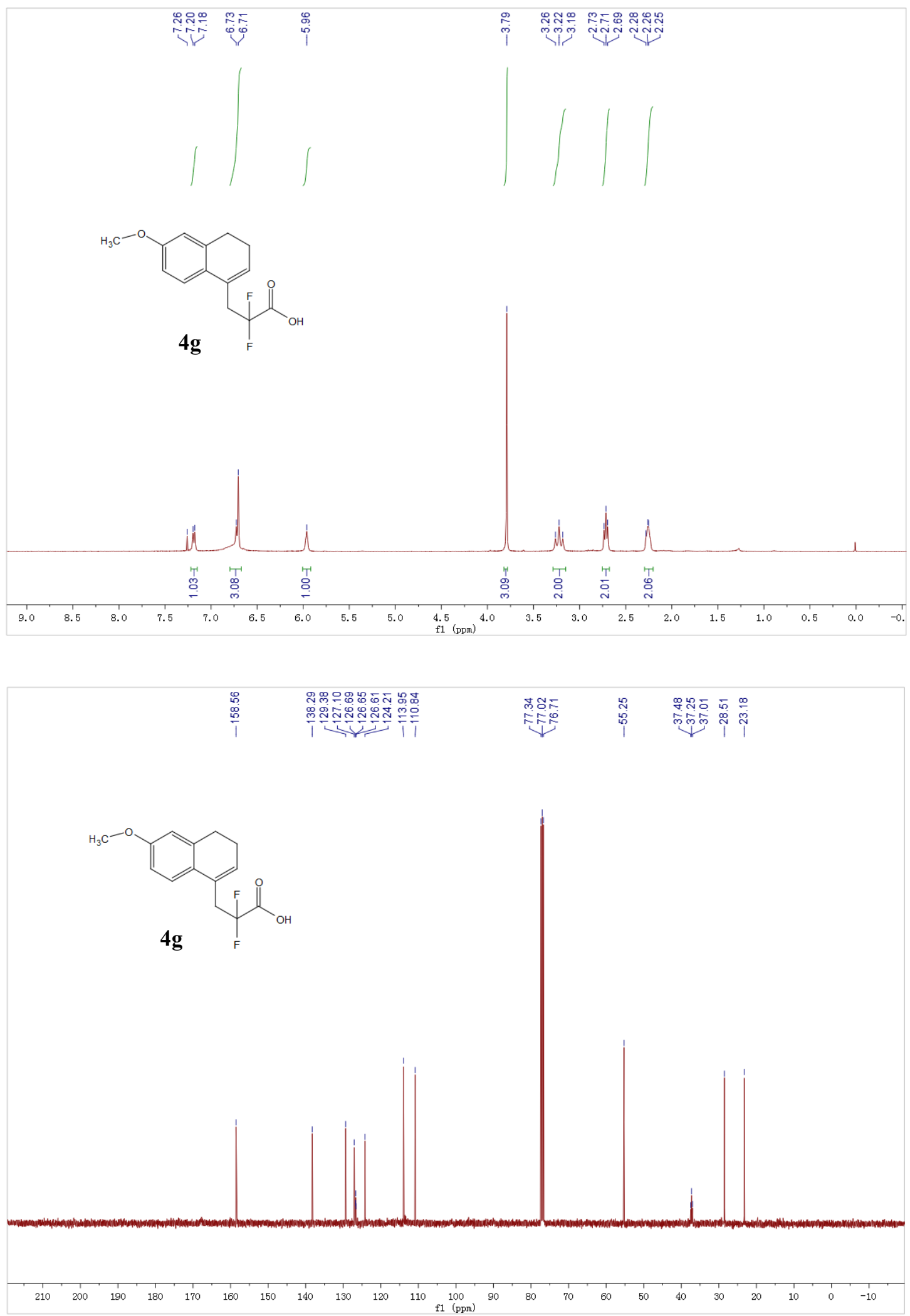

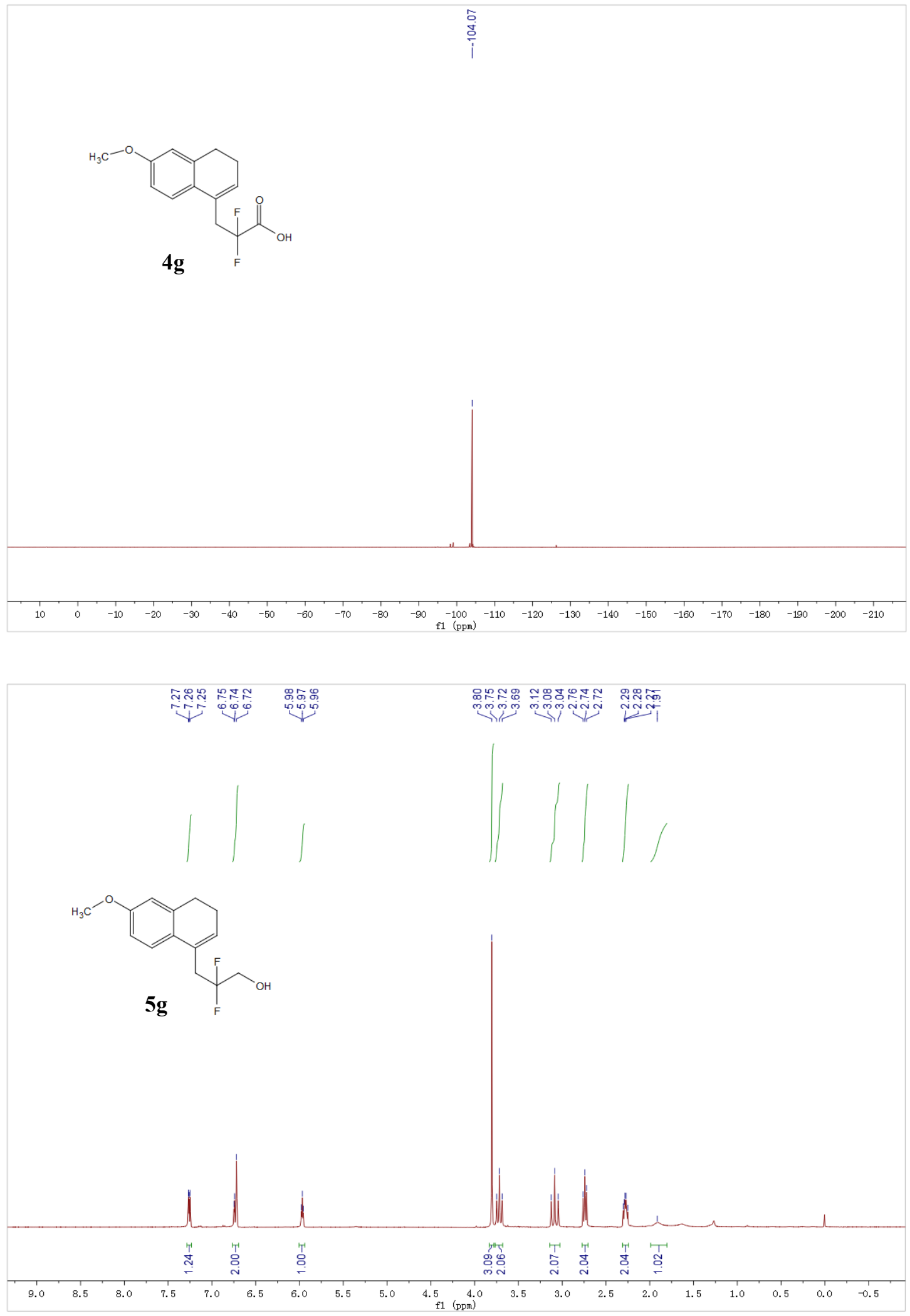

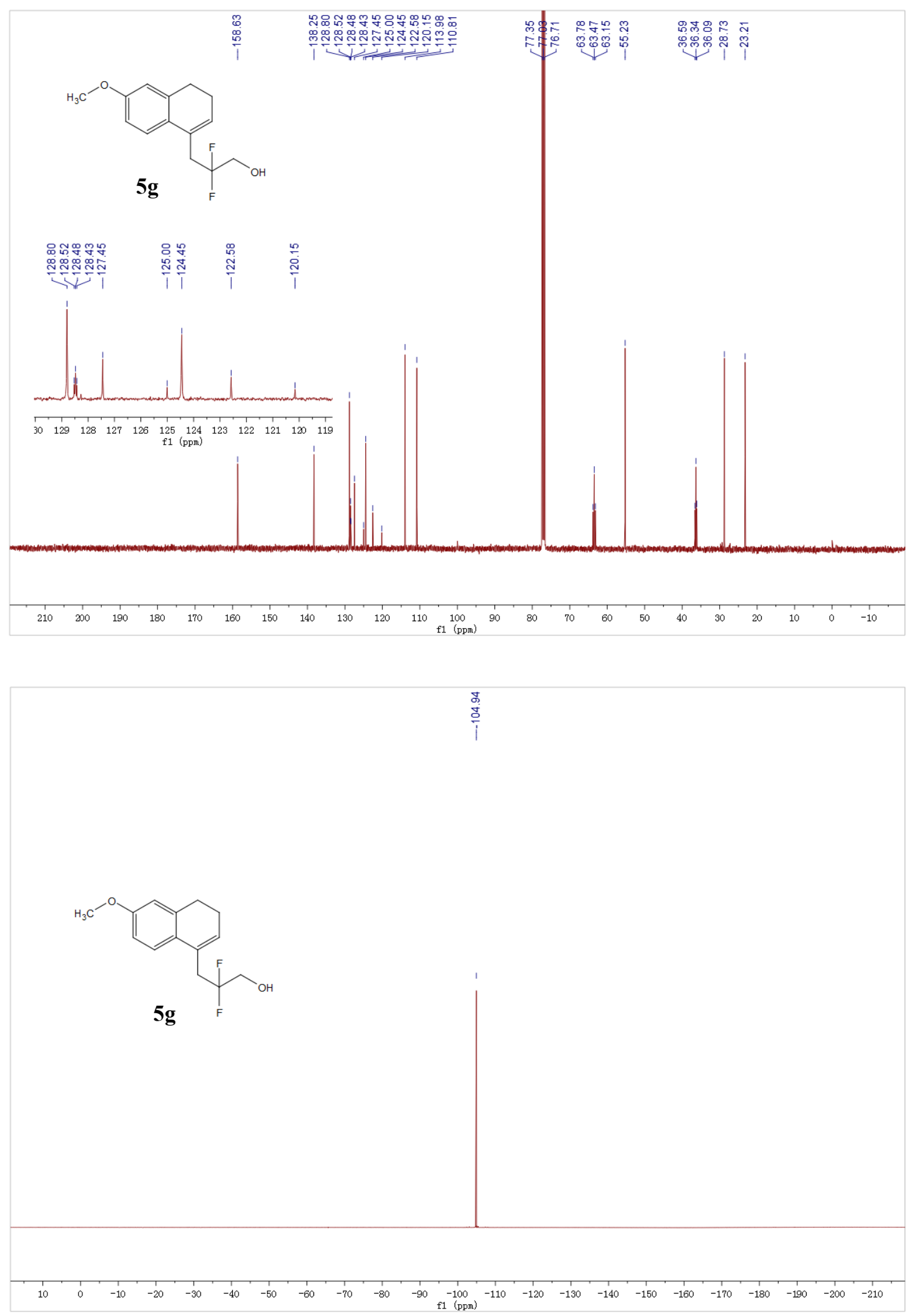

S64 

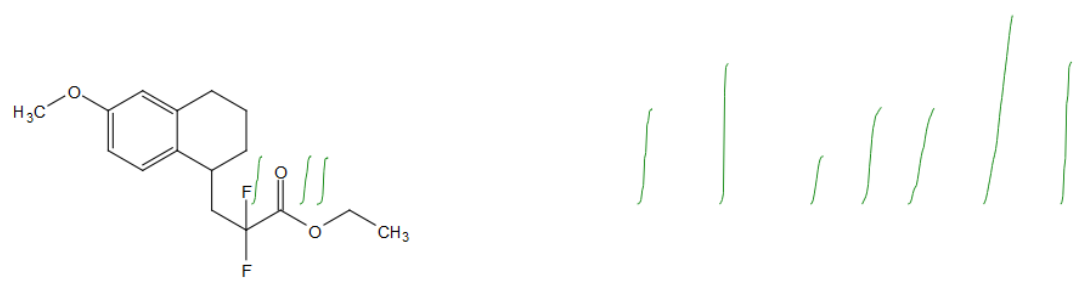

$6 \mathrm{~g}$
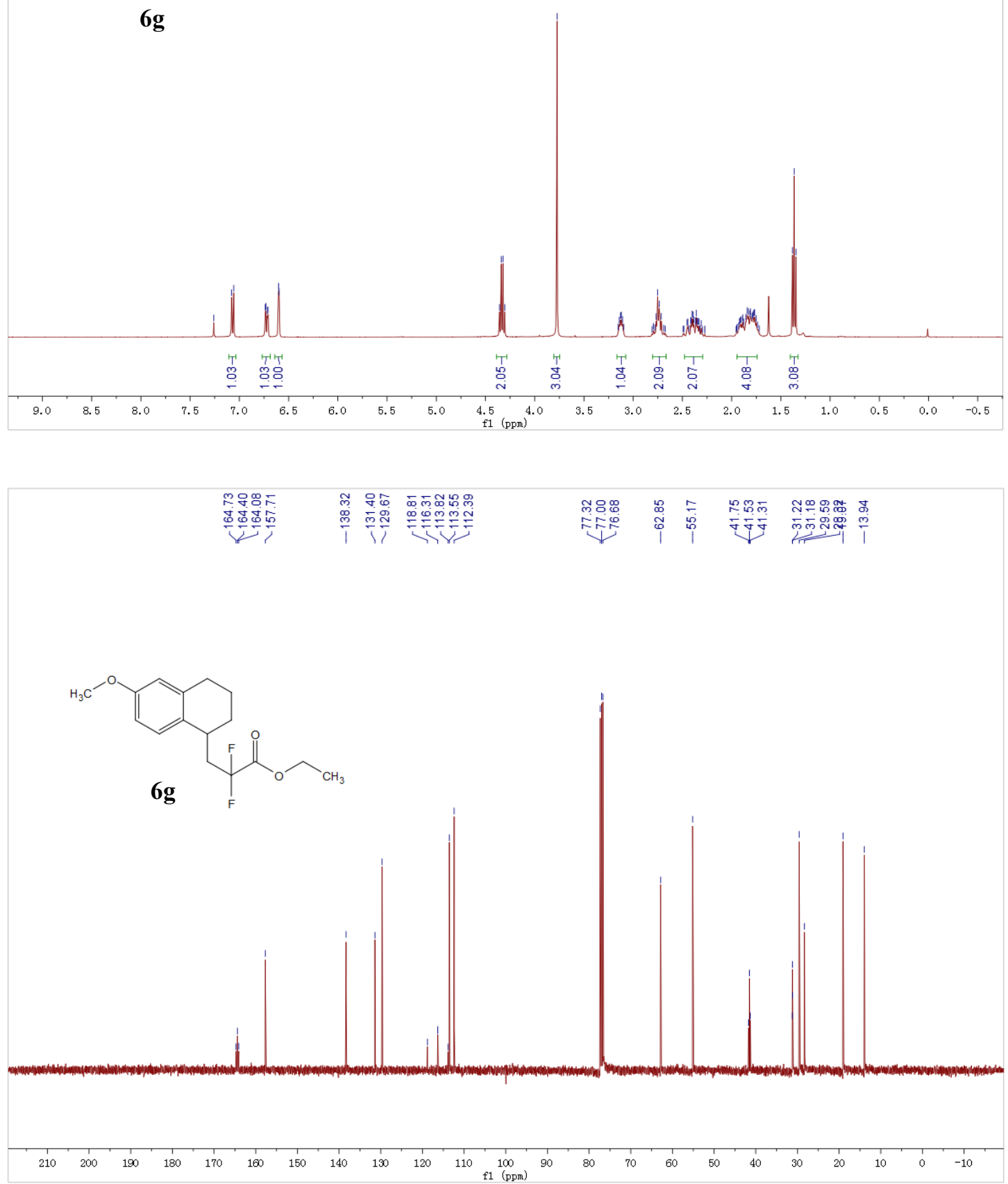

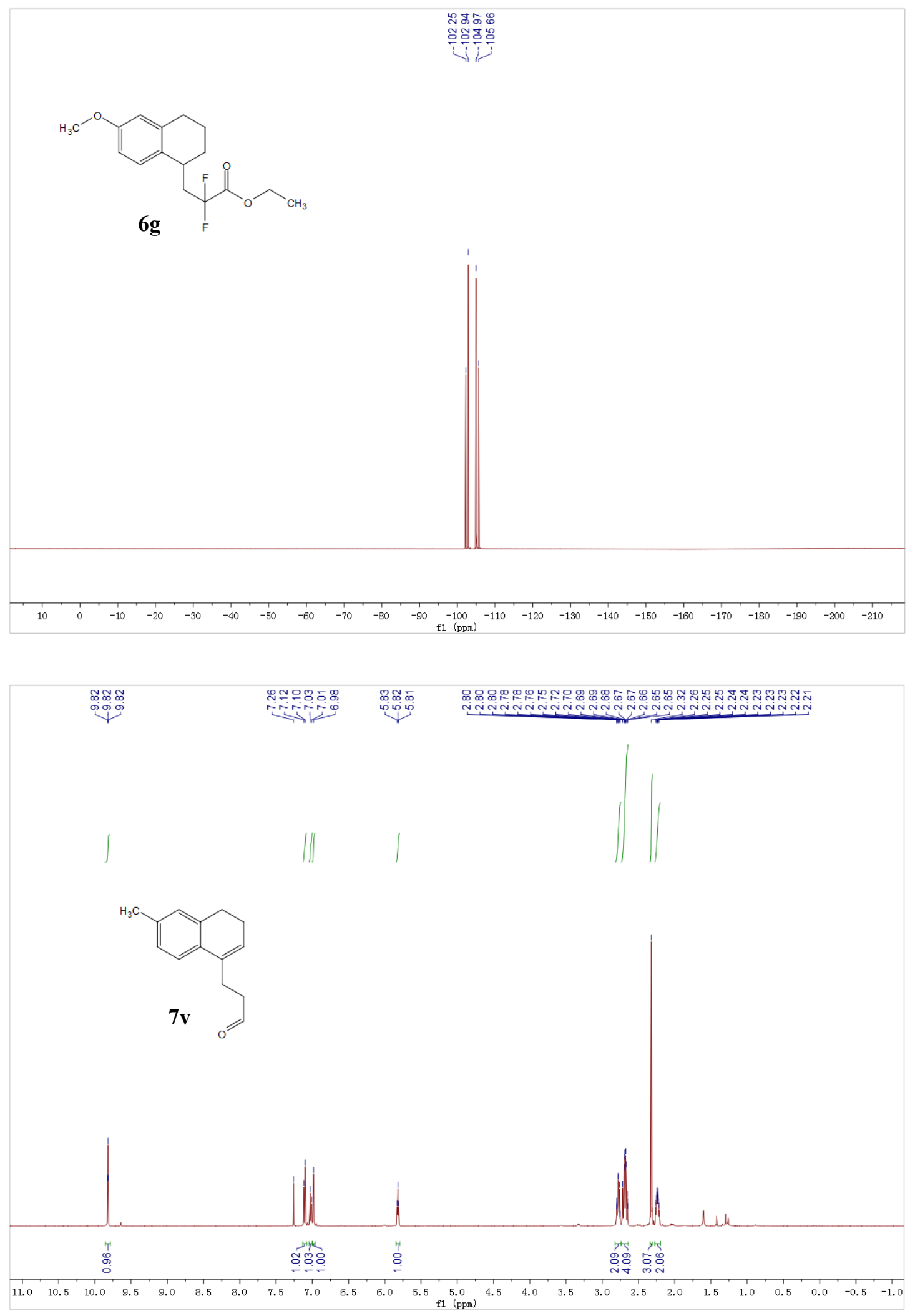

S66 

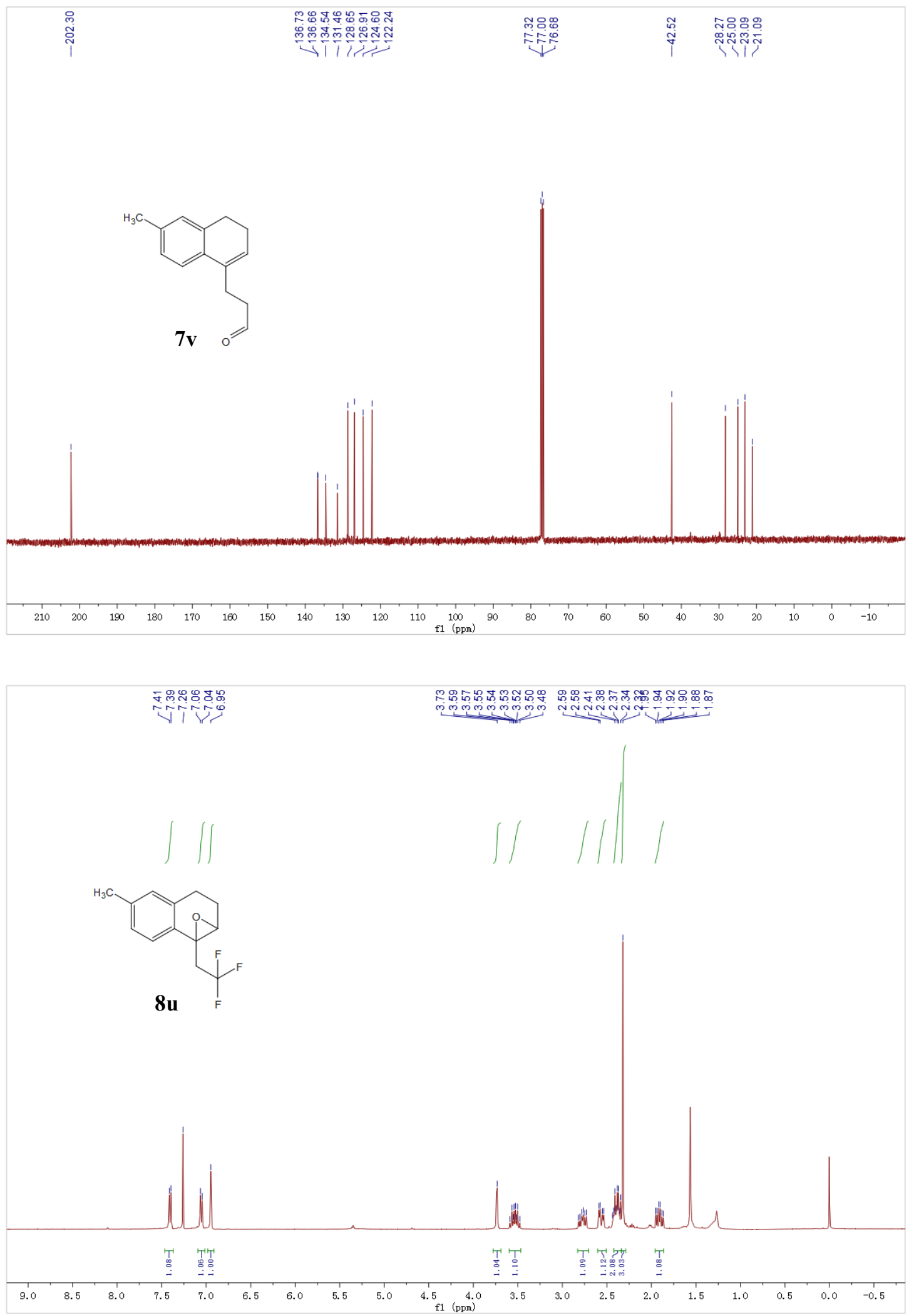

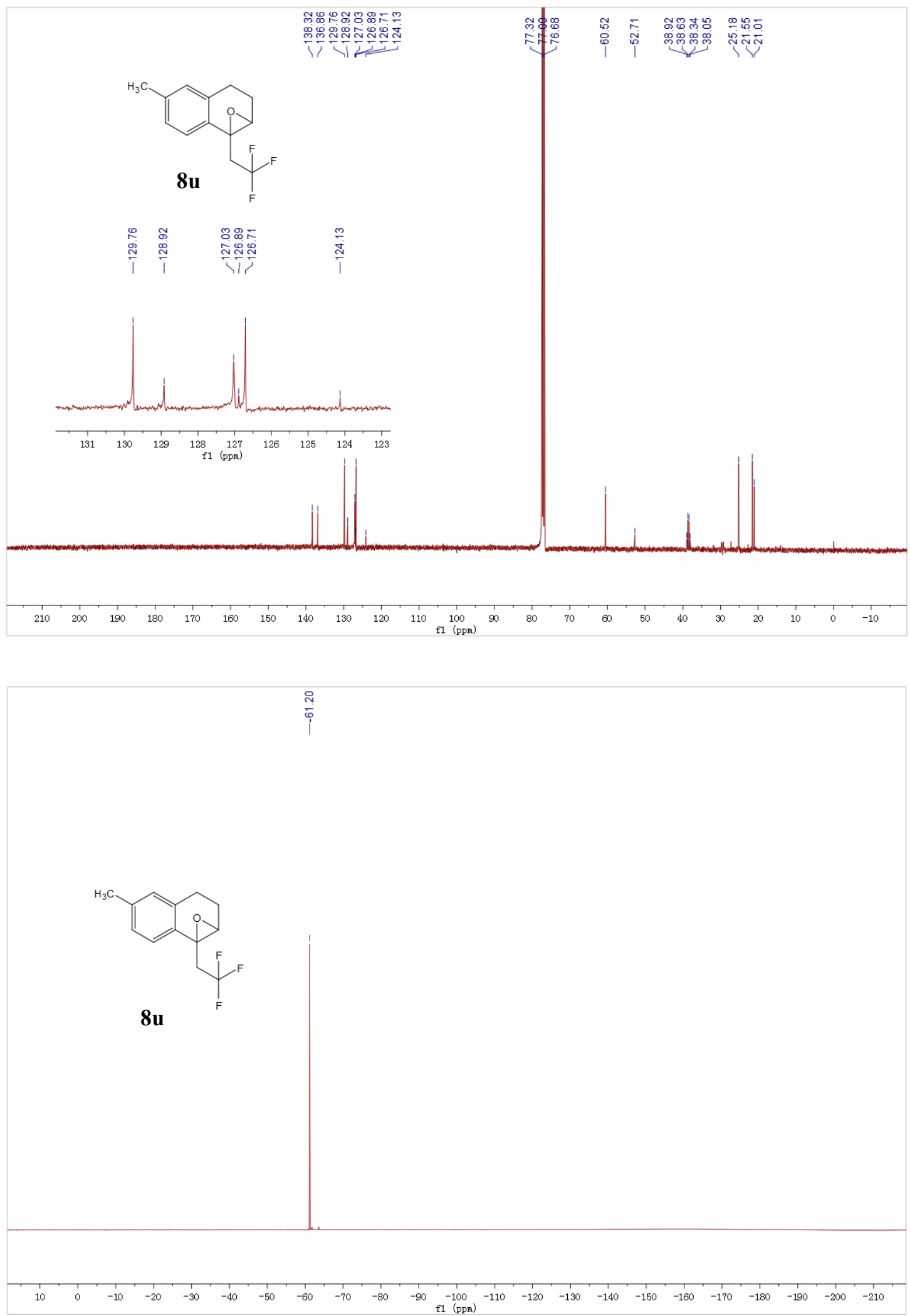


\section{Reference}

[1] Gaussian 09, Revision D.01, M. J. Frisch, G. W. Trucks, H. B. Schlegel, G. E. Scuseria, M. A. Robb, J. R. Cheeseman, G. Scalmani, V. Barone, B. Mennucci, G. A. Petersson, H. Nakatsuji, M. Caricato, X. Li, H. P. Hratchian, A. F. Izmaylov, J. Bloino, G. Zheng, J. L. Sonnenberg, M. Hada, M. Ehara, K. Toyota, R. Fukuda, J. Hasegawa, M. Ishida, T. Nakajima, Y. Honda, O. Kitao, H. Nakai, T. Vreven, J. A. Montgomery, Jr., J. E. Peralta, F. Ogliaro, M. Bearpark, J. J. Heyd, E. Brothers, K. N. Kudin, V. N. Staroverov, T. Keith, R. Kobayashi, J. Normand, K. Raghavachari, A. Rendell, J. C. Burant, S. S. Iyengar, J. Tomasi, M. Cossi, N. Rega, J. M. Millam, M. Klene, J. E. Knox, J. B. Cross, V. Bakken, C. Adamo, J. Jaramillo, R. Gomperts, R. E. Stratmann, O. Yazyev, A. J. Austin, R. Cammi, C. Pomelli, J. W. Ochterski, R. L. Martin, K. Morokuma, V. G. Zakrzewski, G. A. Voth, P. Salvador, J. J. Dannenberg, S. Dapprich, A. D. Daniels, O. Farkas, J. B. Foresman, J. V. Ortiz, J. Cioslowski, and D. J. Fox, Gaussian, Inc., Wallingford CT, 2013.

[2] a) Becke, A. D.; J. Chem. Phys. 1993, 98, 5648; (b) Lee, C.; Yang, W.; Parr, R. G. Phys. Rev. B. 1988, 37, 785. 